\title{
Neck disability \\ in patients with cervical radiculopathy and evaluation of structured postoperative physiotherapy
}

Johanna Wibault

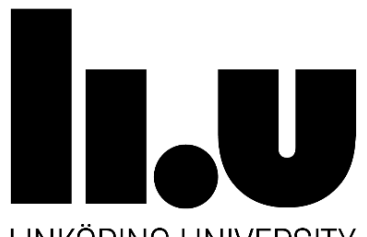

LINKÖPING UNIVERSITY

Division of Physiotherapy

Department of Medical and Health Sciences

Linköping University, Sweden 
Neck disability in patients with cervical radiculopathy and evaluation of structured postoperative physiotherapy

(C) Johanna Wibault, 2015

Cover illustration: Emma Wibault

Illustration in the thesis: Lionel Wibault

Published articles have been reprinted with the permission of the copyright holder.

Printed in Sweden by LiU-Tryck, Linköping, Sweden, 2015

ISBN 978-91-7685-959-9

ISSN 0345-0082 
To Franck, our daughter Stella, and our unborn child

"La rivière perce le rocher non pas par sa force, mais par sa persévérance » 



\section{CONTENTS}

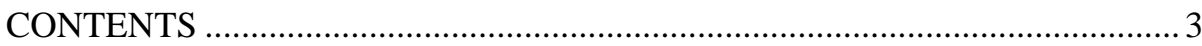

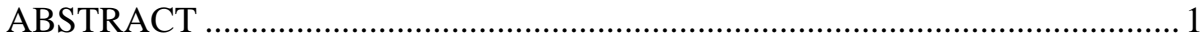

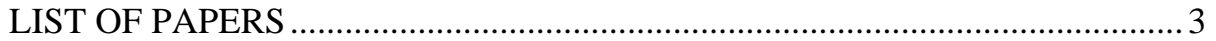

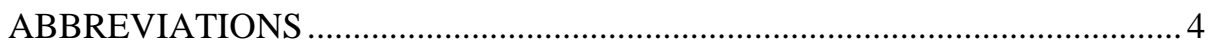

INTRODUCTION

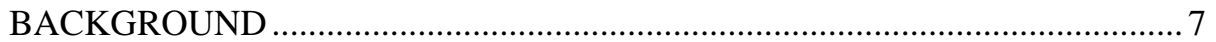

Patients with CR due to disc disease ......................................................... 7

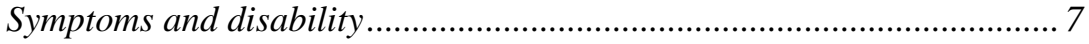

Pathophysiology ………..................................................................... 7

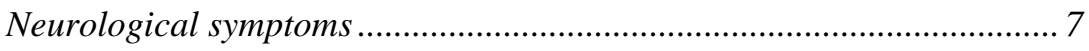

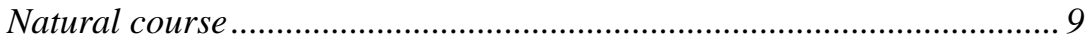

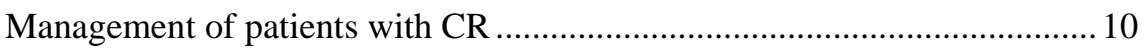

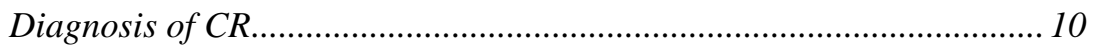

Non-surgical treatments ........................................................................ 10

Surgical treatments............................................................................ 11

Postoperative care and physiotherapy .................................................. 12

Evidence-based physiotherapy in patients with long-lasting neck pain......... 12

Exercise therapy for the neck muscles ................................................. 12

Cognitive-behavioural treatments ........................................................ 13

Facilitators of exercise therapies........................................................... 13

Perspectives on outcome measures .............................................................. 14

The biopsychosocial model of illness and disease …………………...... 14

The international classification of functioning, disability, and health ... 14

The patient's perspective on treatment outcomes .................................. 15

Rationale of the thesis ................................................................................. 17

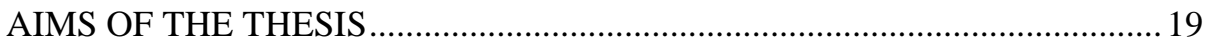

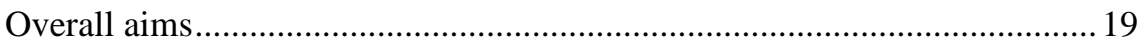

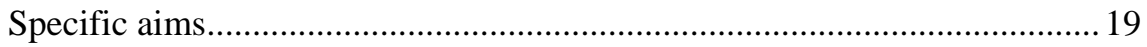




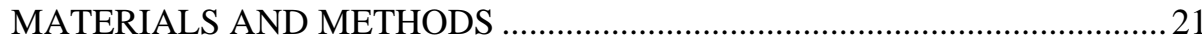

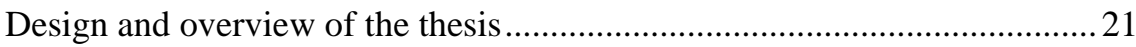

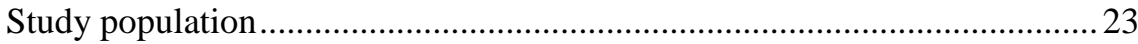

Inclusion/exclusion criteria in the $\mathrm{RCT}$.............................................. 23

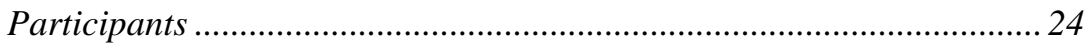

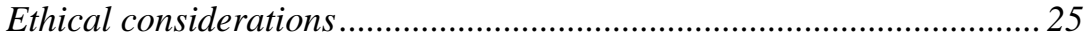

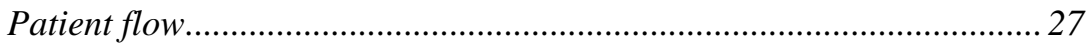

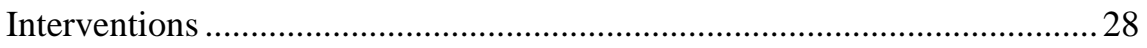

Surgical treatments and standard postoperative care at the spinal centres....................................................................................... 28

Structured postoperative physiotherapy $($ SPT) ................................... 28

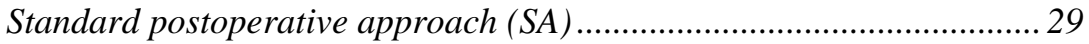

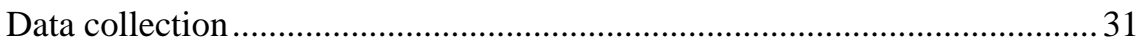

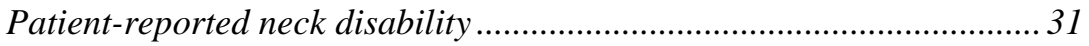

Neck-related body functions .................................................................. 32

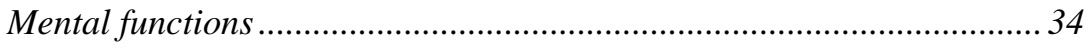

Contextual factors ....................................................................... 35

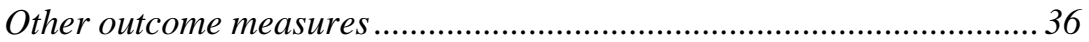

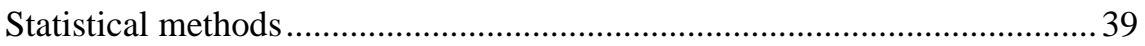

Assessment of HRA in patients with CR and neck-healthy individuals

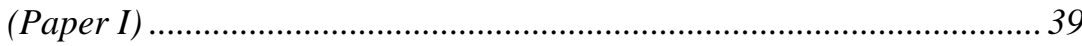

Neck disability in patients with CR and scheduled for surgery (Paper

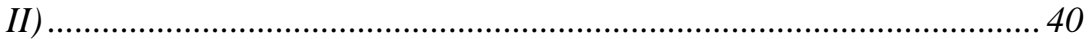

Evaluation of SPT compared to SA in patients with CR (Paper III \&

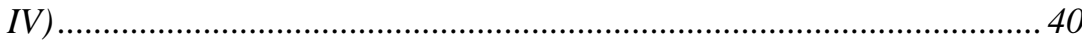

Differences between patients who reported and did not report additional use of postoperative physiotherapy in the SA group ............................. 41

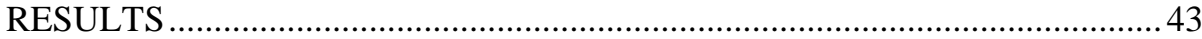

Assessment of HRA in patients with CR and neck-healthy individuals (Paper

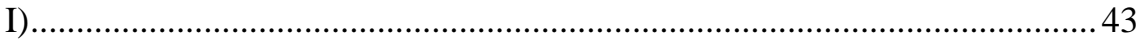

Neck disability in patients with CR and scheduled for surgery (Paper II).... 45

Evaluation of SPT compared to SA in patients with CR (Paper III \& IV) ... 49

Outcomes at 6 months after surgery ............................................... 51

Changes in outcomes from before surgery to 6 months after surgery .... 52 
Treatment effects during the postoperative period 52

Differences between patients who reported and did not report additional use of postoperative physiotherapy in the SA group 61

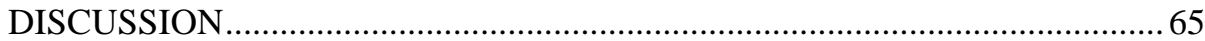

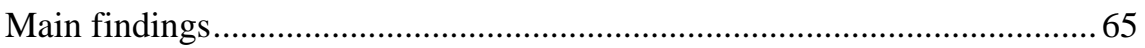

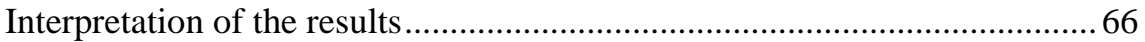

Assessment of HRA in patients with CR and neck-healthy individuals

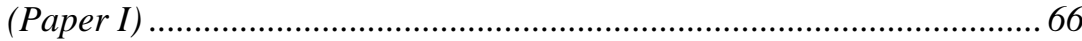

Neck disability in patients with $C R$ and scheduled for surgery (Paper

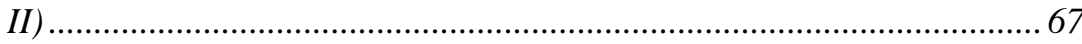

Evaluation of SPT compared to SA in patients with CR (Paper III \& IV)

Differences between patients who reported or did not report additional use of postoperative physiotherapy in the SA group ............................ 71

Methodological considerations........................................................ 72

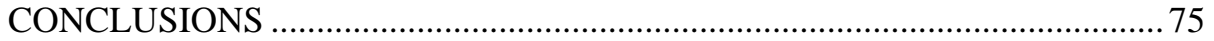

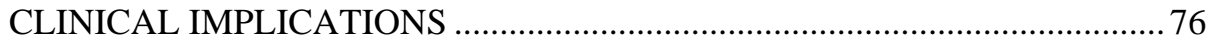

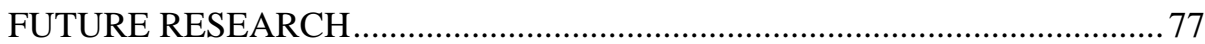

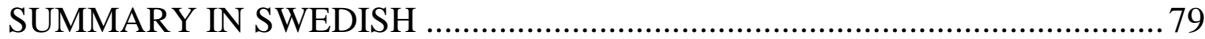

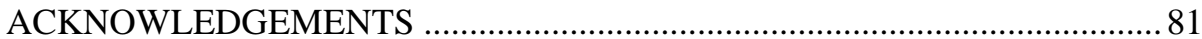

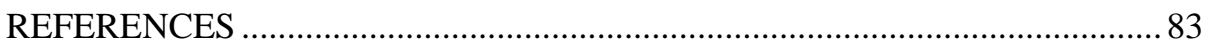




\section{ABSTRACT}

Background: Non-surgical and surgical approaches to treatment are used in patients with cervical radiculopathy (CR) due to disc disease. Overall, good effects of surgery have been reported on arm pain and neurological symptoms. However, the effects on neck functioning are more uncertain. Studies have shown persistent activity limitations; participation restrictions; and impairments in neck-related body functions after surgery. Structured physiotherapy combining neck-specific exercises with a behavioural approach has been suggested as treatment before as well as after surgery to improve clinical outcomes in patients with CR. Randomized clinical trials of postoperative physiotherapy to inform evidence-based clinical guidelines for the treatment of patients with CR are lacking.

Aim: The overall aim of the thesis was to investigate the additional benefit of structured postoperative physiotherapy combining neck-specific exercises with a behavioural approach compared to standard postoperative approach in patients with CR. A further aim was to evaluate the contribution of different aspects of neck-related body functions and mental functions on preoperative neck disability in these patients.

Methods: A total of 202 patients with CR who were scheduled for surgery were recruited, and randomized preoperatively to either structured postoperative physiotherapy, or standard postoperative approach. Standard postoperative approach was in accordance with Swedish postoperative care, and may have included pragmatic physiotherapy after surgery when needed. Patients were evaluated with a set of questionnaires and clinical examinations before surgery and at 3 and 6 months after surgery. Outcomes included patient-reported measures of pain, neck functioning, global outcome, clinical evaluation of neck-related body functions, selfefficacy and coping strategies, as well as expectation fulfilment and enablement. Differences between treatment groups were investigated in complete case and perprotocol approaches (Paper III \& IV). A sub-sample of patients with CR who were scheduled for surgery were also compared with neck-healthy individuals for assessment of head repositioning accuracy with a cervical range of motion device (Paper I). In patients with CR who were scheduled for surgery, associations between preoperative measures of neck-related body functions, mental functions, and other contextual factors with patient-reported neck disability were studied (Paper II).

Results: With the exception of greater expectation fulfilment in patients who received structured postoperative physiotherapy $(p=0.01)$, there were no differences between the treatment groups in outcomes at 6 months after surgery. There were no differences reported for changes in outcomes from before surgery to 6 months 
after surgery between the groups, but all outcomes significantly improved from baseline in both groups ( $<$ 0.001) (Paper III \& IV). However, global outcome and frequency of neck pain improved during the postoperative period only in patients who received structured postoperative physiotherapy ( $p$ < 0.01) (Paper III). Six months after surgery, patients with at least $50 \%$ attendance to treatment sessions in the structured postoperative physiotherapy group reported less neck pain frequency $(\mathrm{p}=0.05)$, and greater expectation fulfilment $(\mathrm{p}=0.001)$, and enablement $(p=0.04)$ than those who received standard postoperative approach. These patients also had larger improvements in neck functioning, arm pain and catastrophizing during the rehabilitation period from 3 to 6 months after surgery ( $p<0.03$ ). Sixtyone percent of the patients who received standard postoperative approach reported additional use of postoperative physiotherapy. These patients had a worse surgical outcome compared with patients who reported no additional use of postoperative physiotherapy. In patients with CR who were scheduled for surgery, larger errors in head repositioning accuracy were found compared to neck-healthy individuals (Paper I). Preoperative measures of neck-related body functions, mental functions and other contextual factors explained $73 \%$ of the variance in Neck Disability Index scores in patients with CR who were scheduled for surgery (Paper II).

Conclusions: The results may suggest a benefit from combining surgery with structured postoperative physiotherapy in patients with CR. Moreover, the results confirm that neck-specific exercises are tolerated by patients with $\mathrm{CR}$ after surgery. However, CR is a heterogeneous condition and specific subgroups of patients are likely to benefit from different interventions. More studies are needed to inform evidence-based clinical guidelines for the treatment of patients with CR. A broader preoperative assessment in patients with $\mathrm{CR}$ improved the description of patientreported neck disability. 


\section{LIST OF PAPERS}

I. Johanna Wibault, Jacques Vaillant, Nicolas Vuillerme, Åsa Dedering, Anneli Peolsson. Using the cervical range of motion (CROM) device to assess head repositioning accuracy in individuals with cervical radiculopathy in comparison to neck- healthy individuals. Man Ther 2013:18:403-9

II. Johanna Wibault, Birgitta Öberg, Åsa Dedering, Håkan Löfgren, Peter Zsigmond, Liselott Persson, Anneli Peolsson. Individual factors associated with neck disability in patients with cervical radiculopathy scheduled for surgery: a study on physical impairments, psychosocial factors, and life style habits. Eur Spine J 2014:23:599-605

III. Johanna Wibault, Birgitta Öberg, Åsa Dedering, Håkan Löfgren, Peter Zsigmond, Anneli Peolsson. Postoperative Physiotherapy in patients with cervical radiculopathy: outcomes at six months in a randomized clinical trial. Submitted 2015

IV. Johanna Wibault, Birgitta Öberg, Åsa Dedering, Håkan Löfgren, Peter Zsigmond, Liselott Persson, Margareta R. Jonsson, Maria Andell, Anneli Peolsson. Neck-related physical function, self-efficacy and coping strategies in patients with cervical radiculopathy - a randomized clinical trial of postoperative physiotherapy. Submitted 2015 


\section{ABBREVIATIONS}

\begin{tabular}{|c|c|}
\hline $\mathrm{ACDF}$ & Anterior cervical decompression and fusion \\
\hline ANOVA & Repeated measures analysis of variance \\
\hline BMI & Body mass index \\
\hline CBT & Cognitive behavioral treatments \\
\hline CI & Confidence interval \\
\hline CONSORT & Consolidated standards of reporting trials \\
\hline CT & Computed tomography \\
\hline $\mathrm{CR}$ & Cervical radiculopathy \\
\hline CROM & Cervical range of motion \\
\hline cAROM & Cervical active range of motion \\
\hline CSQ & Coping Strategy Questionnaire \\
\hline CSQ_CAT & Catastrophizing subscale \\
\hline CSQ_COP & Control over pain subscale \\
\hline CSQ_ADP & Ability to decrease pain subscale \\
\hline EMG & Electromyography \\
\hline HRA & Head repositioning accuracy \\
\hline HRA max & Larger error in HRA measured either after rotation to the right or the left \\
\hline $\mathrm{ICC}$ & Intra-class-correlation coefficient \\
\hline ICF & International classification of functioning, disability, and health \\
\hline IQR & Interquartile range \\
\hline LOA & Limits of agreements \\
\hline MSPQ & Modified Somatic Perception Questionnaire \\
\hline MRI & Magnetic resonance imaging \\
\hline NDI & Neck Disability Index \\
\hline NME & Neck muscle endurance \\
\hline NSAID & Non-steroidal anti-inflammatory drugs \\
\hline PCF & Posterior cervical foraminotomy \\
\hline PEI & Patient Enablement Instrument \\
\hline PPT & $\begin{array}{l}\text { Patients reporting additional use of postoperative physiotherapy in the } \\
\text { standard postoperative approach group }\end{array}$ \\
\hline $\mathrm{RCT}$ & Randomized clinical trial \\
\hline ROC & Receiver operating characteristic \\
\hline SA & Standard postoperative approach \\
\hline SD & Standard deviation \\
\hline SEM & Standard error of measurement \\
\hline SES & Self-efficacy Scale \\
\hline SPT & Structured postoperative physiotherapy \\
\hline $\mathrm{SPT} \geq 50 \%$ & $\begin{array}{l}\text { Patients with at least } 50 \% \text { attendance to treatment sessions in the structured } \\
\text { postoperative physiotherapy group }\end{array}$ \\
\hline VAS & Visual analogue scale \\
\hline WAD & Whiplash associated disorders \\
\hline Zung & Modified Self-rating Depression Scale \\
\hline
\end{tabular}




\section{INTRODUCTION}

Cervical radiculopathy (CR) caused by disc disease is a disabling condition characterized by radicular pain in one or both upper extremities, in combination with sensory, motor, and reflex changes in one or several affected nerve-root distribution [1]. Typically, neck pain is also present [2,3], and physical and psychological disability, absence due to sickness, and reduced health and quality of life are often reported by patients with CR [4]. Epidemiological studies are sparse, but an annual incidence of 83.2/100 000 with a larger proportion of men 107.3/100 000 than women 63.5/100 000 and a peak in the age group 50-54 was reported in one study in a general population [5]. Symptoms of CR have been associated to compression and inflammation of one or several nerve root(s) in the cervical spine caused by spondylotic narrowing of the intervertebral foraminal, intervertebral disc herniation or by both [6] (Fig. 1). The pathophysiological mechanisms of cervical disc disease and their relation with symptoms and disability in patients with CR are not well understood and non-surgical and surgical approaches to treatment are used. Patients with persistent CR symptoms and unsatisfactory results following nonsurgical treatment may be referred to surgery [7]. According to the Swedish spine registry, 902 first time spine surgeries due to radiculopathy were performed in Sweden in 2014 [8]. Overall good effects of surgery have been reported on arm pain and neurological symptoms [3, 7, 9-11], but the effects on neck functioning are more uncertain. Studies have shown persistent activity limitations and participation restrictions after surgery $[12,13]$. Impairments in neck-related body functions such as reduced muscle strength, neck muscle endurance (NME), and cervical active range of motion (cAROM) [13-16], as well as maladaptive coping strategies [17, 18], and fear of movement [19] have been reported in patients with CR after surgery. Neck-specific exercises and cognitive behavioural treatments (CBT) may be recommended in the managements of patients with long-lasting neck pain [20,21], and providing more extensive postoperative rehabilitation with structured physiotherapy has been suggested to improve clinical outcomes in patients with CR. Randomized clinical trials (RCTs) of postoperative physiotherapy to inform evidence-based clinical guidelines for the management of patients with CR are lacking. 


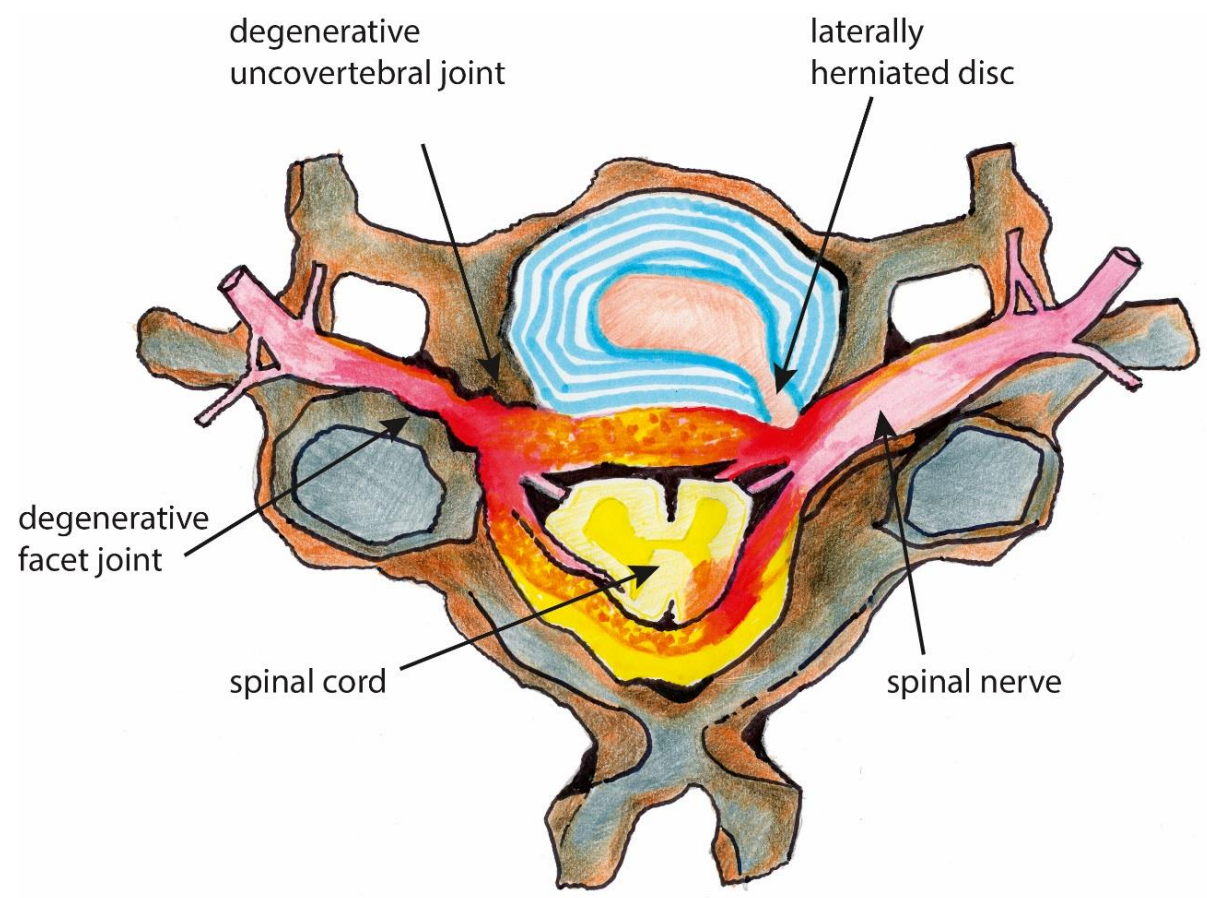

Fig. 1: Compression and inflammation of a cervical nerve root secondary to narrowing of the foraminal canal caused by structural changes of the intervertebral disc and surrounding structures 


\title{
BACKGROUND
}

\section{Patients with CR due to disc disease}

\author{
Symptoms and disability
}

CR refers to symptoms that occur in a specific dermatomal pattern in one or both upper extremities. Patients commonly describe sharp radicular pain and tingling or burning sensations in the arm, and they sometimes have sensory, motor, and reflex changes that correspond to the involved nerve root $[1,2,22]$. Typically axial neck pain is also present, and some patients report headaches and dizziness [2, 3, 2325]. Moreover, CR symptoms are commonly associated with physical and psychological disabilities, absence due to sickness, and reduced health and quality of life $[4,26]$. Evaluating the general health of patients with CR three years after surgical treatments suggests that CR symptoms have a large impact on general health that may be comparable to that reported by patients with other chronic diseases, such as angina pectoris, mental distress, diabetes, asthma, and back and shoulder pain [27].

In 1983, Henderson et al. reviewed the clinical presentation of symptoms in 736 patients with CR who were scheduled for surgery: $99 \%$ had arm pain, $80 \%$ had neck pain, $53 \%$ had scapular pain, $10 \%$ reported headache, $85 \%$ showed changes in the sensory response to pinprick, $68 \%$ had motor deficits, and $71 \%$ had reflex deficits [28]. In addition to the pain symptoms, studies also report that patients with CR may have dizziness and impairments in postural control, including impaired static and dynamic balance [14, 24, 25]. Other studies report that both before and after surgical treatment, patients with CR have impairments in neckrelated body functions such as cervical active range of motion (cAROM), neck muscle strength, and neck muscle endurance (NME) [13, 14, 16, 29, 30]. Low emotional state, sleep disturbances, anxiety and depression, high levels of kinesiophobia and fear of movement have also been observed in patients with CR [13, $18,23,31]$.

\section{Pathophysiology}

\section{Neurological symptoms}

Sensory, motor and/or reflex changes in the upper extremities are associated with mechanical distortion of one or more of the $\mathrm{C} 3-\mathrm{C} 8$ nerve $\operatorname{root}(\mathrm{s})$ in the cervical spine [1,22]. Cervical nerve roots pass through the intervertebral foramina, which are located between the uncovertebral and facet joints; these joints are involved in 
degenerative processes in the cervical spine and in the intervertebral discs in patients with CR $[6,32]$. The foramina are largest in the upper cervical spine and gradually narrow distally, which may explain why the most common level of root compression is C7 (46.3\% to 69\%) followed by C6 (17.6\% to 19\%) [32]. Moreover, the intervertebral foramina form a tunnel-like shape, with the entrance being the narrowest part. The nerve roots, on the other hand, form a conical bundle with their takeoff point in the central dural sac being their largest part. Consequently, the nerve roots are the most vulnerable to compression at the entrance of the intervertebral foramina [32]. The presence of numerous nerve root connections [32] may explain the important dermatomal overlap [33].

Spondylosis, disc herniation, instability, trauma resulting in fractures with dislocation, or more rarely tumours can cause narrowing of the intervertebral foramina; in turn this can result in mechanical compression of the nerve $\operatorname{root}(\mathrm{s})$ [2]. Spondylosis is considered the result of a cascade of degenerative changes that start in the cervical intervertebral disc [22]. For example, there are age-related biochemical, histological, and metabolic changes in the nucleus pulposus and in the annulus fibrosus. Three types of annulus tears can occur: circumferential tears, peripheral rim tears, and radial fissures. Radial fissures progress outward, allowing the nucleus to migrate toward the disc periphery. The structural changes cause the disc to shorten and bulge posteriorly in the canal $[22,34]$. Depending on the extent of nuclear migration, the disc can be said to be herniated (referring to protrusion, extrusion or sequestration of nuclear material), or prolapsed [34]. Secondary to the structural changes in the disc(s), the vertebral bodies may drift toward one another, and the ligament flavum and facet joint capsule may infold posteriorly, further decreasing the dimensions of the foraminal canal [22]. Osteophytes can form around the vertebral bodies, as well as around the uncovertebral joints anteriorly; and the facet joints posteriorly [22, 34]. Interestingly, more than half of the middle age population has radiologic evidence of asymptomatic cervical spondylosis, and spondylosis is regarded as an integral part of physiological ageing [35]. However, spondylosis is associated with symptoms of nerve root(s) or spinal cord compression (myelopathy) in $10 \%-15 \%$ of the population [36]. Spondylosis is the most common cause of CR symptoms, with a reported annual incidence of 58.5 per 100000 residents as compared to cervical disc herniation, which has a reported annual incidence of 18.6 per 100000 [5]. Disc herniation is more common in younger patients, representing $20 \%-25 \%$ of all cases [37].

\section{Radicular pain}

The pathophysiology of radicular pain is not well understood. Notably, nerve-root compression by itself does not always to lead to pain unless the dorsal-root ganglion is involved [1, 22, 38]. In addition, there is increasing evidence that for pain to develop, there must be an inflammatory response in addition to compression and 
distortion of the nerve root [22]. Reduced microcirculation secondary to compression may cause oedema and fibrosis of the nerve root, thereby increasing the sensitivity of the nerve root to pain [22]. Similarly, the release of chemical substances such as inflammatory cytokines from disc tissues in herniated discs is likely to play a role in initiating and perpetuating inflammatory responses and pain processes $[22]$.

\section{Neck pain}

Most patients with CR have neck pain [2, 3, 23, 39]. However, the origin of the neck pain remains controversial, since there are numerous structures in the cervical spine that can generate pain in the neck area [22]. The direct attribution of axial neck pain to degenerative changes in the cervical spine is questionable considering the high prevalence of degenerative changes in an asymptomatic population [35]. Nevertheless, the presence of nerve fibres and nerve endings in the peripheral portion of intervertebral discs [40], and in the facet joints [41] suggests that these structures may be involved and directly responsible for the development of axial neck pain in patients with cervical degenerative changes [22].

It has also been suggested that axial neck pain may develop secondarily to the adaptation of the muscular and ligamentous systems to degenerative changes in the cervical spine [22]. The cervical muscle system includes layers of deep and superficial muscles that play important roles in mechanical support and in the orientation of the head and neck in space [42-44]. Both structural changes and the presence of radicular pain could indirectly impact patient posture, work efficiency, and stress and could thus induce muscular fatigue with increased sensitization of nerve endings in the cervical muscle causing neck pain. However, the pathophysiology of muscular pain remains poorly understood [22]. Moreover, deconditioned neck muscles may be responsible for persistent neck pain symptoms in patients with other long-lasting neck disorders [45]. Studies have shown that muscle behaviour is altered in patients with long-lasting neck pain. Specially, there may be increased activity in the superficial neck muscles, reduced activity in the deep cervical muscles [46, 47], increased co-activation [48, 49], and reduced muscle strength and endurance [50]. In patients with CR, neck muscle strength and NME is impaired both before and after surgical treatment relative to neck-healthy individuals $[13-16,29]$. Such impairments may contribute to the development of pain and disability in patients with CR.

\section{Natural course}

Little is known about the natural course of CR due to the lack of prospective longterm cohort studies of untreated patients [51]. Spontaneous improvement was reported in $46 \%$ of patients $(n=41)$ in one 10-year follow-up study [52]. Most studies in patients with $\mathrm{CR}$ include various treatment alternatives and do not reflect the natural history of the disease. However, based on reports of symptom improvement 
regardless of intervention assignment, the natural course of the condition is considered to be favourable $[37,53]$. A recent systematic review on the course and prognosis of cervical disc herniation found that; substantial improvements were reported within the first 4 -6 months after onset, and $83 \%$ of all cases recovered completely within $2-3$ years [54]. Studies of the course of CR associated with spondylosis are lacking [54].

\section{Management of patients with CR}

\section{Diagnosis of CR}

Patient history and clinical examination are essential for confirming a diagnosis of $\mathrm{CR}$ as well as for ruling out concomitant myelopathy. Patients commonly describe a slow onset that can be explained by gradual foraminal narrowing. However, onset may also be more sudden in cases of acute disc herniation. Radiating arm pain and sensory deficits are often aggravated by a movement that involves neck extension and rotation of the head toward the affected side; when this movement causes pain, the patient is said to have a positive Spurling's test [55]. The Spurling's test has high sensitivity but low specificity and is considered more useful for confirming the $\mathrm{CR}$ diagnosis than for ruling it out $[55,56]$. For the diagnosis, examination of sensory and motor disturbances are performed to determine the level of suspected nerve root compression. However, the clinical findings are generally not very precise because of the substantial overlap of cervical nerve roots in the brachial plexus [33].

Accordingly, magnetic resonance imaging (MRI) or its predecessor computed tomography (CT) should be used to confirm the diagnosis of CR. Moreover, the findings on these imaging modalities must always be correlated with the symptoms and findings from the clinical examination [57].

\section{Non-surgical treatments}

Initially, patients with CR are usually treated non-surgically given the rather favourable natural course of the condition [53]. However, little is known about the effectiveness of these non-surgical treatments compared with no treatment or surgical care [53, 58]. Moreover, there are no evidence-based clinical guidelines for non-surgical treatment of CR due to the lack of well-designed studies [53], and due to the lack of uniform diagnostic criteria in the studies that evaluated nonsurgical treatments [59].

Analgesics and a wait-and-see policy are often used in the early phase [37]. Analgesics include non-steroidal anti-inflammatory drugs (NSAIDs), paracetamol, and various opioids [37]. Transforaminal steroid injections may also be used 
[60-62], and have been shown to relieve pain in prospective studies [61, 62]. However, no evidence of pain relief was found in one RCT, and notably, evidence supporting the use of drugs remains weak [60].

Other common treatment modalities include physiotherapy, and neck immobilization with a neck collar [53]. Physiotherapy may include passive and active treatments such as cervical traction, application of heat or cold, massage, transcutaneous electrical nerve stimulation, manual therapy, exercise therapy, and CBT [63]. Neural tissue management is another suggested physiotherapy treatment for patients with CR [64]. The evidence of the effectiveness of different physiotherapy treatments in the management of patients with CR is inconclusive [63]. However, the use of manual therapies, exercise therapies, and CBT appear to be somewhat beneficial [63]. Recently, structured physiotherapy that combined neck-specific exercises and a behavioural approach was compared to surgery and additional SPT in patients with CR. Based on the 2-year results, the authors suggested that structured physiotherapy be tried before surgery [65, 66]. Notably, an RCT is currently investigating the benefits of structured physiotherapy that combine neck exercises with a behavioural approach versus prescribed physical activity for patients with CR [67].

\section{Surgical treatments}

Patients with persistent CR symptoms and unsatisfactory results after non-surgical treatment may be referred to surgery $[7,57,68]$. Surgery primarily aims to address the structural changes in the cervical spine to relieve arm pain and prevent further neurological symptoms by decompressing the nerve root [69]. Both anterior and posterior surgical approaches have been developed [70]. Anterior cervical decompression and fusion (ACDF) is a common approach that includes removal of the $\operatorname{disc}(s)$ and adjacent osteophytes plus fusion [69]. The original technique was developed by Cloward, Smith and Robinson in the 1950s [71]. This group used either autogenous bone transplants from the iliac crest or allogenous bone transplants to replace the disc(s), restore disc height, and achieve fusion. Others evaluated the use of different types of artificial intervertebral implants [9, 11, 69]. Bone autografts have been associated with improved fusion rates $[9,11,72]$, whereas artificial intervertebral cages reduce donor site pain $[9,11]$.

Evaluation of clinical outcomes has not yet identified a single ideal material or surgical method [72]; accordingly, the choice of surgical technique is based on the patient's and surgeon's experience, and preferences as well as on the costs [7, $69,70]$. The clinical outcomes after surgery for CR vary from fair -to - good, depending on the outcome measure that is used and on the time to follow-up [10, 12, 13, 73-75]. It is not clear whether surgery is superior to other non-surgical approaches due to a lack of studies and to the difficulties that are inherent in performing well -designed studies in patients with CR [31, 58, 65]. 


\section{Postoperative care and physiotherapy}

Few reports in the literature address postoperative care and postoperative physiotherapy in patients with CR. Patients are generally encouraged to return to normal activities after 6 weeks [3]. In one prospective study, 30\% of patients with CR reported using postoperative physiotherapy [76]. Based on the results of a pilot study, using a rigid cervical collar for the first 6 postoperative weeks may help some patients cope with the pain and disability after surgery [77]. In Sweden, patients undergoing cervical spine surgery due to disc disease are generally advised to minimise heavy lifting, driving a car, and overhead work in the first 6 weeks after surgery. However, they are encouraged to stay active and are given instructions and information about good posture plus mobility exercises for the shoulders and, later on, for the neck. Patients are discharged from the spinal centres after a follow-up visit with the surgeon at approximately 6 weeks; thereafter, they are advised to contact primary health care centres for additional treatment after surgery that may include pragmatic physiotherapy when needed.

Some studies have reported on persistent activity limitations and participation restrictions after surgery $[12,13]$ and; on post-surgical impairments in neck-related body functions such as reduced muscle strength, NME, and cAROM [13-16]. Other reports that patients with CR may display maladaptive coping strategies [17, 18], and a fear of movement after surgery [19]. The provision of more extensive and structured postoperative physiotherapy has been suggested to improve the clinical outcomes of patients with CR after surgery [13, 14]. One recent RCT compared surgery combined with SPT with structured physiotherapy alone in patients with CR [65]. Based on the 2-year outcomes, the results looked promising for structured physiotherapy before and after surgery in patients with CR [65, 66]. Due to the lack of studies that address the use of postoperative physiotherapy, evidencebased clinical guidelines for postoperative physiotherapy cannot be developed in patients with CR [7]. Moreover, based on my own clinical experience as a physiotherapist, many physiotherapists lack knowledge of and experience with physiotherapy treatments in patients with CR. Accordingly, neck-specific exercises are rarely used.

\section{Evidence-based physiotherapy in patients with long-lasting neck pain}

\section{Exercise therapy for the neck muscles}

Many patients with neck pain also have impairments in neck muscle function [78]. Consequently, numerous studies describe the use of exercise therapy as a treatment approach in the management of patients with neck disorders [20]. The literature 
described a broad spectrum of exercise approaches and suggested doses; such approaches include specific neck and shoulder exercises, general exercises, and stretching, strengthening, endurance, functional and proprioception exercises [20, 79-81]. However, few conclusions can be drawn because of the variety of exercise approaches and the general low quality of the studies [20]. Exercise therapy is regarded as a safe treatment approach for mechanical neck pain [20]. There is moderate quality evidence for the use of strengthening and endurance exercises for the cervico-scapulothoracic and shoulder region to reduce pain and improve function at short- and intermediate -term [20]. Currently, there is no evidence that a particular exercise approach is superior to others [20, 81, 82].

\section{Cognitive-behavioural treatments}

The aetiology of neck pain is multifactorial, and risk factors include both social and psychological factors [83]. Specially, long-lasting neck pain has been linked to psychological factors including distress, anxiety and depressed mood, as well as to cognitive and behavioural factors that may directly contribute to disability and pain and act as barriers to recovery [84]. Higher levels of catastrophizing, and lower levels of self-efficacy are associated with higher disability in patients with long-lasting neck pain. Accordingly, physiotherapy treatments often utilise strategies that aim to address these factors $[85,86]$. CBT is an umbrella term for different types of interventions that target cognitive and behavioural factors. CBT can be used alone or in addition to other treatments, and it can be delivered by different kinds of professionals [21]. Overall, there is low to moderate quality evidence supporting the use of CBT in patients with long-lasting neck pain [21]. There is no clear benefit to adding physiotherapist-led CBT to an exercise program in patients with chronic neck pain and whiplash associated disorders (WAD) [87, 88]. In lumbar fusion patients, on the other hand, postoperative physiotherapy that targeted maladaptive pain cognitions, behaviours, and motor control showed better outcomes than home-based exercises [89].

\section{Facilitators of exercise therapies}

Exercise intervention in physiotherapy can vary according to exercise type, dosage, and mode of delivery; the latter may include individual treatment, group programs, home-based programs, or a mixed-mode delivery that combine individual treatment sessions with home-based programs [90]. No single mode of delivery has shown clear superiority to the others, but in patients with knee osteoarthritis, individual treatments as compared to class-based and home-based programs show the greatest treatment effects [90]. Likewise, patients with knee osteoarthritis reported higher adherence with exercise regimens during regular physiotherapist visits [91]. A systematic review showed that in patients with chronic low back pain, 
individually designed supervised exercise programs were associated with decreased pain and improved function [92]. Professional supervision during regular physiotherapist visits is regarded as important for patient adherence to exercise therapy and for the effects of treatment on pain and function [92].

\section{Perspectives on outcome measures}

\section{The biopsychosocial model of illness and disease}

The biopsychosocial model of illness introduces a broader perspective on health and illness; and suggests that psychological and social factors be considered along with biological variables in order to understand individuals' experiences of illness and disease [93, 94]. Moreover, biopsychosocial factors have been linked to chronicity of symptoms and disability in musculoskeletal disorders including neck pain $[84,95]$. Biopsychosocial prognostic factors are known to be important determinant of outcomes in musculoskeletal disorders, although, no clear set of prognostic factors has been identified yet [96]. Most research has focused on low back pain and screening for psychosocial risk factors is recommended in the management of low back pain $[97,98]$. Psychosocial factors have also been investigated in patients with $\mathrm{CR}$, however, there are conflicting results regarding their predictive value for surgical outcome $[19,99,100]$. It has been suggested that psychosocial factors should not only be regarded as prognostic factors, but that outcomes should also be evaluated from a biopsychosocial perspective to improve understanding of the development of illness and disease over time [96].

\section{The international classification of functioning, disability, and health}

In 2001, the World Health Organization (WHO) endorsed the international classification of functioning, disability and health (ICF) as a conceptual framework for improving and facilitating the understanding and organization of all of the information that is gathered and associated with particular health conditions [101]. Functioning and disability are umbrella terms used to describe human experiences. "Functioning" refers to body functions and structures, as well as, to activities and participation in activities. "Disability" describes impairments, such as changes or loss of body functions and structures; activity limitations, such as difficulties experienced in performing activities; and participation restrictions such as problems experienced in real life situations [101]. The ICF framework is based on an integrative biopsychosocial model and acknowledges the influence of contextual factors, both personal and environmental, on individuals' experiences of functioning and disability [101]. 
According to the ICF, an evaluation of disability in patients with $\mathrm{CR}$ should include evaluations of impairments at different levels, including body functions and structures, activity limitations, and participation restrictions. No ICF core set has been developed so far to evaluate all the aspects of disability and functioning in patients with $\mathrm{CR}$, but empirical guidelines recommend the use of separate ratings for neck and arm pain and use of the NDI to evaluate patient-reported neck disability [7, 102]. Some studies have reported the outcomes of clinical evaluations of neck-related body functions including neck muscle strength, NME, and cAROM [13-16, 30]. Disturbances in sensorimotor function have been associated with symptoms of neck pain and dizziness, and assessment of head repositioning accuracy (HRA) is recommended in the management of patients with other neck pain disorders [103, 104]. No studies have evaluated sensorimotor function in patients with CR. Moreover, a biopsychosocial approach to illness and disease may suggested that it is appropriate to evaluate other ICF domains, including mental function, and contextual factors to broaden the clinical picture of disability in patients with CR [96]. In the present thesis, the ICF framework was used to classify the outcome measures as measures of neck-related body functions, mental functions, and contextual factors.

\section{The patient's perspective on treatment outcomes}

In chronic pain trials, estimating patients' perceptions of the advantages and disadvantages of treatment is an important outcome measure [105]. This can be assessed using different approaches; in particular it may be appropriate to use a single-item scale or rating to measure patients' perceptions of improvement as well as changes in symptoms [105]. Patient satisfaction with treatment has been suggested as an alternative outcome for evaluating treatment success [106], and it is generally accepted that a measure of patient satisfaction should be included in evaluation after cervical spine surgery [107]. Patient satisfaction after cervical spine surgery has been associated with improved functional outcomes [107]. However, patient satisfaction as outcome measure is controversial, and it has been suggested that it may be related more to patients' expectations and fulfilment of expectations than to functional outcomes [108]. When assessing patient satisfaction with treatment, one limitation is that this measure may reflect satisfaction with the outcome, with delivery of care, or with both [109]. One objective of physiotherapy for chronic health conditions is to promote both short- and long-term self-management [110]. It may therefore be important to evaluate the extent to which the treatment enhances an individual's confidence and his or her ability to cope with their illness or disease [111]. The Patient Enablement Instrument (PEI) was developed for the purpose of capturing dimensions other than patient satisfaction in primary health care research such as the impact of a consultation on a patient's self-perceived ability to understand and cope with health issues and disease [109]. One study 
suggests that enablement be used as an alternative outcome measure of patient satisfaction, since this requires patients to evaluate outcomes rather than to simply evaluate aspects of the care process [109]. 


\section{Rationale of the thesis}

Patients with persistent CR symptoms and unsatisfactory results after non-surgical treatment may be referred to surgery $[7,57,68]$. Overall, good effects on arm pain and neurological symptoms have been reported after surgery in patients with CR $[3,9-11,75]$. However, the effects on neck functioning are more uncertain. Studies have shown persistent activity limitations, and participation restriction after surgery $[12,13]$. Impairments in neck-related body functions such as neck muscle strength, NME, cAROM, and postural control [13-16, 25]; maladaptive coping strategies [17, 18], as well as fear of movement [19] have been reported after surgery in patients with CR. Neck-specific exercises and CBT may be recommended in patients with long-lasting neck pain [20,21], and providing more extensive postoperative rehabilitation with structured physiotherapy has been suggested to improve clinical outcomes in patients with CR [13, 17]. Structured physiotherapy combining neck-specific exercises with a behavioural approach has been suggested as treatment before as well as after surgery in patients with CR $[65,66]$. RCTs of postoperative physiotherapy to inform evidence-based clinical guidelines for the treatment of patients with $\mathrm{CR}$ are lacking. The contribution of different aspects of neck-related body functions, mental functions, as well as contextual factors on preoperative patient-reported neck disability in patients with CR also need to be studied to increase understanding about neck disability and develop effective treatment strategies for the management of patients with CR. 



\section{AIMS OF THE THESIS}

\section{Overall aims}

The overall aim of this thesis was to investigate the additional benefit of structured postoperative physiotherapy (SPT) combining neck-specific exercises with a behavioural approach compared to standard postoperative approach (SA) in patients with CR. A further aim was to evaluate different aspects of neck-related body functions and mental functions on preoperative neck disability in these patients.

\section{Specific aims}

- to evaluate in patients with CR scheduled for surgery head repositioning accuracy (HRA) using a cervical range of motion (CROM) device and in comparison to neck-healthy individuals

- to study in patients with CR scheduled for surgery associations between measures of neck-related body functions, mental functions, and contextual factors with patient-reported neck disability as measured with the Neck Disability Index (NDI)

- to compare SPT with SA in patients with CR at 6 months after surgery based on patient-reported measures of pain, neck functioning, global outcome, clinical evaluations of neck-related body functions, self-efficacy, coping strategies, expectation fulfilment, and enablement 


\section{MATERIALS AND METHODS}

\section{Design and overview of the thesis}

The thesis is based on data collected in patients with CR undergoing surgery $(\mathrm{n}=$ 202) who were enrolled in a RCT of postoperative physiotherapy (Paper II, III \& $I V)$. A sub-sample of patients with CR who were participating in the RCT ( $\mathrm{n}=71)$, and a sample of neck-healthy individuals $(\mathrm{n}=173)$ were also recruited to participate in an experimental study about HRA assessment with a CROM device ( $\mathrm{Pa}$ per I). In addition to the results presented in the papers (Paper I-IV), extra analysis are presented in the frame of the thesis.

An overview of the papers included in the thesis is presented in Table 1:

In patients with CR who were scheduled for surgery, assessment of HRA with a CROM device was compared to age- and sex-specific reference values in neckhealthy individuals. Patients were also classified as having or not HRA impairment and some of the measurement properties of the CROM device to assess HRA in patients with CR were investigated (Paper I). Associations between measures of neck-related body functions, mental functions and contextual factors with patientreported neck disability as measured with the NDI were studied in patients with CR who were scheduled for surgery (Paper II). The additional benefit of SPT compared to SA in patients with CR was investigated in a RCT. Between-group differences in outcomes at 6 months after surgery and in changes in outcomes from before surgery to 6 months after surgery were studied for patient-reported measures of pain intensity, neck functioning, and global outcome (Paper III); as well as clinical evaluations of neck-related body functions, self-efficacy and coping strategies (Paper IV). Additional use of postoperative physiotherapy 6 months after surgery was collected in patients who received SA (Paper III). Within- and between-group differences in treatment effects during the postoperative period were analysed (Paper IV).

In addition, the following analysis were added in the thesis:

Assessment of HRA with the CROM device in patients with CR 6 months after surgery was compared with reference values in neck-healthy individuals. The sensitivity and specificity of different discriminative value for HRA impairment were studied. In the RCT, between- and within-group differences were investigated based on measures of frequency of pain symptoms, consumption of analgesics, expectation fulfilment, and enablement. Finally, patients who reported additional use of postoperative physiotherapy were compared with patients who did no report additional use of postoperative physiotherapy in the SA group. 


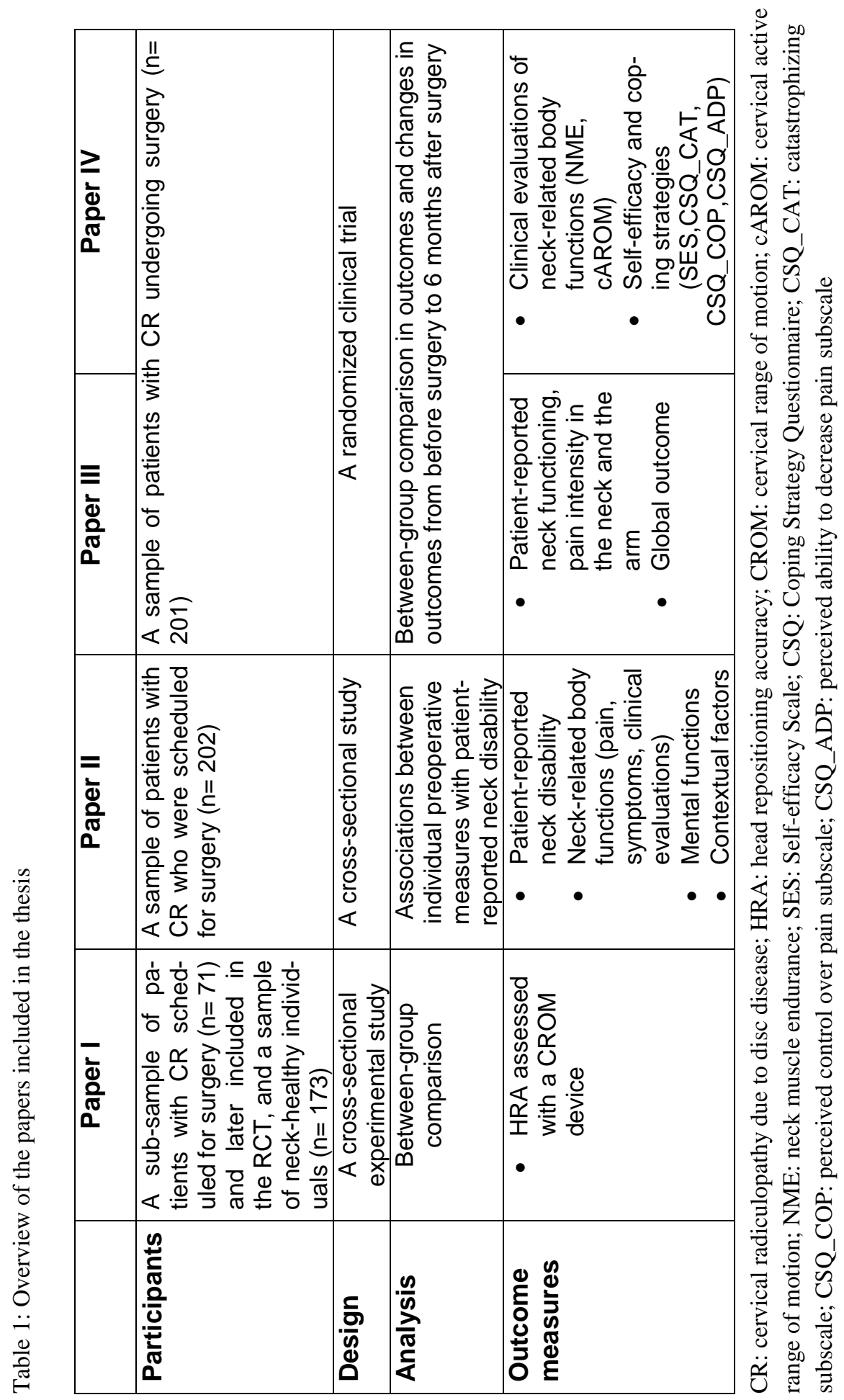




\section{Study population}

\section{Inclusion/exclusion criteria in the RCT}

Patients with persistent CR symptoms and unsatisfactory results after non-surgical treatment who were referred to surgery at one of four spinal centres in the south of Sweden between February 2009 and November 2012 were eligible to participate in the RCT of postoperative physiotherapy. The inclusion criteria were age 18 to 70 years; and symptoms and clinical findings compatible with verified cervical disc disease on MRI. The exclusion criteria included different conditions that could imply a contraindication to exercise-based physiotherapy (Table 2).

Table 2: Exclusion criteria in the randomized clinical trial of postoperative physiotherapy in patients with cervical radiculopathy.

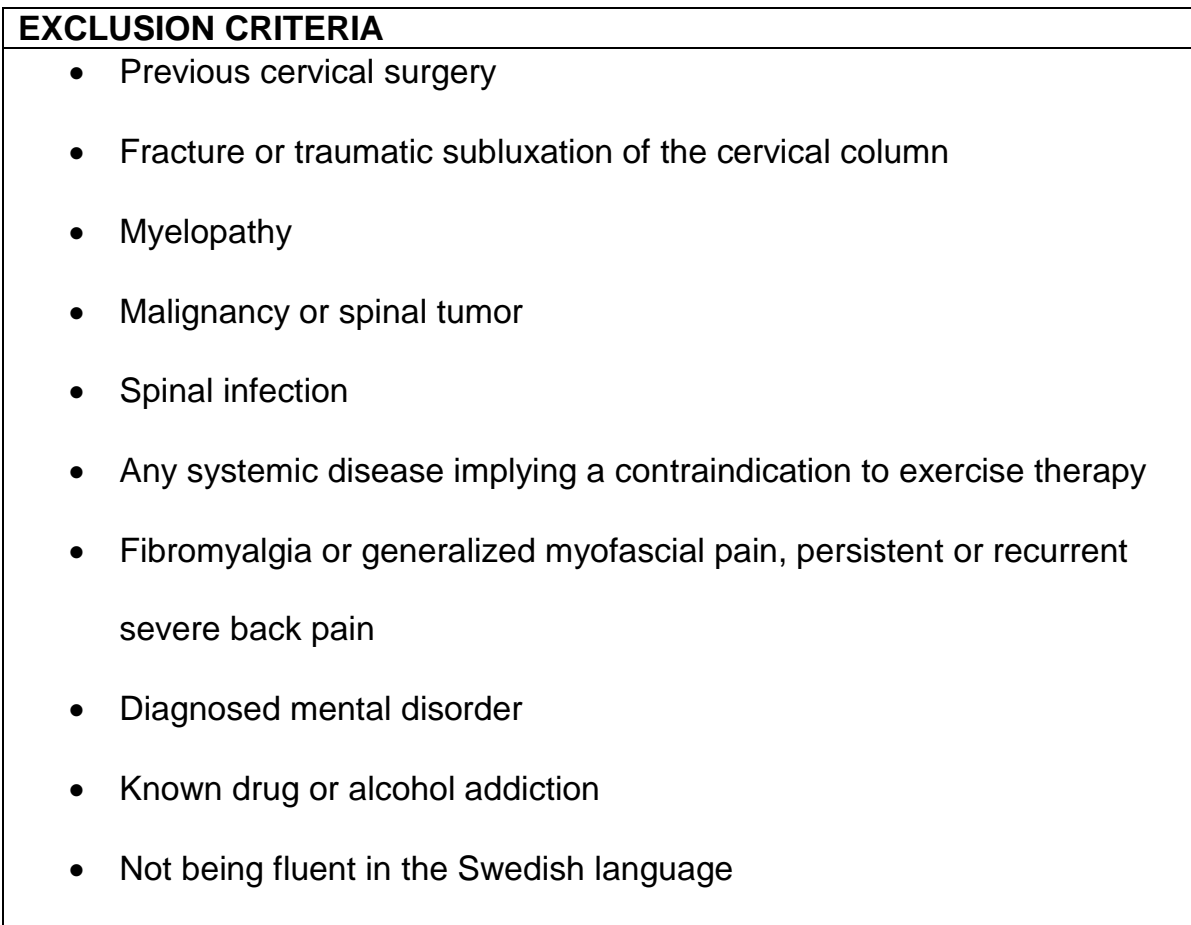




\section{Participants}

\section{Patients with $C R$}

A total of 202 patients with CR who were scheduled for surgery and fulfilled the criteria for participation in the RCT were included at the four spinal centers. Participants were randomized pre-operatively to receive SPT $(n=101)$ or SA after surgery $(n=101)$. Randomization was performed by the central project leader who was not involved in any of the treatments or measurements. A random computer list developed by a statistician was used. One patient was excluded due to cancelled surgery $(n=201)$. Background variables for the study participants are presented in Table 3.

Table 3: Background variables for patients with cervical radiculopathy who were scheduled for surgery and included in the randomized clinical trial $(n=201)$

\begin{tabular}{lrr} 
BACKGROUND VARIABLES & Scores & Ranges \\
\hline Male sex, \% $(\mathrm{n})$ & $52(105)$ & \\
Age in years, mean (SD) & $50(8.4)$ & $22-70$ \\
Height in cm, mean (SD) & $174(8.9)$ & $152-195$ \\
Weight in kg, mean (SD) & $81(15.0)$ & $50-125$ \\
BMI kg/m², mean (SD) & $27(3.9)$ & $19-38$ \\
Right hand dominant, \% (n) & $95(188)$ & \\
Unilateral symptoms, \% $(\mathrm{n})$ & $92(176)$ & \\
\hline
\end{tabular}

$\mathrm{BMI}=$ body mass index

A sub-sample of patients with $\mathrm{CR}$ ( $\mathrm{n}=71,38$ men and 33 women) was asked to participate in the experimental study of HRA assessment with a CROM device (Paper I). These patients were scheduled for surgery and recruited at the neurosurgery department at Linköping University Hospital in Sweden between February 2009 and December 2011. They were later enrolled in the RCT of postoperative physiotherapy. Twenty-four of these patients (14 men, 10 women) also contributed to the evaluation of the test-retest reliability and measurement error of the CROM device to assess HRA in patients with CR (Table 4).

\section{Neck-healthy individuals (Paper I)}

A sample of neck-healthy individuals was recruited to provide age- and sex- specific reference values for the assessment of HRA with a CROM device. Individuals permanently employed at the University Hospital in Linköping were stratified according to sex and age and randomly selected (computerized random list developed by a statistician) to be asked to volunteer in the comparative study of HRA assessment (640 individuals; 340 men; 300 women). A total of 149 individuals (75 
men; 74 women) met the inclusion criteria of no self-reported current neck disorders that included score on the NDI < 20\% [112], pain on the visual analogue scale (VAS) $\leq 10 \mathrm{~mm}$ [113]; and no recurrent neck or low back pain, inflammatory joint disease, or other systemic disease during the last three years. Ten of the recruited men were unable to attend the testing. The sample was filled with 34 individuals (employees and students from a university) to include at least 80 men and 80 women (20 individuals in each of the following age intervals: $25-34$, 35- 44, 4554 and 55- 64 years) [114]. Background variables for the 173 neck-healthy individuals ( 86 men and 86 women) are presented in Table 4 . The neck-healthy individuals differed significantly from the patients with $\mathrm{CR}$ included in the experimental study $(n=71)$ for age, and body mass index $(B M I)(p<0.001)$.

Table 4: Background variables for patients with cervical radiculopathy $(\mathrm{n}=71)$ and neckhealthy individuals $(\mathrm{n}=173)$ who were included in paper I.

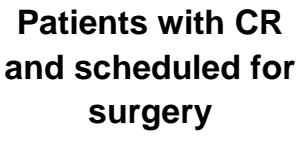

\begin{tabular}{lccc}
\hline BACKGROUND VARIABLES & Total & $\begin{array}{c}\text { Reliability } \\
\text { study }\end{array}$ & Total \\
n & 71 & 24 & 173 \\
Male sex, \% (n) & $53(38)$ & $58(14)$ & $50(86)$ \\
Age in years, mean (SD) & $50(10.0)$ & $51(8.4)$ & $44(12.0)$ \\
Height in cm, mean (SD) & $175(8.9)$ & $176(9.0)$ & $173(8.4)$ \\
Weight in kg, mean (SD) & $84(15.7)$ & $83(12.0)$ & $74(11.6)$ \\
BMI kg/m ${ }^{2}$, mean (SD) & $27(4.4)$ & $27(3.7)$ & $24(3.0)$ \\
Right hand dominant, \% (n) & $94(67)$ & $92(22)$ & $93(160)$ \\
Duration neck pain in months & & & \\
median (IQR) & $19.5(26.0)$ & & \\
NDI \%, mean (SD) & $43(14.4)$ & $42(15.0)$ & $2(0)$ \\
Neck pain VAS mean (SD) & $48(23.0)$ & $43(26.1)$ & $0(0)$ \\
\hline CR:
\end{tabular}

CR: cervical radiculopathy; BMI= body mass index; NDI: Neck Disability Index; VAS: visual analogue scale

\section{Ethical considerations}

The studies were performed in accordance with the Declaration of Helsinki ethical principles for medical research. Participation was voluntary and all participants received oral and written information about the study. Written informed content was provided before patients were included. Patients were thereafter free to interrupt their participation at any time without explanation and without negative consequences on future treatment. There was no known risks associated with partici- 
pation in the study, except possible muscle soreness after exercise. The physiotherapists involved in the study were all registered at the National Board of Health and Welfare in Sweden. The study was approved by the Regional Ethics Review board in Linköping, Sweden (Dnr- M126-08). The protocol for the RCT was registered in Clinical Trial Identifier (NCT01547611), and published [66]. The questionnaires, and all data collected during the clinical examinations were anonymized and stored in secure lockers at Linköping University. 


\section{Patient flow}
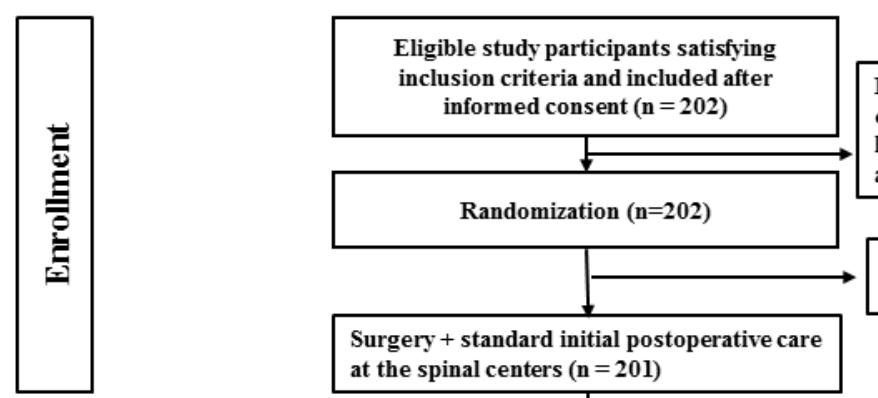

Participation in the experimental study on head repositioning accuracy $(n=71)$

Excluded due to cancelled surgery $(n=1)$

Surgery + standard initial postoperative care at the spinal centers $(n=201)$

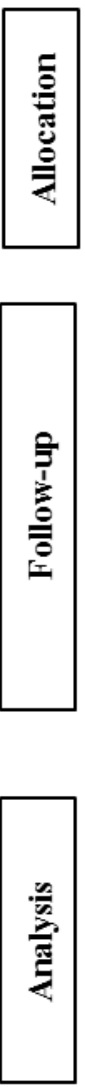

Structured postoperative physiotherapy

- Allocated to intervention $(n=101)$

- Did not receive allocated intervention $(n=29)$; reasons: never started ( $n=10)$, interrupted ( $n$ =19)

- Missing report on attendance rate $(n=5)$

- $\geq 50 \%$ attendance to treatment sessions ( $n=67$ )

Follow-up at 3 months

Primary outcome NDI $(\mathrm{n}=91)$, Lost to follow-up $(n=10)$; Clinical evaluations of neck-related body functions ( $\mathrm{n}=65-95)$, Lost to follow-up $(n=6-36)$; Self-efficacy and coping strategies $(\mathrm{n}=85-87)$, Lost to follow-up $(n=14-16)$

\section{Follow-up at 6 months}

Primary outcome NDI $(\mathrm{n}=89)$, Lost to follow-up $(n=12)$; Clinical evaluations of neck-related body functions $(\mathrm{n}=65-89)$, Lost to follow-up $(n=12$ $36)$; Self-efficacy and coping strategies ( $n=88-90$ ), Lost to follow-up $(n=11-13)$
Standard postoperative approach - Allocated to intervention $(n=100)$
Follow-up at 3 months

Primary outcome NDI $(\mathrm{n}=79)$, Lost to follow-up $(n=21)$; Clinical evaluations of neck-related body functions ( $\mathrm{n}=61-93)$, Lost to follow-up $(n=$ 7-39); Self-efficacy and coping strategies $(\mathrm{n}=78$ 80), Lost to follow-up $(n=20-22)$

\section{Follow-up at 6 months}

Primary outcome NDI $(\mathrm{n}=81)$, Lost to follow-up $(n=19)$; Clinical evaluations of neck-related body functions $(\mathrm{n}=56-82)$, Lost to follow-up ( $n=$ 18-44); Self-efficacy and coping strategies ( $\mathrm{n}=$ 79-81), Lost to follow-up $(n=19-21)$

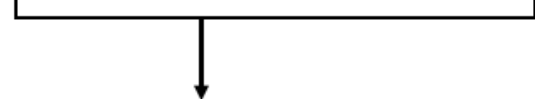

Primary outcome NDI $(n=81) ; \geq 50 \%$ attendance to treatment sessions $(n=59)$

Clinical evaluations of neck-related body functions ( $n=40-84) ; \geq 50 \%$ attendance to treatment sessions $(n=29-60)$

Self-efficacy and coping strategies $(\mathrm{n}=56-86)$; $\geq 50 \%$ attendance to treatment sessions ( $n=43-62$ )
Primary outcome NDI $(\mathrm{n}=74)$

Clinical evaluations of neck-related body functions $(n=28-79)$

Self-efficacy and coping strategies $(n=42-80)$

Fig. 2: Flow-chart of the inclusion process for patients with CR who participated in the randomized clinical trial and the experimental study. 


\section{Interventions}

\section{Surgical treatments and standard postoperative care at the spinal centres}

The surgical procedures included ACDF $(\mathrm{n}=163)$ or posterior cervical foraminotomy (PCF) with or without laminectomy $(\mathrm{n}=38)$. In $\mathrm{ACDF}$, cages filled with autologous bone or bone substitute collected during decompression were used to fuse the segment(s) after the disc(s) and osteophyte(s) were removed. No iliac crest graft was taken. In two-level $(n=62)$ and three-level ACDF $(n=2)$, an anterior plate was added in most cases to achieve primary stability. The standard cage(s) at each spinal centre was used. PCF was performed at one-level $(\mathrm{n}=7)$, two levels $(n=15)$, or $>$ three levels $(n=16)$ without fusion. During the first 6 weeks after surgery, all the patients received standard postoperative care at the spinal centres. This included recommendations to minimise heavy lifting, driving a car, and overhead work; information and instructions about good posture; as well as instructions about mobility exercises for the shoulders. The patients returned to the spinal centres for a follow-up visit with the surgeon at approximately 6 weeks after surgery. They were on that occasion examined and instructed in mobility exercises for the neck by the physiotherapist working at the spinal centre (Table 5). Patients were thereafter discharged from the spinal centres and advised to contact primary health care centres for additional treatment after surgery when needed.

\section{Structured postoperative physiotherapy (SPT)}

Patients randomized to SPT were after discharge from the spinal centres referred to a physiotherapist working in outpatient care who was recruited on a geographical basis and introduced to the study by the central project leader. A total of 45 physiotherapists monitored SPT in patients with CR. SPT combined exercise therapy for the neck, trunk and scapula with a cognitive-behavioral approach to pain and stress management. Swedish physiotherapists have basic knowledge in CBT, and the recruited physiotherapist were introduced to the study by the project leader through written and oral communication, as well as a short practical training session. The neck-specific exercises aimed to activate the deep cervical muscles, and next to improve neuromuscular control and endurance of the neck muscles [115]. The exercises were to be progressed by the physiotherapists. Patients visited the physiotherapist once weekly from week 6 to 12 after surgery, and twice weekly thereafter, and also performed exercises at home. The rehabilitation was to continue for a maximum of 20 weeks, and at discharge, patients were encouraged to continue with the exercises and increase their overall activity level (Table 5). 
Standard postoperative approach (SA)

SA was in accordance to Swedish standard postoperative care and not specially design for the study. Patients randomized to SA were after discharge from the spinal centres advised to contact their primary health care provider for additional treatments after surgery that may have included pragmatic physiotherapy when needed (Table 5).

Table 5: Content of standard postoperative care at the spinal centres, structured postoperative physiotherapy, and standard postoperative approach

\begin{tabular}{|c|c|c|}
\hline \multirow{2}{*}{$\begin{array}{l}\text { Weeks } \\
0-6^{\text {th }}\end{array}$} & \multicolumn{2}{|c|}{ Standard postoperative care at the spinal centres } \\
\hline & \multicolumn{2}{|c|}{$\begin{array}{l}\text { - Advices about good posture, and about movements and } \\
\text { activities to avoid during the first postoperative weeks. } \\
\text { - Instructions about mobility exercises for the shoulders }\end{array}$} \\
\hline \multirow[t]{2}{*}{ Week 6} & \multicolumn{2}{|c|}{$\begin{array}{l}\text { - Routine visit to the surgeon and the physiotherapist at } \\
\text { the spinal centre } \\
\text { - Instructions in mobility exercises for the neck }\end{array}$} \\
\hline & $\begin{array}{c}\text { Structured postoperative } \\
\text { physiotherapy }\end{array}$ & $\begin{array}{l}\text { Standard } \\
\text { postoperative } \\
\text { approach }\end{array}$ \\
\hline $\begin{array}{l}\text { Weeks } \\
6-12^{\text {th }}\end{array}$ & $\begin{array}{l}\text { One physiotherapy session weekly } \\
\text { home exercises } \\
\text { - Non-resistance exercises in su- } \\
\text { pine position to activate the } \\
\text { deep neck muscles, dose: } 1-3 \\
\text { sets, } 3-5 \text { reps, } 2-3 \text { times daily } \\
\text { - } \text { Relaxation and body awareness } \\
\text { exercises in sitting, standing } \\
\text { and walking to reduce muscular } \\
\text { tension and inappropriate pos- } \\
\text { ture, dose: once daily } \\
\text { - } \text { Vestibular rehabilitation if } \\
\text { needed, dose: several times daily }\end{array}$ & $\begin{array}{l}\text { Advise to contact } \\
\text { primary health care } \\
\text { centre for additional } \\
\text { treatments that may } \\
\text { have included prag- } \\
\text { matic physiotherapy } \\
\text { when needed }\end{array}$ \\
\hline $\begin{array}{l}\text { Week } \\
13\end{array}$ & $\begin{array}{l}\text { Two physiotherapy sessions weekly + } \\
\text { home exercises } \\
\text { - Isometric exercises to improve } \\
\text { neuromuscular control and en- } \\
\text { durance of the deep neck mus- } \\
\text { cles, dose: } 5 \mathrm{sec}, 3 \text { sets, } 10 \text { reps, } \\
2-3 \text { times daily } \\
\text { - Activity goal setting } \\
\text { - Patient education on healing } \\
\text { and pain processes }\end{array}$ & \\
\hline
\end{tabular}




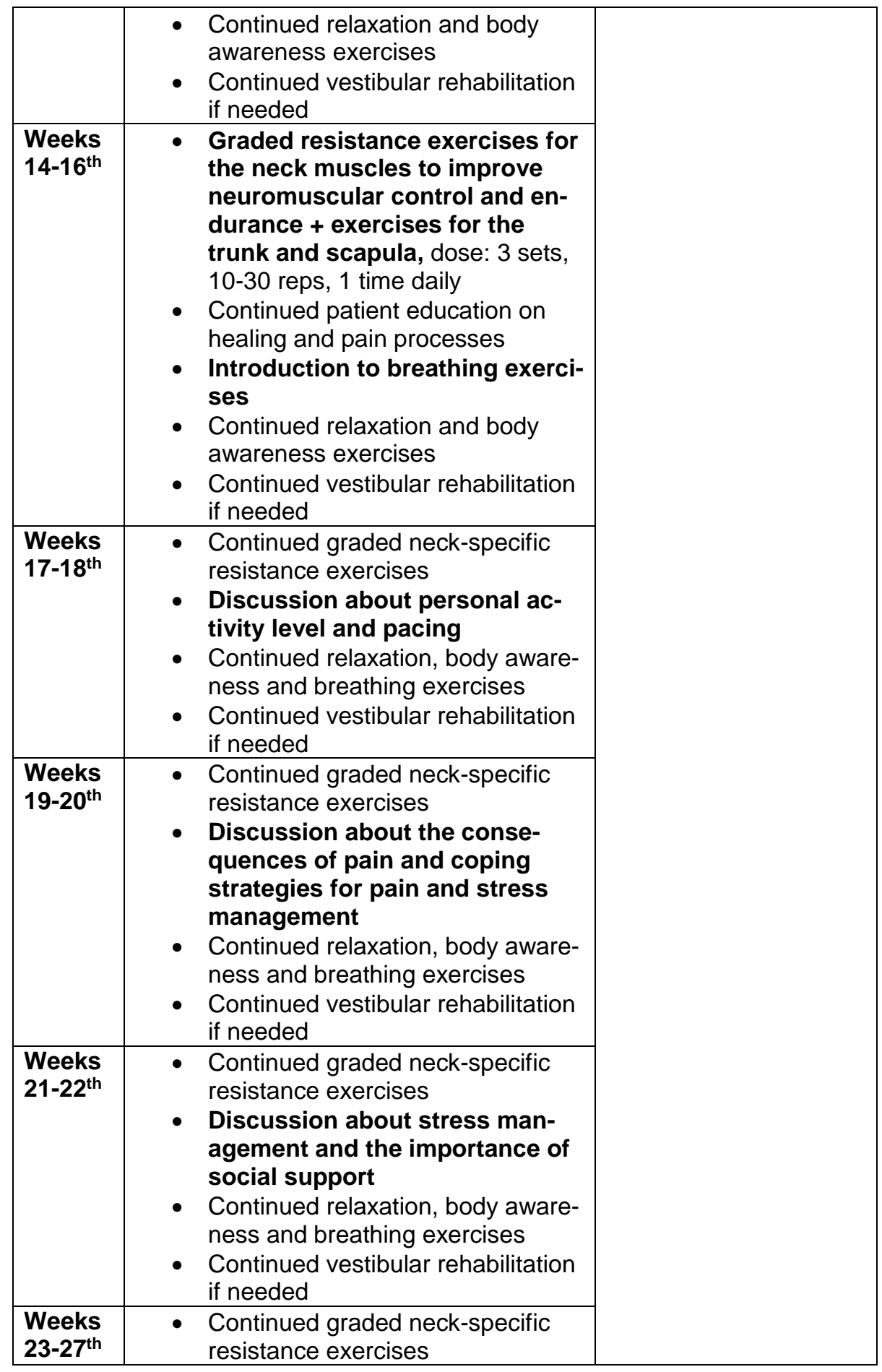




\begin{tabular}{|c|c|}
\hline & $\begin{array}{l}\text { - Patient education and implica- } \\
\text { tions regarding ergonomy and } \\
\text { physical activity } \\
\text { - Reinforcement of pain and } \\
\text { stress management strategies } \\
\text { - Prescription of general physical } \\
\text { activity } \\
\text { - Continued relaxation, body aware- } \\
\text { - } \text { ness and breathing exercises } \\
\text { if needinued vestibular rehabilitation }\end{array}$ \\
\hline
\end{tabular}

\section{Data collection}

Measurements were collected with a set of questionnaires and clinical examinations before and after treatment. Patients completed a preoperative questionnaire and were followed up at 6 weeks, 3 and 6 months after surgery. The questionnaires were sent by postal mail and collected by an independent investigator who was blinded to the randomization. Patients were reminded by postal mail and telephone contact to complete the questionnaires. The background variables age, sex, height and weight, dominant hand, presence of unilateral or bilateral arm symptoms, duration of neck and arm pain symptoms in months, and use of preoperative physiotherapy treatments in primary care or other settings during the past 12 months (yes/no) were collected in the preoperative questionnaire. The 6-week questionnaire included only a few outcome measures.

A clinical examination was performed before treatment and at 3 and 6 months follow-up. Four trained physiotherapists, one at each of the four spine centres who were blinded to the patient's randomization performed the clinical examinations. The clinical examinations were standardized and included assessment of cAROM, hand-grip strength, and NME. A neurologic examination was also performed at baseline. HRA in patients with CR was assessed before surgery and at follow-ups at two of the four spinal centres.

Surgical data included surgery with ACDF or PCF, as well as the number of operated levels and was collected though medical journals.

\section{Patient-reported neck disability}

The primary outcome in the RCT patient-reported neck disability was evaluated with the NDI [116]. The NDI was modified from the Oswestry Low Back Pain Index [112] to be suitable for cervical spine conditions and consists of 10 items (pain intensity, personal care, lifting, sleeping, car driving, recreation, headaches, concentration, reading and work). The NDI items have been connected to the ICF 
domains of body functions, activity and participation [117]. Each item is scored from 0 to 5 with a maximum point score of $50(0=$ no disability, and $50=$ complete disability). Either the point score (0-50) or a percentage score (0-100) may be used. The NDI has been evaluated in different populations with neck disorders with reported fair to moderate test-retest reliability (ICC ranging from 0.55 to 0.76 ). Acceptable values for construct validity and responsiveness have been reported in patients with CR $[118,119]$. The use of the NDI as primary outcome in patients with CR is recommended by the North American Spine Society [7]. A Swedish version of the NDI was used in the thesis [120].

\section{Neck-related body functions}

\section{Patient-reported pain and symptoms}

Current pain intensity, as well as maximal and minimal pain intensity in the past week were recorded for the neck, arm and head with a 100 mm VAS [121]. Average pain intensity in the past week was calculated as the mean of maximal and minimal pain intensity in the past week. Good reliability and validity for the 0-100 mm VAS have been reported in patients with pain [122]. Separate assessment of axial neck pain and radicular arm pain is recommended in patients with cervical spine disorders [102].

Frequency of neck pain, arm pain, headache, hand numbness, hand weakness, neck stiffness, and dizziness/unsteadiness was assessed on a 5-point scale with the following possible answers: 1 = never, 2 = sometimes, 3 = several times per week, $4=$ daily and $5=$ always. The scores were dichotomized into daily symptoms (45) or more occasional symptoms (1-3).

\section{Clinical evaluations}

\section{Neck muscle endurance}

NME was evaluated in seconds during flexion and extension [114]. NME of the cervical anterior muscles was measured with the participants in the supine position and the legs straight. Participants were instructed to flex the cervical spine by performing a slight nod, and lift the head just off the examination table [114]. NME of the cervical posterior muscles was measured with the participant in the prone position with a 2-kg weight for women and a 4-kg weight for men; and participants were instructed to extend the upper neck and point the tip of the chin towards the floor [114]. Participants were to stay in these position for as long as possible, and the tests ended at exhaustion or before if participants interrupted the test due to discomfort in the neck or the arm. Such NME measurements have shown good to acceptable reliability in patients with non-specific neck pain [123, 124]. 

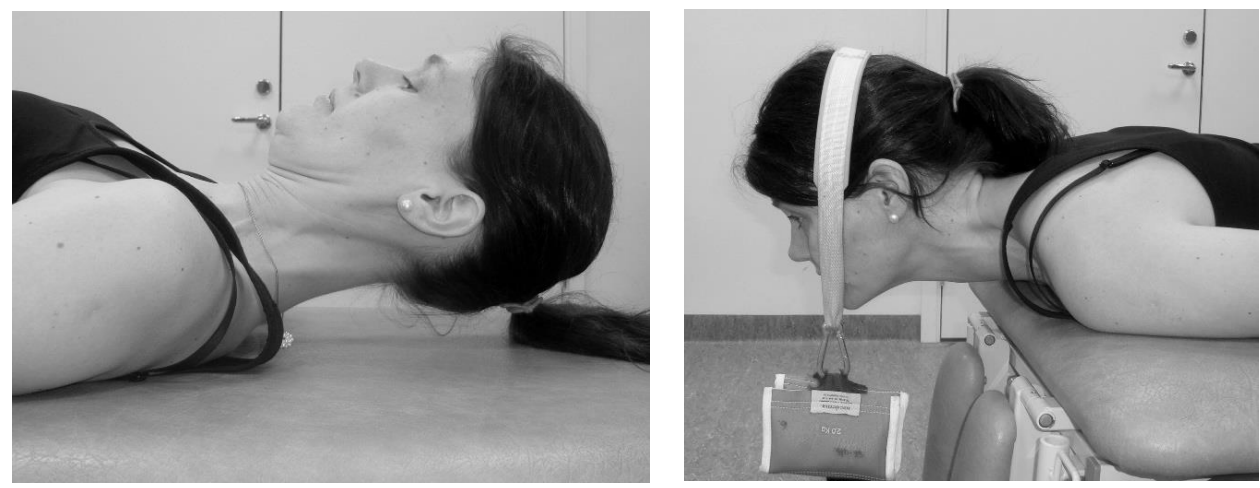

\section{Cervical active range of motion}

cAROM in the sagittal, transverse and frontal planes of movement were measured in degrees using a CROM device (Performance Attainment Associated, Roseville, MN) [125], with reportedly good reliability in patients with neck pain [126]. The patient was seated in an upright position, and the angular displacement of the head in relation to the thoracic spine was measured in flexion and extension, lateral flexion right and left, and rotation right and left [125].

\section{Hand strength}

Bilateral hand-grip strength was measured in $\mathrm{kg}$ with a Jamar isometric hydraulic hand dynamometer (Sammons Preston, Inc., Bolingbrook) [127]. Patients were standing with the elbow in $90^{\circ}$ flexion, the wrist in neutral position, and the size of the handle was set at the second position for women, and the third position for men [127].

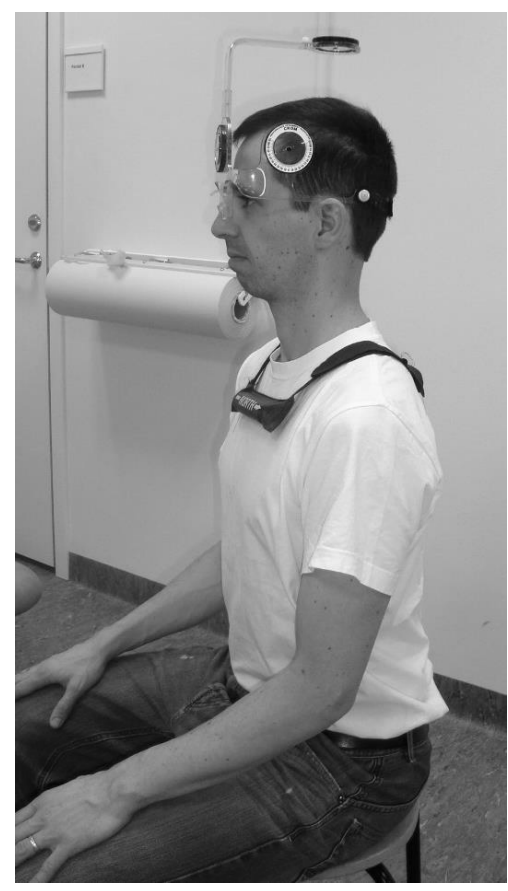
The patients were asked to squeeze the handle as hard as possible for a few seconds and the peak value was registered [127]. High reliability has been reported for measuring hand-grip strength with the Jamar dynamometer in patients with CR [127]. The percentage difference (imbalance) in hand-grip strength between sides was calculated. 


\section{Neurological symptoms}

A neurologic examination was performed by the physiotherapist who tested bilateral sensibility with a pin prick and a light touch in dermatomes C4-C8; motor function with manual muscle testing of the $\mathrm{C} 4-\mathrm{C} 8$ myotomes; and the reflexes for C5, C6, and C7 with a standard reflex hammer [128]. A preoperative impairment or asymmetry in sensibility, motor function, or reflexes was defined as any abnormal response or asymmetry in at least one of the tested dermatomes, myotomes, or reflexes [129].

\section{Assessment of head repositioning accuracy}

Assessment of HRA in patients with CR and neck-healthy individuals was performed with a CROM device according to a previous protocol [130]. Individuals were seated on a stool with no backrest, with both feet on the floor and in an upright position with a CROM device on their head. A self-chosen neutral head position was established as the starting and reference position, and the CROM device was adjusted to zero in the primary plane of movement. Individuals were instructed to close their eyes, memorize the starting position, actively rotate their head $30^{\circ}$, and reposition their head to the starting position with a maximum of precision but no requirements for speed. HRA was measured as the difference in degrees in the primary plane of movement between the starting and the return positions because this protocol previously proved valid for detecting differences in HRA between neck-healthy individuals and individuals with neck disorders [131, 132]. Individuals performed three repetitions within $60 \mathrm{~s}$ in each rotation direction, providing a total of six trials. HRA assessment in patients with CR were performed by two physiotherapists at two of the four spinal centres. HRA assessment in neck-healthy individuals were performed by three students from the Department of Physiotherapy at the University of Linköping, Sweden. The physiotherapists and the students were all previously trained in the testing procedure. The test- retest reliability and standard error of measurement (SEM) of the CROM device for assessment of HRA in patients with $\mathrm{CR}(\mathrm{n}=24)$ were determined by two repeated measurements performed by one single physiotherapist within a 1-hour interval.

\section{Mental functions}

\section{Patient beliefs, self-efficacy and use of coping strategies}

Patient's own confidence in their ability to successfully perform certain activities despite pain was assessed using the Swedish version of the Self-efficacy Scale (SES) [133-135]. The SES consists of 20 items describing the following activities of daily living: taking out the trash, concentrating on a project, going shopping, playing cards, shovelling snow, driving the car, eating in a restaurant, watching television, visiting friends, working on the car, raking leaves, writing a letter, doing a load of laundry, working on a house repair, going to a movie, washing the car, 
riding a bicycle, going on vacation, going to a park, and visiting relatives. The patients rated their ability on an 11-grade scale, with $0=$ not confident at all about performing the activity and $10=$ very confident. The total score range from 0-200, and higher scores indicate higher perceived self-efficacy.

Patient's current use of coping strategies were assessed with three subscales of the Coping Strategy Questionnaire (CSQ) [136]. The Swedish version of the CSQ was used [137]. The CSQ subscales assess the use of different strategies to cope with pain (diverting attention, reinterpret pain sensations, positive self-statements, ignore pain, praying/hoping, catastrophizing, increase activity, pain behaviour). Each subscales comprises a number of items that are scored by the patients on a 7 -point scale $(1=$ never to $7=$ always $)$. The catastrophizing subscale (CSQ_CAT) comprises 6 items that describes catastrophic thoughts (items 5, 11, $13,25,33$ and 37 ) and assess the use of negative thinking as a reaction to pain. For the CSQ_CAT, the total score range from 0-36 with higher scores representing higher levels of catastrophizing. Self-perceived control over pain (CSQ_COP) and ability to decrease pain (CSQ_ADP) using coping strategies were measured by two single item scales ranging from $0=$ no control to $6=$ complete control.

Symptom satisfaction was evaluated with the question "How would you feel about having your current symptoms for the rest of your life?" [138]. Responses were rated on a 7 -point scale ranging from $1=$ delighted to $7=$ terribly unhappy. These answers were dichotomized into high (1-3) and low symptom satisfaction (4-7).

Recovery expectations [139] was measured on a 4-point scale ranging from 1 $=$ expected to be completely restored to $4=$ no expectations of recovery or relief. These answers were dichotomized into high (1-2) and low (3-4) recovery expectations.

\section{Emotional responses}

Depression was evaluated with the Modified Self-rating Depression Scale (Modified Zung) [140], which included 23 items and scores of $0-69$; higher scores were indicative of depressed moods.

Somatic anxiety was evaluated with the Modified Somatic Perception Questionnaire (MSPQ) [141], which included 22 items and scores of $0-39$; higher scores were indicative of a higher level of somatic anxiety.

\section{Contextual factors}

\section{Lifestyle habits}

Smoking was recorded as yes/no. Patients were also asked to report their daily physical activity and weekly habits of exercise, sports, and open-air activities dur- 
ing the preceding 12 months. Answers to these questions were combined and interpreted on the basis of a 4-point scale ranging from $1=$ inactivity to $4=$ high activity [114]. The scores were dichotomized into physically active (3-4), or physically inactive (1-2).

\section{Environmental factors}

Sickness-related absence due to the neck and arm symptoms and perceived support from relatives were assessed with a yes/no alternative.

\section{Other outcome measures}

\section{Global outcome}

Patients were asked to score their perceived global outcome of treatment on a 6point scale with the following alternatives: complete recovery, much better, better, unchanged, worse, and much worse. The answers were dichotomized into "substantial improvement" including the alternatives complete recovery and much better as compared to "no or little improvement" including the alternatives better, unchanged, worse and much worse [142, 143].

\section{Consumption of analgesics}

Consumption of analgesics was rated as $1=$ never, $2=$ occasionally, $3=$ yes every day and 4 = yes several times daily and scores were dichotomized into daily (3-4) or occasional (1-2).

\section{Additional use of postoperative physiotherapy among patients who received SA}

Additional use of postoperative physiotherapy among patients who received SA was recorded in the 6-month questionnaire based on self-reported data.

\section{Expectation fulfilment and enablement}

Expectation fulfilment regarding postoperative care was assessed on 3-point scale including the answer alternatives "yes", "partially" and "no".

Enablement after surgery was assessed with the Swedish version of the Patient Enablement Instrument (PEI), which reportedly has shown high internal consistency and moderate to good reliability [144]. The PEI is a 6-item scale that evaluate patient's ability after treatment to cope with life, to understand their illness, to cope with their illness, to remain healthy, to feel confident about their health, and to help themselves [109]. Each items are scored on a four-point scale including the alternatives "much more than before", "a little more than before", "the same as before", and "less than before". The total score range from 0-12 with higher scores indicating greater enablement. 


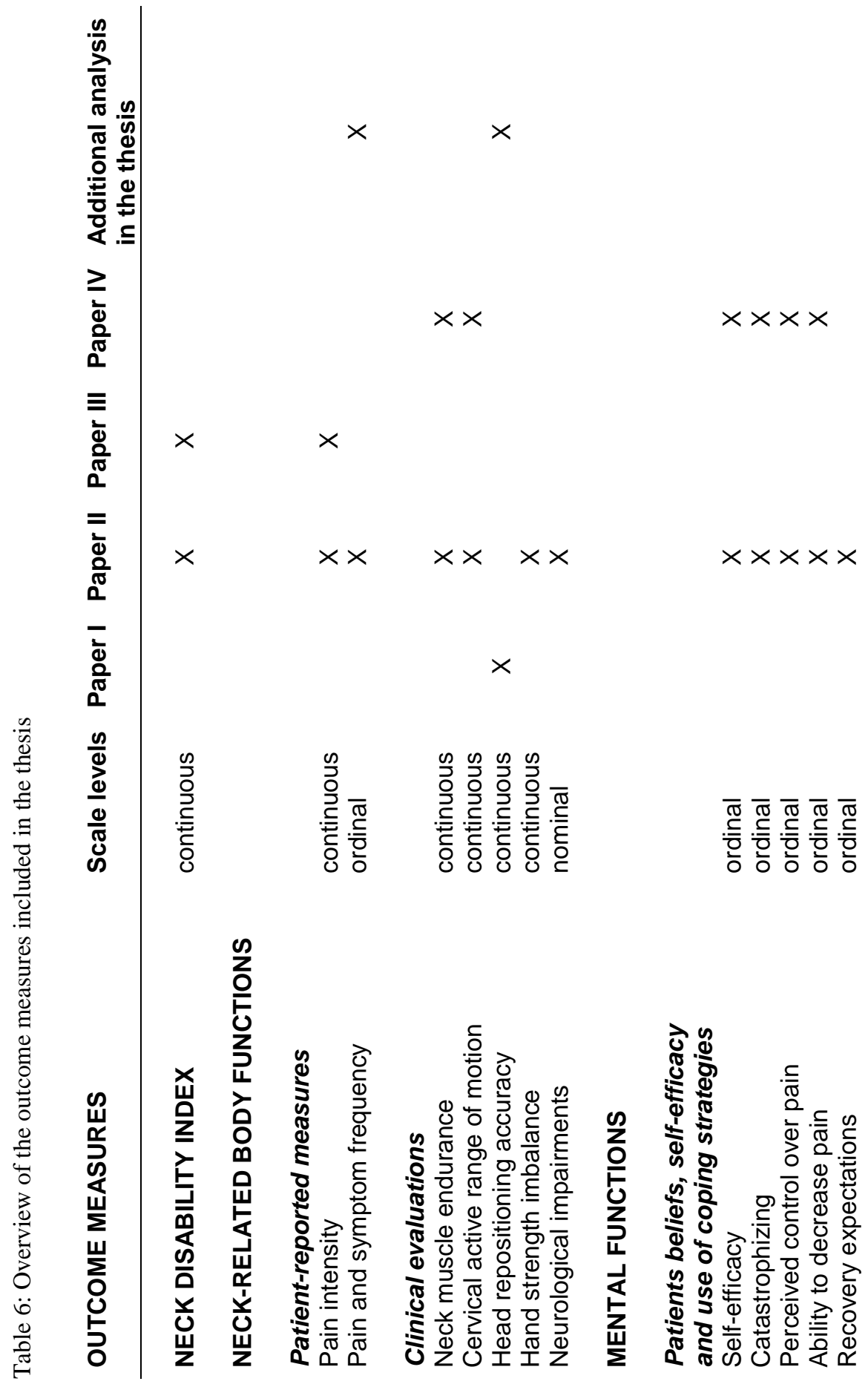




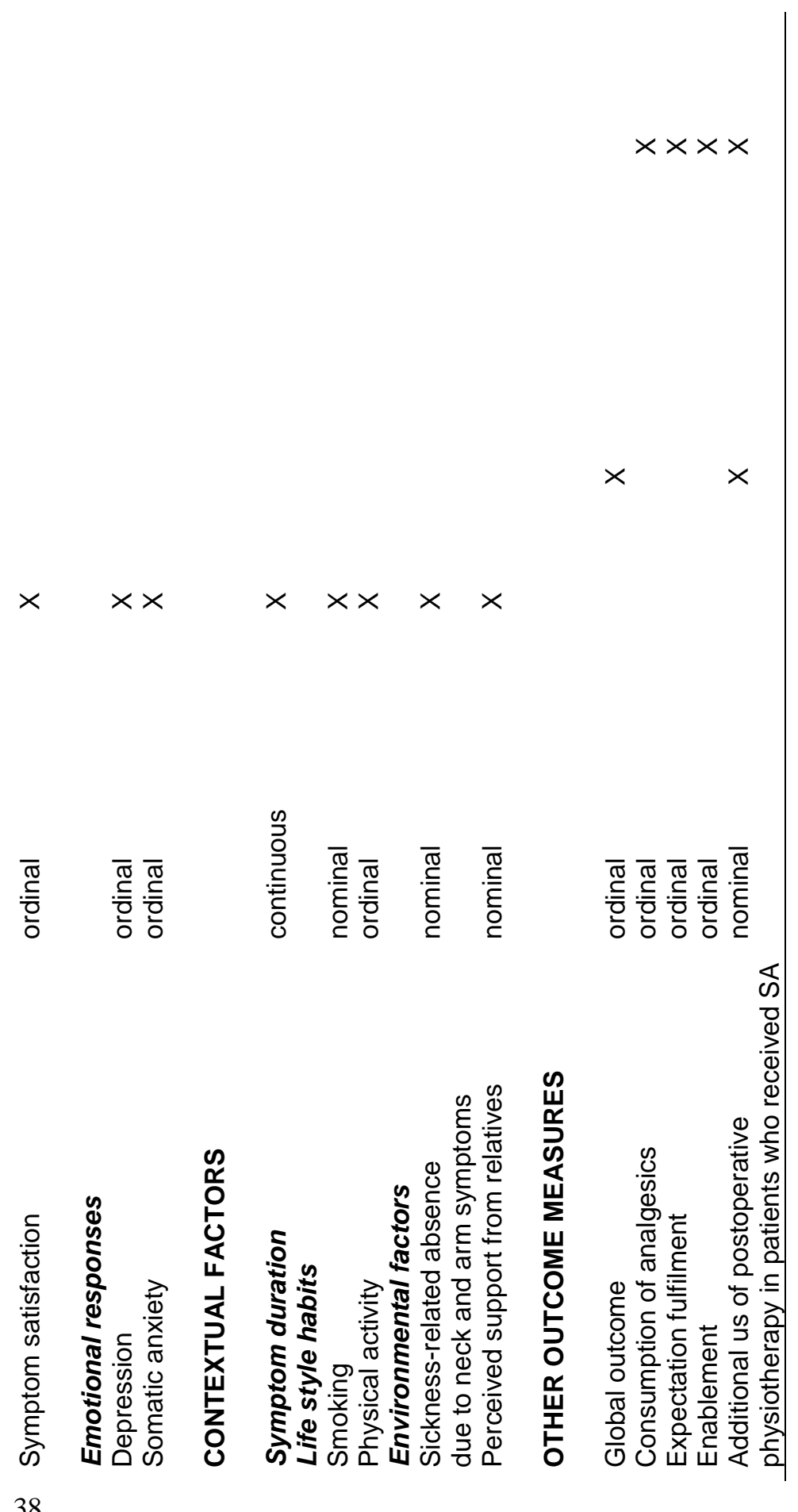




\section{Statistical methods}

Descriptive data were presented as means and standard deviations (SD), medians and interquartile ranges (IQR), or number and proportions. When no more than one item was missing in the NDI or SES, and two items in the Zung or MSPQ, the values were substituted with the average item score of the instrument for that participant. This was performed in order to decrease the risk of excluding score values in the NDI, SES, Zung and MSPQ due to omitted answers to one or two items in the questionnaire. When more item answers were missing in a questionnaire, the participant was omitted from the analysis. The statistical software package SPSS version 20.0 or 22.0 (IBM Corporation, New York, USA) was used for all analyses and the significance level was set at $\mathrm{p}<0.05$.

\section{Assessment of HRA in patients with CR and neck-healthy individuals (Pa- per I)}

\section{Group comparisons}

HRA was calculated in both rotation directions for each individual based on the mean of the absolute errors of three repeated repositioning trials. Maximal error in HRA (HRA max) was the larger mean error measured after rotation to either the right or the left for every individual. The Kolomogorov- Smirnov test showed the data not to meet the assumptions of normality and non- parametric statistics were used. Within-group differences in HRA between rotations directions were investigated with the Wilcoxon signed rank test. Differences in HRA between age groups in the sample of neck-healthy individuals were investigated with the Kruskal- Wallis test. Finally, differences between sex, and differences between patients with CR and neck-healthy individuals were investigated with the Mann- Whitney U test.

\section{Determination of HRA impairments}

The upper $90^{\text {th }}$ percentile of the mean of HRA max in neck-healthy individuals [15], and a receiver operating characteristic (ROC) curve were used to identify HRA impairments in patients with CR. The sensitivity and specificity of different discriminative values for HRA impairments were investigated.

\section{Measurement properties of the CROM device to assess HRA}

Test-retest reliability of the CROM device for assessment of HRA was determined in patients with CR using intra-class- correlation coefficients (ICCs absolute agreement and consistency agreement, two-way random effects model, average measures) with 95\% CI for ICC. Measurement errors were investigated with SEM [145]; and Bland and Altman plots with 95\% limits of agreements (LOAs) [146]. 


\section{Neck disability in patients with CR and scheduled for surgery (Paper II)}

Exploratory stepwise linear regressions were conducted to study associations between preoperative NDI scores with measures of neck-related body functions, mental functions and contextual factors. Variables were arbitrary grouped into pain and symptoms; clinical evaluations of neck-related body functions; measures of patients' beliefs, self-efficacy and use of coping strategies; emotional responses; lifestyle habits; and environmental factors. The models were adjusted for sex and age [147]. The study of the associations between the independent variables with Durbin- Watson values, variance inflation factors, and tolerances suggested no multicollinearity, and that the assumptions of independent errors were met [148]. To compare models, the adjusted coefficient of determination (Adj. $\mathrm{R}^{2}$ ) was used. Significant factors $(\mathrm{p}<0.05)$ were presented with B coefficients, standard errors, and $\mathrm{p}-$ values. The final model included all the factors identified in the first step, and beta coefficients were presented to allow comparison between significant factors.

\section{Evaluation of SPT compared to SA in patients with CR (Paper III \& IV)}

The required sample size in the RCT was determined based on a $10 \%$ betweengroup difference in the primary outcome NDI with an $\alpha$-level of $5 \%$ and a power goal of $80 \%$, resulting in 60 patients with CR being required for each treatment arm. To allow a drop-out rate of up to $15 \%, 200$ patients were to be recruited. Differences between treatment groups at baseline were investigated using parametric and non-parametric statistics depending on the data level. Differences between treatment groups at follow-ups were investigated in complete case and perprotocol approaches. In a per-protocol approach, patients with at least $50 \%$ attendance to treatment sessions in the SPT group (SPT $\geq 50 \%$ ) were compared with patients who received SA.

\section{Outcomes at 6 months after surgery}

Differences between treatment groups in outcome measures at 6 months after surgery were investigated with the independent t-test, Mann-Whitney $U$ test or Chisquare test depending on the data level.

\section{Changes in outcomes from before surgery to 6 months after surgery}

Differences between treatment groups in changes in outcome measures from before surgery to the 6 months follow-up were investigated for the NDI, VAS neck and arm pain, NME, cAROM, HRA max, SES, CSQ_CAT, CSQ_COP and CSQ_ADP with two-ways repeated measures analysis of variance (ANOVA). Non-normally distributed interval data and ordinal data were log transformed to 
fulfil the assumptions for ANOVA and Greenhouse-Geisser correction was used depending on sphericity.

\section{Treatment effects during the postoperative period}

Differences between groups in treatment effects during the rehabilitation period from 3 to 6 months after surgery were investigated for the NDI, VAS neck and arm pain, cAROM, HRA max, CSQ_CAT, CSQ_COP and CSQ_ADP with simple analysis of outcome score changes using independent t-test of Mann-Withney $U$ test depending on the data level. Differences in global outcome, frequency of neck and arm pain, and consumption of analgesics were investigated within groups during the postoperative period with the McNemar or Cochrane's Q test.

Differences between patients who reported and did not report additional use of postoperative physiotherapy in the SA group

Differences between patients who reported additional use of postoperative physiotherapy at 6 months after surgery with patients who did not report additional use of postoperative physiotherapy in the SA group were investigated for background variables; and for the NDI, VAS neck and arm pain and global outcome before surgery and at 6 weeks, 3 and 6 months after surgery with the independent t-test, Mann-Whitney $\mathrm{U}$ test or Chi square test were used depending on the data level. 
Table 7: Overview of the statistical methods used in the thesis

\begin{tabular}{lccccc} 
& $\begin{array}{c}\text { Paper } \\
\text { I }\end{array}$ & $\begin{array}{c}\text { Paper } \\
\text { II }\end{array}$ & $\begin{array}{c}\text { Paper } \\
\text { III }\end{array}$ & $\begin{array}{c}\text { Paper } \\
\text { IV }\end{array}$ & $\begin{array}{c}\text { Addi- } \\
\text { tiona } \\
\text { analys }\end{array}$ \\
\hline Descriptive statistics & $\mathrm{X}$ & $\mathrm{X}$ & $\mathrm{X}$ & $\mathrm{X}$ & \\
$\begin{array}{l}\text { Parametric statistics } \\
\text { Independent t-test }\end{array}$ & & & & & \\
$\begin{array}{l}\text { Two-ways repeated measures } \\
\text { ANOVA }\end{array}$ & & & $\mathrm{X}$ & $\mathrm{X}$ & $\mathrm{X}$ \\
& & & & &
\end{tabular}

\section{Non-parametric statistics}

Chi-square test

Mann-Whitney $U$ test

Kruskal-Wallis test

Wilcoxon signed rank test

McNemar test

$\begin{array}{lll}X & X \\ X & X \\ X & & X \\ X & X \\ & & \end{array}$

\section{Regression}

Multiple regression analyses

$X$

\section{Reliability}

ICC

SEM

Bland and Altman plots with 95\% LOA

$x$
$X$
$X$

Discrimination

ROC curve

$X$

ANOVA: analysis of variance; ICC: intra-class-correlation coefficient; SEM: standard error of measurement; LOA: limits of agreements; ROC: receiver operating characteristic 


\section{RESULTS}

\section{Assessment of HRA in patients with $\mathrm{CR}$ and neck-healthy individuals (Paper I)}

\section{Assessment of HRA in neck-healthy individuals}

HRA median (IQR) in neck-healthy individuals $(\mathrm{n}=173)$ was after rotation to the right $1.7^{\circ}(2.7)$, and after rotation to the left $1.3^{\circ}(2.7)$ (Table 8). HRA max median (IQR) was $2.7^{\circ}(2.8)$. No significant difference was found between age groups ( $\mathrm{p}$ $=0.28$ to $\mathrm{p}=0.42)$, between men and women $(\mathrm{p}=0.15$ to $\mathrm{p}=0.26)$, or between rotation directions $(\mathrm{p}=0.59$ to $\mathrm{p}=0.69)$ in neck-healthy individuals (Table 8 ).

\section{Assessment of HRA in patients with CR who were scheduled for surgery}

HRA median (IQR) in patients with CR scheduled for surgery $(\mathrm{n}=71)$ was after rotation to the right $2.7^{\circ}(6.0)$, and after rotation to the left $2.7^{\circ}$ (3.3) (Table 8). HRA max median (IQR) was $4.0^{\circ}$ (5.3). There was no significant difference between men and women $(\mathrm{p}=0.17$ to $\mathrm{p}=0.31)$, or between rotation directions $(\mathrm{p}=$ 0.18 to $\mathrm{p}=0.79$ ) in patients with CR (Table 8). Significant differences were reported between individuals with CR who were scheduled for surgery and neckhealthy individuals for HRA after rotation to the right $(\mathrm{p}=0.012)$, rotation to the left $(\mathrm{p}=0.021)$, and HRA max $(\mathrm{p}<0.001)$.

Table 8: Head repositioning accuracy after rotation to the right and the left assessed with the CROM device and expressed with median and interquartile range in neckhealthy individuals $(\mathrm{n}=173)$ and in patients with cervical radiculopathy who were scheduled for surgery $(\mathrm{n}=71)$.

\begin{tabular}{lcccc} 
& & $\begin{array}{c}\text { HRA rotation } \\
\text { right }\end{array}$ & $\begin{array}{c}\text { HRA rota- } \\
\text { tion left }\end{array}$ & \\
\hline Participants & $\mathbf{n}$ & Median (IQR) & $\begin{array}{c}\text { Median } \\
\text { (IQR) }\end{array}$ & $\mathbf{p}$ \\
& & & & \\
$\begin{array}{l}\text { Neck-healthy individuals } \\
\text { Total sample }\end{array}$ & 173 & $1.7(2.7)$ & $1.3(2.7)$ & 0.59 \\
& & & & \\
Women & 86 & $1.7(2.7)$ & $1.7(3.0)$ & 0.64 \\
20-34 years & 21 & $1.3(2.7)$ & $1.7(3.0)$ & \\
35-44 years & 20 & $1.7(2.0)$ & $1.3(3.0)$ & \\
45-54 years & 24 & $2.3(3.8)$ & $1.7(3.2)$ & \\
55-65 years & 21 & $1.7(3.2)$ & $1.7(2.2)$ &
\end{tabular}




\begin{tabular}{lllll} 
Men & 87 & $1.7(2.0)$ & $1.3(2.7)$ & 0.69 \\
$20-34$ years & 23 & $1.3(2.7)$ & $1.3(2.7)$ & \\
35-44 years & 24 & $1.0(2.7)$ & $0.7(2.7)$ & \\
45-54 years & 20 & $1.3(1.7)$ & $1.3(2.7)$ & \\
$55-65$ years & 20 & $1.7(2.5)$ & $2.3(2.5)$ & \\
& & & & \\
Patients with CR who were- & & & & \\
scheduled for surgery & & & & \\
Total sample & 71 & $2.7(6.0)$ & $2.7(3.3)$ & 0.62 \\
Women & 33 & $3.7(5.3)$ & $2.7(2.0)$ & 0.18 \\
Men & 38 & $2.3(5.7)$ & $2.0(6.2)$ & 0.79 \\
\hline
\end{tabular}

HRA: head repositioning accuracy; CR: cervical radiculopathy; IQR: interquartile range Within-group differences in head repositioning accuracy between rotation to the right and rotation to the left were analyzed with the Wilcoxon signed rank test.

\section{Assessment of HRA in patients with CR 6 months after surgery}

HRA median (IQR) in patients with CR 6 months after surgery $(\mathrm{n}=127)$ was after rotation to the right $2.7^{\circ}(4.3)$, and after rotation to the left $1.3^{\circ}$ (4.7). No difference was reported between patients with CR 6 months after surgery and reference values in neck-healthy individuals ( $\mathrm{p}=0.21$ to $\mathrm{p}=0.51$ ).

\section{HRA impairments}

The $90^{\text {th }}$ percentile of HRA max in neck-healthy individuals was $6.7^{\circ}$, and $31 \%$ of the patients with CR $(n=22)$ were classified with HRA impairments. This criteria for HRA impairments corresponded to a sensitivity of $31 \%$ and a specificity of $89 \%$ based on a ROC curve. The best discriminant value based on HRA max to differentiate between patients with CR and neck-healthy individuals was found at $3.3^{\circ}$ which corresponded to a sensitivity of $61 \%$ and a specificity of $68 \%$. This resulted in $60 \%$ of the patients with CR $(\mathrm{n}=42)$ and $35 \%$ of the neck-healthy individuals $(\mathrm{n}=55)$ classified with HRA impairments $(\mathrm{p}<0.001)$.

\section{Measurement properties of the CROM device to assess HRA}

The test-retest reliability of the CROM device for assessment of HRA in patients with CR showed for rotation to the right ICC of 0.79 (95\% CI: 0.50 to 0.91), SEM $2^{\circ}$ with $95 \%$ LOA (-5.57 to 5.68); and for rotation to the left ICC of 0.85 (95\% CI: 0.64 to 0.93 ), SEM $1.4^{\circ}$ with $95 \%$ LOA (-3.89 to 4.03) (Fig. 3). The Bland and Altman plots did not reveal any systematic change in the magnitude of differences between repeated measurements with increasing mean values (Fig. 3). 


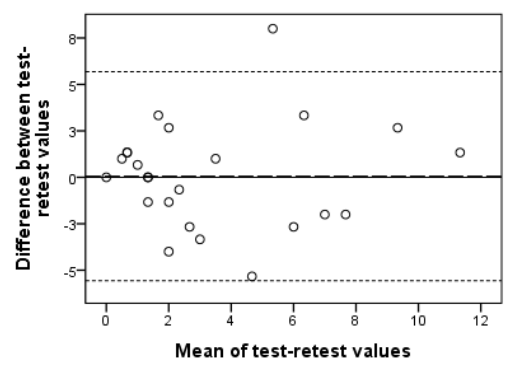

a) Test- retest reliability of the CROM after rotation to the right

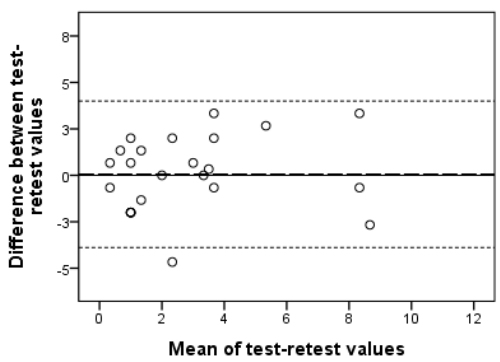

b) Test- retest reliability of the CROM after rotation to the left

Fig. 3: Bland and Altman plots with 95\% limits of agreement (LOA) for the test-retest reliability of head repositioning accuracy assessment with the CROM device after rotation to the right (a) and to the left (b) in individuals with cervical radiculopathy scheduled for surgery $(n=24)$. The difference between the two measurements is presented on the $y$-axis, and the mean of the two measurements on the $x$-axis, with the lines showing the observed average difference, 95\% LOA, and $(y=0)$ the perfect average difference.

\section{Neck disability in patients with CR and sched- uled for surgery (Paper II)}

Table 9: Preoperative measurements in patients with cervical radiculopathy $(n=201)$.

\begin{tabular}{lrrr} 
& $\mathbf{n}$ & Scores & Ranges \\
\hline NECK DISABILITY INDEX \% score ${ }^{\mathrm{a}}$, mean (SD) & 192 & $42.8(15.1)$ & $4-84$ \\
& & & \\
NECK-RELATED BODY FUNCTIONS & & & \\
Patient-reported pain and symptoms & & & \\
Duration of neck pain in months, median (IQR) & 173 & $14(27)$ & $0-288$ \\
Duration of arm pain in months, median (IQR) & 166 & $12(16)$ & $0-100$ \\
Neck pain past week VAS (0-100), mean (SD) & 195 & $55(21.8)$ & $0-99$ \\
Arm pain past week VAS (0-100), mean (SD) & 191 & $50(24.7)$ & $0-100$ \\
Headache past week VAS (0-100), mean (SD) & 193 & $27(25.5)$ & \\
Neck pain daily, \% (n) & 194 & $91(177)$ & \\
Arm pain daily, \% (n) & 192 & $83(160)$ & \\
Headache daily, \% (n) & 190 & $34(64)$ & \\
Hand numbness daily, \% (n) & 192 & $81(156)$ & \\
Hand weakness daily, \% (n) & 186 & $63(118)$ & \\
Neck stiffness daily, \% (n) & 191 & $82(157)$ \\
Dizziness/ unsteadiness daily, \% (n) & 193 & $21(40)$ \\
Clinical evaluations & & & \\
cAROM sagittal, mean (SD) & 198 & $83(26.7)$ \\
cAROM transversal, mean (SD) & 198 & $100(25.5)$ & $7-175$
\end{tabular}


cAROM frontal, mean (SD)

Imbalance in hand strength \%, mean (SD)

NME ventral in men, median (IQR)

NME ventral in women, median (IQR)

NME dorsal in men, median (IQR)

NME dorsal in women, median (IQR)

Impairment in sensibility, \% ( $\mathrm{n}$ )

Impairment in motor function, \% (n)

Asymmetry in reflexes, \% (n)
198

196

100

92

99

92

191

191

191
$55(17.8)$

$$
26(23.1)
$$

$45(75)$

$22(27)$

135)

$29(54)$

$85(165)$

$178(150)$

$57(103)$

\section{MENTAL FUNCTIONS}

Beliefs, self-efficacy and coping strategies

Self-efficacy, SES (0-200) a, median (IQR)

Catastrophizing, CSQ_CAT (0-36), median (IQR)

Control over pain, CSQ_COP (0-6), median (IQR)

Ability to decrease pain, CSQ_ADP (0-6),

median (IQR)

High recovery expectations, \% (n)

Low symptom satisfaction, \% ( $n$ )

\section{Emotional responses}

Depression: Modified Zung (0-69) a , median (IQR)

Somatic anxiety: Modified Somatic Perception

Questionnaire MSPQ (0-39) a, median (IQR)

\section{CONTEXTUAL FACTORS}

\section{Life style habits}

Smoking, \% ( $\mathrm{n}$ )

Physically active, \% (n)

\section{Environmental factors}

Sickness-related absence (partial or full) due to arm/ neck symptoms, \% ( $\mathrm{n}$ )

Perceived support from relatives, \% (n)

194

195

$25(49)$

49 (96)

181

$55(100)$

191
87 (167)

SD: standard deviation; IQR: interquartile range; VAS: visual analog scale; CSQ: coping strategy questionnaire; cAROM: cervical active range of motion; NME: neck muscle endurance. ${ }^{\text {a }}$ Transformation score: when no more than one item in the Neck Disability Index or the Self-efficacy Scale, and two items in the Modified Zung scale or the Modified Somatic Perception Questionnaire were missing, it was replaced by the average score of all other items in the questionnaire for that patient 
Daily neck pain, daily dizziness/unsteadiness, and high scoring on the VAS for neck pain and headache in the past week were factors related to pain and symptoms that were associated with higher preoperative NDI scores $\left(\mathrm{p}<0.001, \mathrm{R}^{2}=0.56\right)$ (Table 10). Restricted cAROM in the transversal plane, and NME in flexion were clinical evaluations of neck-related body functions that were associated with higher preoperative NDI scores $\left(\mathrm{p}<0.001, \mathrm{R}^{2}=0.15\right)$ (Table 10). Low self-efficacy scored on the SES, low satisfaction with symptoms, and high catastrophizing scored on the CSQ_CAT were factors related to patient beliefs, self-efficacy and coping strategies that were associated with higher preoperative NDI scores $(\mathrm{p}<$ $0.001, \mathrm{R}^{2}=0.54$ ) (Table 10). Likewise, depressed moods and somatic anxiety as scored on the modified Zung and MSPQ were emotional responses that were associated with higher preoperative NDI scores $\left(\mathrm{p}<0.001, \mathrm{R}^{2}=0.37\right)($ Table 10). Sickness-related absence due to arm/ neck symptoms was the only environmental factor associated with higher preoperative NDI scores $\left(\mathrm{p}<0.001, \mathrm{R}^{2}=0.14\right)$ (Table 10). Life style habits were not associated with preoperative NDI scores. The final model was based on data from 156 participants; and measures of pain and symptoms, clinical evaluations of neck-related body functions; measures of mental functions; and environmental factors explained together $73 \%(\mathrm{p}<0.001)$ of the variation in preoperative NDI scores (Table 11). Low self-efficacy scored on the SES emerged as the strongest factor (Table 11). The excluded patients in the final model $(n=45)$ were older $(\mathrm{p}=0.007)$ but did not differ from the patients included in the analysis $(n=156)$ based on sex or preoperative NDI scores $(p>0.73)$.

Table 10: Measures of neck-related body functions, mental functions and contextual factors associated with high preoperative scores on the Neck Disability Index in patients with CR scheduled for surgery

\begin{tabular}{|c|c|c|c|c|}
\hline & B & Error & $\mathbf{p}$ & Adj. $R^{2}$ \\
\hline Pain and symptoms ${ }^{a} \quad(n=184)$ & & & & 0.56 \\
\hline Constant & 22.30 & 5.72 & & \\
\hline Dizziness/ unsteadiness daily & 8.13 & 1.93 & $<0.001$ & \\
\hline Neck pain daily & 6.60 & 2.95 & 0.03 & \\
\hline Neck pain past week VAS & 0.25 & 0.04 & $<0.001$ & \\
\hline Headache past week VAS & 0.22 & 0.03 & $<0.001$ & \\
\hline Clinical evaluations $^{\text {a }}(n=179)$ & & & & 0.15 \\
\hline Constant & 78.64 & 8.54 & & \\
\hline cAROM transversal & -0.12 & 0.04 & 0.004 & \\
\hline NME flexion & -0.09 & 0.02 & $<0.001$ & \\
\hline $\begin{array}{l}\text { Beliefs, self-efficacy and coping strat- } \\
\text { egies }{ }^{\text {a }} \\
(n=177)\end{array}$ & & & & 0.54 \\
\hline Constant & 68.23 & 7.84 & & \\
\hline Low symptom satisfaction & 13.01 & 3.91 & 0.001 & \\
\hline
\end{tabular}


Catastrophizing (CSQ-CAT)

Self-efficacy (SES)

Emotional responses ${ }^{a}(n=186)$

Constant

Depression (Modified Zung)

Somatic anxiety (MSPQ)

Environmental factors ${ }^{a}(n=173)$

Constant

Sickness- related absence due to arm/ neck symptoms

$$
\begin{array}{lll}
0.25 & 0.11 \quad 0.02
\end{array}
$$$$
\begin{array}{lll}
-0.23 & 0.02<0.001
\end{array}
$$

$27.39 \quad 6.66$

$\begin{array}{lll}0.71 & 0.12<0.001\end{array}$

$\begin{array}{lll}0.63 & 0.22 & 0.006\end{array}$

cAROM: cervical active range of motion; NME: neck muscle endurance; SES: Self-efficacy Scale; CSQ: Coping Strategy Questionnaire; Zung: modified self-rating depression scale; MSPQ: Modified Somatic Perception Questionnaire. ${ }^{a}$ Residual scatter-plots and normal probability plots did not reveal evidence of violated assumptions

Table 11: Final model of the measures associated with high preoperative scores on the Neck Disability Index in patients with CR scheduled for surgery $(n=156)$

\begin{tabular}{|c|c|c|c|c|c|}
\hline & & B & Error & Beta & p \\
\hline Constant & & 44.43 & 8.07 & & \\
\hline Demographic & Age & - & - & & ns \\
\hline & Sex & - & - & & ns \\
\hline Pain and & Neck pain daily & 6.93 & 2.51 & 0.14 & 0.007 \\
\hline symptoms & $\begin{array}{l}\text { Dizziness/ unsteadiness } \\
\text { daily }\end{array}$ & 6.50 & 1.90 & 0.17 & 0.001 \\
\hline & $\begin{array}{l}\text { Neck pain past week } \\
\text { VAS }\end{array}$ & 0.14 & 0.04 & 0.20 & 0.001 \\
\hline & $\begin{array}{l}\text { Headache past week } \\
\text { VAS }\end{array}$ & 0.13 & 0.03 & 0.22 & $<0.001$ \\
\hline Clinical & cAROM transversal & -0.06 & 0.03 & -0.10 & 0.03 \\
\hline & & & & & \\
\hline $\begin{array}{l}\text { Beliefs, self- } \\
\text { efficacy and } \\
\text { coping }\end{array}$ & $\begin{array}{l}\text { Self-efficacy (SES) } \\
\text { Catastrophizing (CSQ- } \\
\text { CAT) }\end{array}$ & -0.13 & $\begin{array}{c}0.02 \\
-\end{array}$ & $\begin{array}{c}-0.34 \\
-\end{array}$ & $\begin{array}{c}<0.001 \\
\mathrm{~ns}\end{array}$ \\
\hline strategies & $\begin{array}{l}\text { Low symptom satisfac- } \\
\text { tion }\end{array}$ & - & - & - & ns \\
\hline $\begin{array}{l}\text { Emotional } \\
\text { responses }\end{array}$ & $\begin{array}{l}\text { Depression (Modified } \\
\text { Zung) }\end{array}$ & 0.27 & 0.10 & 0.18 & 0.01 \\
\hline & $\begin{array}{l}\text { Somatic anxiety } \\
\text { (MSPQ) }\end{array}$ & - & - & - & ns \\
\hline
\end{tabular}




\begin{tabular}{llllll}
$\begin{array}{l}\text { Environmen- } \\
\text { tal factors }\end{array}$ & $\begin{array}{l}\text { Sickness- related ab- } \\
\text { sence due to arm/ neck } \\
\text { symptoms }\end{array}$ & 3.71 & 1.40 & 0.13 & 0.009 \\
\hline
\end{tabular}

VAS: visual analogue scale; cAROM: cervical active range of motion; NME: neck muscle endurance; SES: Self-efficacy Scale; CSQ: Coping Strategy Questionnaire; MSPQ: Modified Somatic Perception Questionnaire. Residual scatter-plots and normal probability plots did not reveal evidence of violated assumptions.

\section{Evaluation of SPT compared to SA in patients with CR (Paper III \& IV)}

Table 12: Background variables and surgical data in randomization group - structured postoperative physiotherapy (SPT) and standard postoperative approach (SA), and for patients with at least $50 \%$ attendance to treatment sessions in the structured postoperative physiotherapy group (SPT $\geq 50 \%$ ).

\begin{tabular}{|c|c|c|c|c|c|c|}
\hline & \multicolumn{2}{|c|}{$\begin{array}{c}\text { SPT } \\
(n=101)\end{array}$} & \multicolumn{2}{|c|}{$\begin{array}{l}\mathrm{SPT} \geq 50 \% \\
(\mathrm{n}=67)\end{array}$} & \multicolumn{2}{|c|}{$\begin{array}{c}\text { SA } \\
(n=100)\end{array}$} \\
\hline $\begin{array}{l}\text { BACKGROUND } \\
\text { VARIABLES }\end{array}$ & $\mathrm{n}$ & & $\mathrm{n}$ & & $\mathrm{n}$ & \\
\hline Age, mean (SD) & 101 & $50(8.2)$ & 67 & $51(8.2)$ & 100 & $50(8.7)$ \\
\hline Male sex, \% (n) & 101 & $51(51)$ & 67 & $49(33)$ & 100 & $54(54)$ \\
\hline $\begin{array}{l}\text { Duration of neck pain } \\
\text { in months, median (IQR) }\end{array}$ & 84 & $18(35.5)$ & 56 & $16(39)$ & 89 & $12(16.5)$ \\
\hline $\begin{array}{l}\text { Duration of arm pain } \\
\text { in months, median (IQR) }\end{array}$ & 84 & $15(26.0)$ & 53 & $12(28)$ & 82 & $12(11.5)$ \\
\hline Smoking, \% (n) & 98 & $25(24)$ & 64 & $16(10)$ & 96 & $26(25)$ \\
\hline $\begin{array}{l}\text { Sickness-related ab- } \\
\text { sence due to neck/-arm } \\
\text { symptoms, \% (n) }\end{array}$ & 92 & $57(52)$ & 60 & $53(32)$ & 86 & $56(48)$ \\
\hline $\begin{array}{l}\text { Preoperative neck-re- } \\
\text { lated physiotherapy } \\
\text { treatments, } \%(n)\end{array}$ & 95 & $66(63)$ & 62 & $65(40)$ & 92 & $66(61)$ \\
\hline \multicolumn{7}{|l|}{ SURGICAL DATA } \\
\hline ACDF, \% (n) & 101 & $76(77)$ & 67 & 79 (53) & 100 & $86(86)$ \\
\hline
\end{tabular}


Operated levels, \% (n)

101

67

1-level surgery

2-level surgery

$\geq 3$ level surgery

SPT: structured postoperative physiotherapy; SPT $\geq 50 \%$ : patients with at least $50 \%$ attendance to treatment sessions in the structured postoperative physiotherapy group; SA: standard postoperative approach; SD: standard deviation; IQR: interquartile range; ACDF: Anterior Cervical Decompression and Fusion.

\section{Randomization}

Except from significantly longer preoperative duration of neck and arm pain in patients who received SPT compared to patients who received SA $(\mathrm{p}=0.02$ to $\mathrm{p}=$ 0.03 ), no difference was found in background variables between the randomization groups $(\mathrm{p}=0.08$ to $\mathrm{p}=0.99$ ) (Table 12$)$. There was no difference between the groups in outcome measures at baseline $(\mathrm{p}=0.15$ to $\mathrm{p}=0.98)($ Table 13-15), except from less preoperative frequency of arm pain in patients who received SA ( $\mathrm{p}=$ 0.05) (Table 13).

\section{Patients lost to follow-up}

Fifteen percent of the patients were lost to follow-up at 6 months after surgery based on the primary outcome NDI (12\% in SPT and $19 \%$ in SA) (Fig. 1). These patients scored worse at baseline on the NDI $(\mathrm{p}=0.004)$. They also scored worse on the Zung, MSPQ and SES ( $\mathrm{p}=0.006$ to 0.04 ), and a larger proportion were operated with ACDF $(\mathrm{p}=0.05)$. No difference was found for age, sex or randomization $(\mathrm{p}=0.16$ to $\mathrm{p}=0.75)$. The patients that were lost to follow-up at 6 months after surgery based on secondary outcome measures were $14-16 \%$ for VAS neck and arm pain, 15-18\% for clinical evaluations of neck-related body functions (NME and CAROM), and 15-19\% for measures of self-efficacy and coping strategies. These patients showed lower NME and cAROM at baseline ( $\mathrm{p}=0.01$ to $\mathrm{p}=$ 0.03 ), but they did not differ based on measures of pain intensity, self-efficacy and coping strategies ( $\mathrm{p}=0.08$ to 0.87 ). There was no difference with regard to randomization ( $\mathrm{p}=0.07$ to 0.60$)$.

\section{Attendance rate to treatment sessions in patients who received SPT}

An attendance rate of more than $50 \%$ to treatment sessions was reported for $67 \%$ of the patients who were randomized to SPT (SPT $\geq 50 \%, n=67$, mean age 51 years, SD 8.2; 33 men and 34 women). Thirty-four patients were excluded in a per-protocol approach (mean age 48 years, SD 8.1; 18 men and 16 women). The reasons for no or $\leq 50 \%$ attendance to treatment sessions were lack of time and difficulties with absences from work for training $(n=19)$, and not starting the intervention for unknown reasons $(n=10)$. Report about attendance rate was missing for 5 patients. The patients excluded in a per-protocol approach $(n=34)$ did not differ from 
SPT $\geq 50 \%$ based on background variables and preoperative outcome measures ( $\mathrm{p}=$ 0.10 to 0.92 ), except that they were more smokers ( $41 \%$ versus $16 \%, p=0.005)$ and had lower self-efficacy as scored on the SES $(\mathrm{p}=0.04)$. No difference was found between SPT $\geq 50 \%$ and SA based on background variables and preoperative outcome measures $(\mathrm{p}=0.08$ to $\mathrm{p}=0.89)$.

\section{Surgery with ACDF or PCF}

The patients who were operated with PCF $(n=38)$ were older, they were more men, and they were operated at several levels $(\mathrm{p}<0.001)$ compared with patients who were operated with ACDF $(n=163)$. No difference was reported between patients who were operated with ACDF or PCF based on patient-reported measures of pain and neck functioning before surgery $(p=0.08$ to $p=0.67)$, as well as 3 months after surgery ( $\mathrm{p}=0.58$ to 0.87$)$.

\section{Outcomes at 6 months after surgery}

\section{Patient-reported measures of pain, neck functioning, and global outcome}

There was no difference between the treatment groups at 6 months follow-up based on the NDI, measures of neck and arm pain intensity and frequency, global outcome, or consumptions of analgesics $(\mathrm{p}=0.21$ to $\mathrm{p}=0.82)$. Neither was any between-group difference found in a per-protocol approach $(p=0.15$ to $p=0.58)$, except for significantly less frequency of neck pain at 6 months after surgery in SPT $\geq 50 \%(p=0.05)$ compared with patients who received SA. Descriptive data for measures of pain, neck functioning, and global outcome are presented in Table 13 and Table 16.

\section{Clinical evaluations of neck-related body functions, self-efficacy and coping strategies}

There was no difference between the treatment groups at 6 months follow-up based on clinical evaluations of neck-related body functions, measures of self-efficacy, and coping strategies both in a complete case analysis and a per-protocol approach $(p=0.30$ to $p=0.95)$. Descriptive statistics are presented in Table 14-15.

\section{Expectation fulfilment and enablement}

Patients who received SPT showed higher expectation fulfilment at 6 months follow-up ( $\mathrm{p}=0.01)$ compared to patients who received SA, but no difference was found in enablement ( $p=0.06$ to $p=0.88$ ) (Table 17). In a per-protocol approach, SPT $\geq 50 \%$ patients showed higher expectation fulfilment $(\mathrm{p}=0.001)$ compared to patients who received SA, and they also reported greater enablement $(p=0.04)$ as was shown in reported higher ability to understand and cope with their illness after treatment $(\mathrm{p}=0.006$ to $\mathrm{p}=0.02)$ (Table 17$)$. 


\section{Changes in outcomes from before surgery to 6 months after surgery}

The results from two-ways repeated-measures ANOVA showed no between-group difference for changes in outcome measures from before surgery to 6 months after surgery based on measures of pain intensity in the neck and the arm, neck functioning, clinical evaluations of neck related body functions, self-efficacy and coping strategies $(\mathrm{p}=0.25$ to $\mathrm{p}=0.96)$. All outcomes were significantly improved from before surgery $(\mathrm{p}<0.001)$ except from cAROM in the transversal plane $(\mathrm{p}=$ $0.35)$. No different results were found in a per-protocol approach $(\mathrm{p}=0.16$ to $\mathrm{p}=$ $0.88)$.

\section{Treatment effects during the postoperative period}

No between-group difference was found for outcome score changes during the rehabilitation period from 3 to 6 months after surgery in a complete case analysis ( $p$ $=0.10$ to $\mathrm{p}=0.97$ ). In a per-protocol approach, significantly larger improvement in the NDI, VAS arm pain and CSQ_CAT ( $\mathrm{p}=0.03$ to $\mathrm{p}=0.04)$ were reported in $\mathrm{SPT} \geq 50 \%$ compared to patients who received SA patients (Table 18). During the postoperative period, global outcome, and neck pain frequency improved in patients who received SPT (and SPT $\geq 50 \%)(\mathrm{p}<0.01)$ (Table 16), and consumption of analgesics decreased in SPT $\geq 50 \%(\mathrm{p}=0.02)$ (Table 16). No significant change was found in global outcome, pain frequency, and consumption of analgesics during the postoperative period in patients who received $\mathrm{SA}(\mathrm{p}=0.17$ to $\mathrm{p}=1.0$ ) (Table 16). 


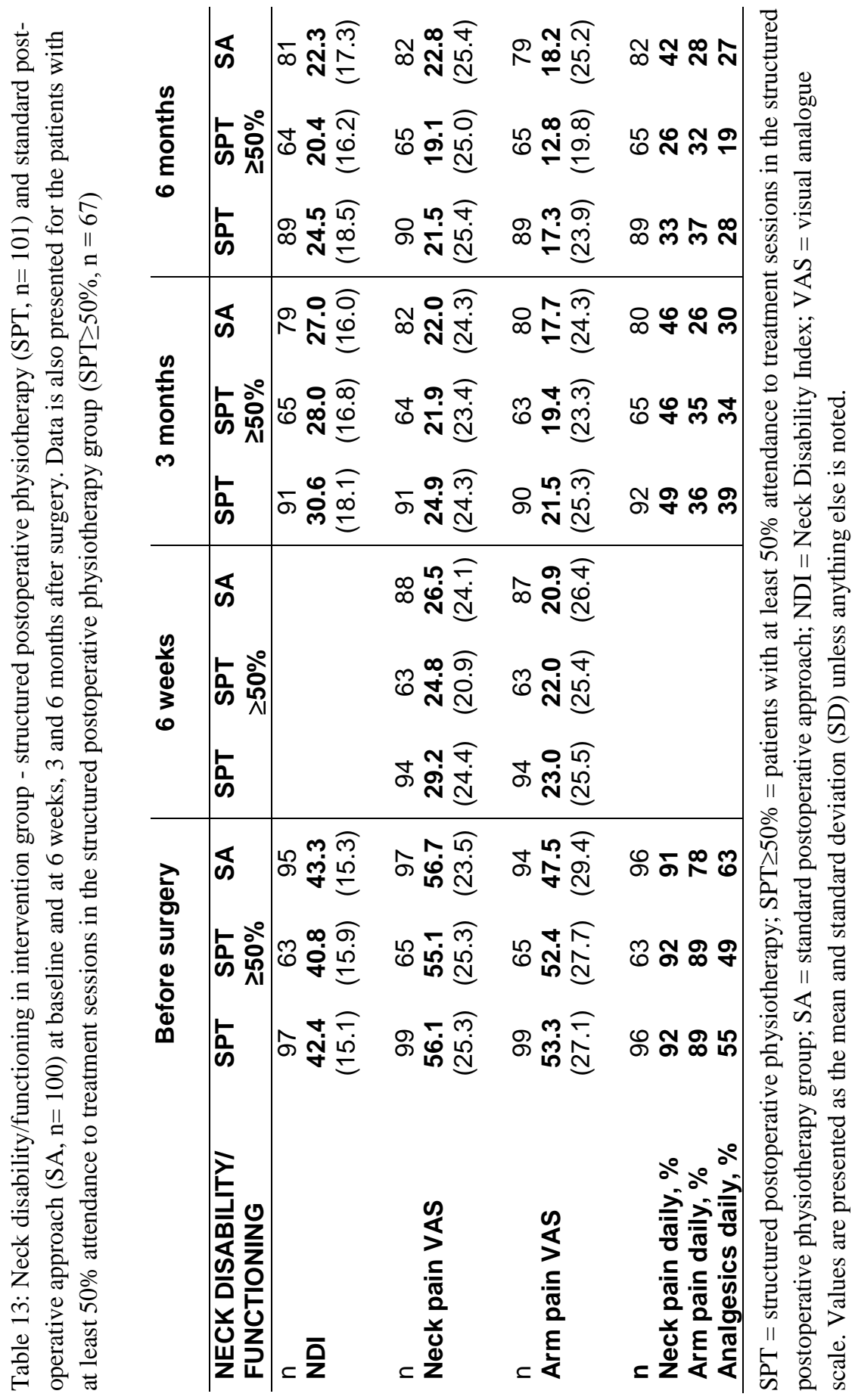




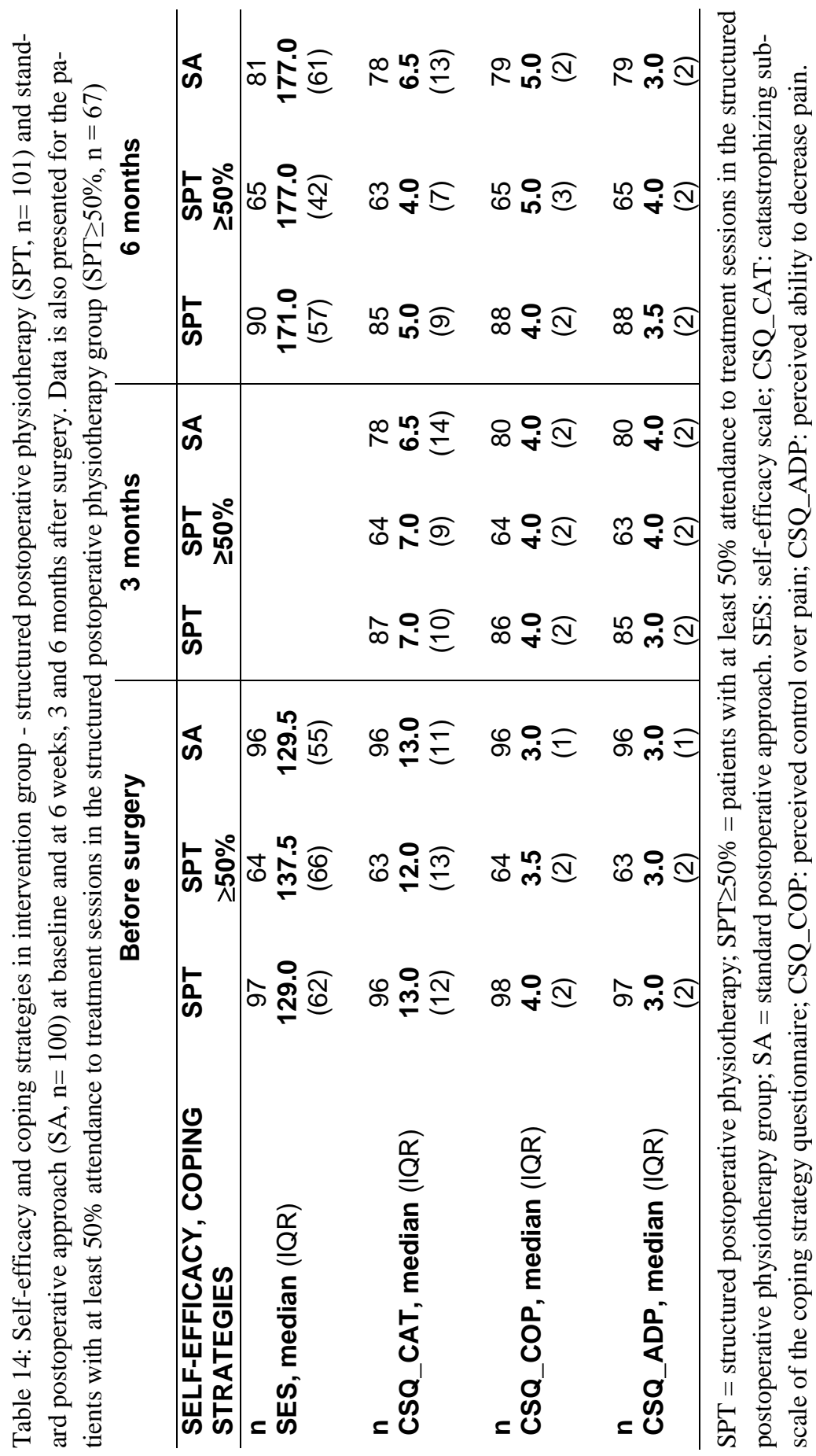




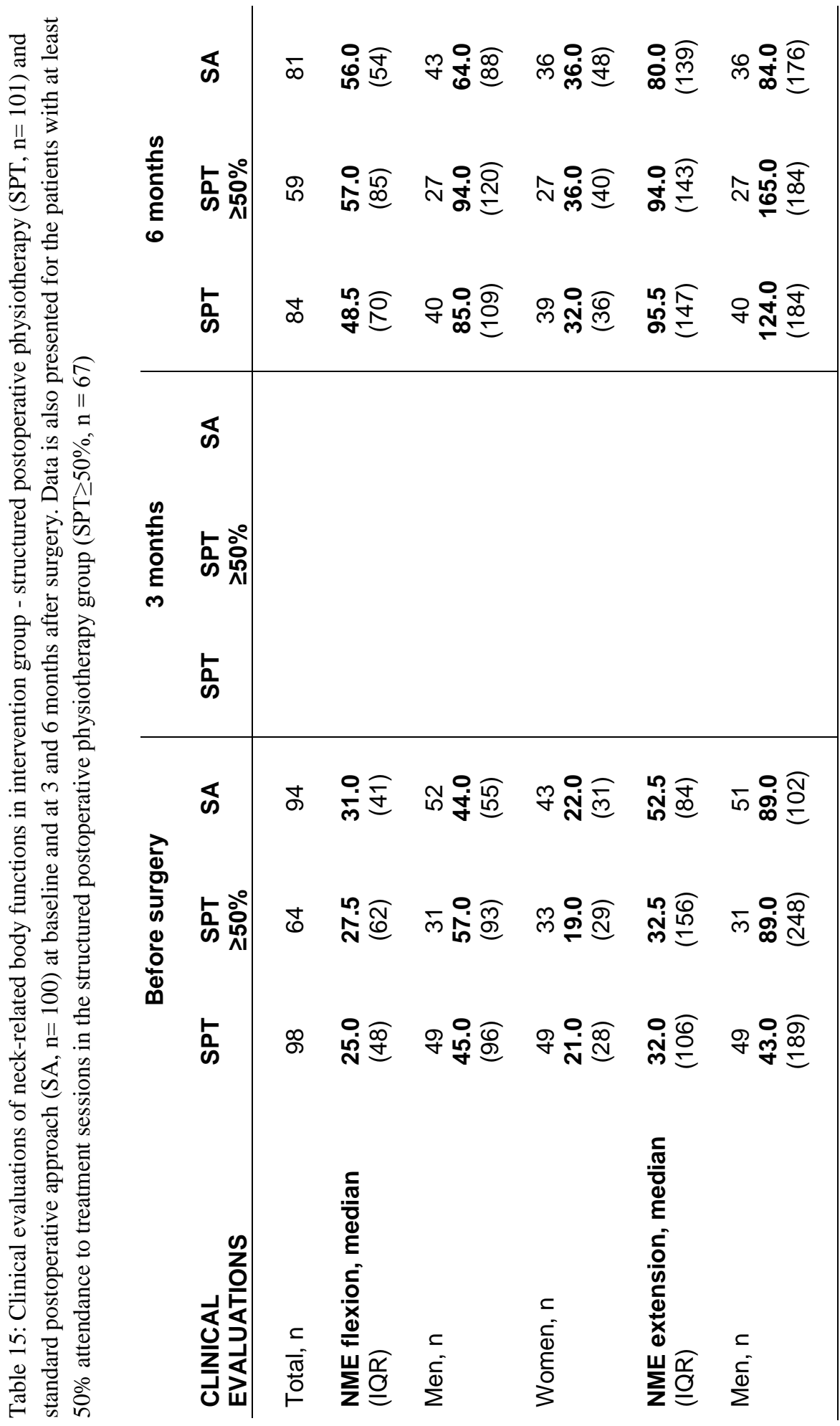




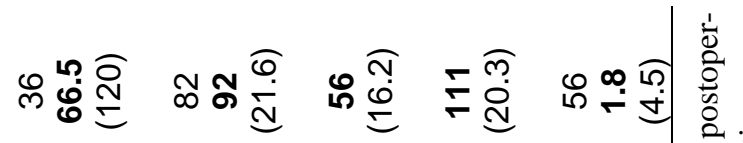

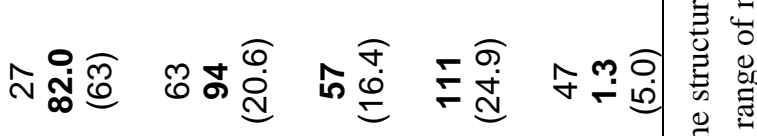

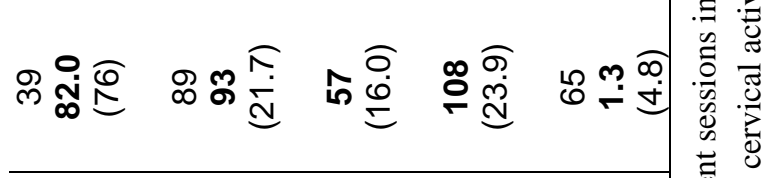

๓ø⿺辶丅 ம 원 은

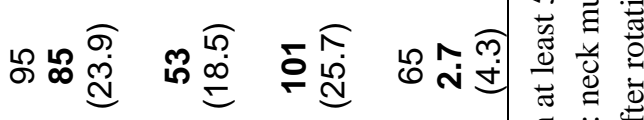
프 भํำ m

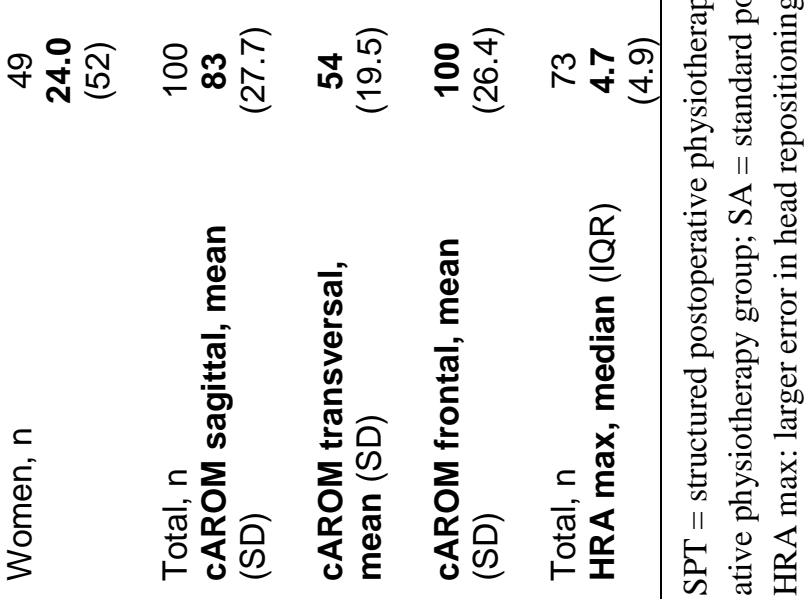
感 
Table 16: Global outcome, frequency of neck and arm pain and consumptions of analgesics at 6 weeks, 3 and 6 months after surgery in the intervention group - structured postoperative physiotherapy (SPT) and standard postoperative approach (SA) Data is also presented for the patients with at least $50 \%$ attendance to treatment sessions in the structured postoperative physiotherapy group (SPT $\geq 50 \%$ )

\begin{tabular}{|c|c|c|c|c|c|c|}
\hline & & $\begin{array}{c}\text { SPT } \\
(n=101)\end{array}$ & & $\begin{array}{c}\mathrm{SPT} \geq 50 \% \\
(\mathrm{n}=67)\end{array}$ & & $\begin{array}{c}\text { SA } \\
(n=100)\end{array}$ \\
\hline $\begin{array}{l}\text { Global outcome } \\
\text { "Substantial improve- } \\
\text { ment" }\end{array}$ & $\mathrm{n}$ & & $\mathrm{n}$ & & $n$ & \\
\hline 6 weeks, \% & 94 & 43 & 62 & 43 & 87 & 47 \\
\hline 3 months, \% & 92 & 48 & 65 & 49 & 80 & 56 \\
\hline 6 months, \% & 89 & 60 & 64 & 67 & 80 & 56 \\
\hline Change over time, $p$ & & 0.01 & & $<0.001$ & & 0.17 \\
\hline Daily neck pain & $\mathrm{n}$ & & $\mathrm{n}$ & & $\mathrm{n}$ & \\
\hline 3 months, \% & 92 & 49 & 65 & 46 & 80 & 46 \\
\hline 6 months, \% & 89 & 33 & 65 & 26 & 82 & 42 \\
\hline Change over time, $p$ & 86 & 0.003 & 64 & 0.002 & 75 & 0.63 \\
\hline Daily arm pain & $n$ & & $\mathrm{n}$ & & $\mathrm{n}$ & \\
\hline 3 months, \% & 92 & 36 & 65 & 35 & 80 & 26 \\
\hline 6 months, \% & 89 & 37 & 65 & 32 & 82 & 28 \\
\hline Change over time, $p$ & 86 & 0.82 & 64 & 0.77 & 75 & 1.0 \\
\hline $\begin{array}{l}\text { Daily consumption of } \\
\text { analgesics }\end{array}$ & $\mathrm{n}$ & & $\mathrm{n}$ & & $\mathrm{n}$ & \\
\hline 3 months, \% & 92 & 39 & 65 & 34 & 80 & 30 \\
\hline 6 months, \% & 89 & 28 & 65 & 19 & 82 & 27 \\
\hline Change over time, $p$ & 84 & 0.27 & 62 & 0.02 & 74 & 1.0 \\
\hline
\end{tabular}

$\mathrm{SPT}=$ structured postoperative physiotherapy; SPT $\geq 50 \%=$ patients with at least $50 \%$ attendance to treatment sessions in the structured postoperative physiotherapy group; $\mathrm{SA}=$ standard postoperative approach. Within-group changes during the postoperative period were investigated with the McNemar or the Cochrane Q test. 
Table 17: Expectation fulfilment and enablement at 6 months after surgery in the intervention group - structured postoperative physiotherapy (SPT, $\mathrm{n}=101)$ and standard postoperative approach $(\mathrm{SA}, \mathrm{n}=100)$. Data is also presented for the patients with at least $50 \%$ attendance to treatment sessions in the structured postoperative physiotherapy group (SPT $\geq 50 \%, \mathrm{n}=67$ )

\begin{tabular}{|c|c|c|c|c|}
\hline & & SPT & $\begin{array}{c}\text { SPT } \\
\geq 50 \%\end{array}$ & SA \\
\hline \multirow[t]{4}{*}{ Expectation fulfilment } & Total, n & 90 & 65 & 80 \\
\hline & Yes, \% & 62 & 71 & 43 \\
\hline & Partially, \% & 28 & 23 & 41 \\
\hline & No, \% & 10 & 6 & 16 \\
\hline $\begin{array}{l}\text { PEI total score } \\
\text { median (IQR) }\end{array}$ & Total, $\mathrm{n}$ & $\begin{array}{l}79 \\
6.0 \\
(7.0)\end{array}$ & $\begin{array}{c}56 \\
7.0 \\
(6.8)\end{array}$ & $\begin{array}{c}66 \\
5.0 \\
(7.3)\end{array}$ \\
\hline \multirow[t]{4}{*}{ 1- Able to cope with life } & Total, $\mathrm{n}$ & 80 & 57 & 70 \\
\hline & Much better, \% & 39 & 47 & 41 \\
\hline & Better, \% & 36 & 35 & 30 \\
\hline & Same or less, \% & 25 & 18 & 29 \\
\hline \multirow{4}{*}{$\begin{array}{l}\text { 2- Able to understand } \\
\text { your illness }\end{array}$} & Total, $\mathrm{n}$ & 78 & 56 & 63 \\
\hline & Much better, \% & 36 & 41 & 27 \\
\hline & Better, \% & 41 & 41 & 40 \\
\hline & Same or less, \% & 23 & 18 & 33 \\
\hline \multirow{4}{*}{$\begin{array}{l}\text { 3- Able to cope with } \\
\text { your illness }\end{array}$} & Total, $\mathrm{n}$ & 86 & 63 & 65 \\
\hline & Much better, \% & 36 & 40 & 20 \\
\hline & Better, \% & 41 & 44 & 51 \\
\hline & Same or less, \% & 23 & 16 & 29 \\
\hline \multirow{4}{*}{$\begin{array}{l}\text { 4- Able to keep yourself } \\
\text { healthy }\end{array}$} & Total, $\mathrm{n}$ & 77 & 57 & 62 \\
\hline & Much better, \% & 22 & 28 & 23 \\
\hline & Better, \% & 46 & 46 & 40 \\
\hline & Same or less, $\%$ & 32 & 26 & 37 \\
\hline \multirow{4}{*}{$\begin{array}{l}\text { 5- Confident about your } \\
\text { health }\end{array}$} & Total, $\mathrm{n}$ & 86 & 62 & 74 \\
\hline & Much more, \% & 24 & 31 & 30 \\
\hline & More, \% & 43 & 42 & 31 \\
\hline & Same or less, \% & 33 & 27 & 39 \\
\hline \multirow[t]{4}{*}{ 6- Able to help yourself } & Total, n & 83 & 61 & 70 \\
\hline & Much more, \% & 29 & 36 & 23 \\
\hline & More, \% & 37 & 33 & 37 \\
\hline & Same or less, $\%$ & 34 & 31 & 40 \\
\hline
\end{tabular}

$\mathrm{SPT}=$ structured postoperative physiotherapy; SPT $\geq 50 \%=$ patients with at least $50 \%$ attendance to treatment sessions in the structured postoperative physiotherapy group; $\mathrm{SA}=$ standard postoperative approach. PEI: Patient enablement instrument (score 0-12) 


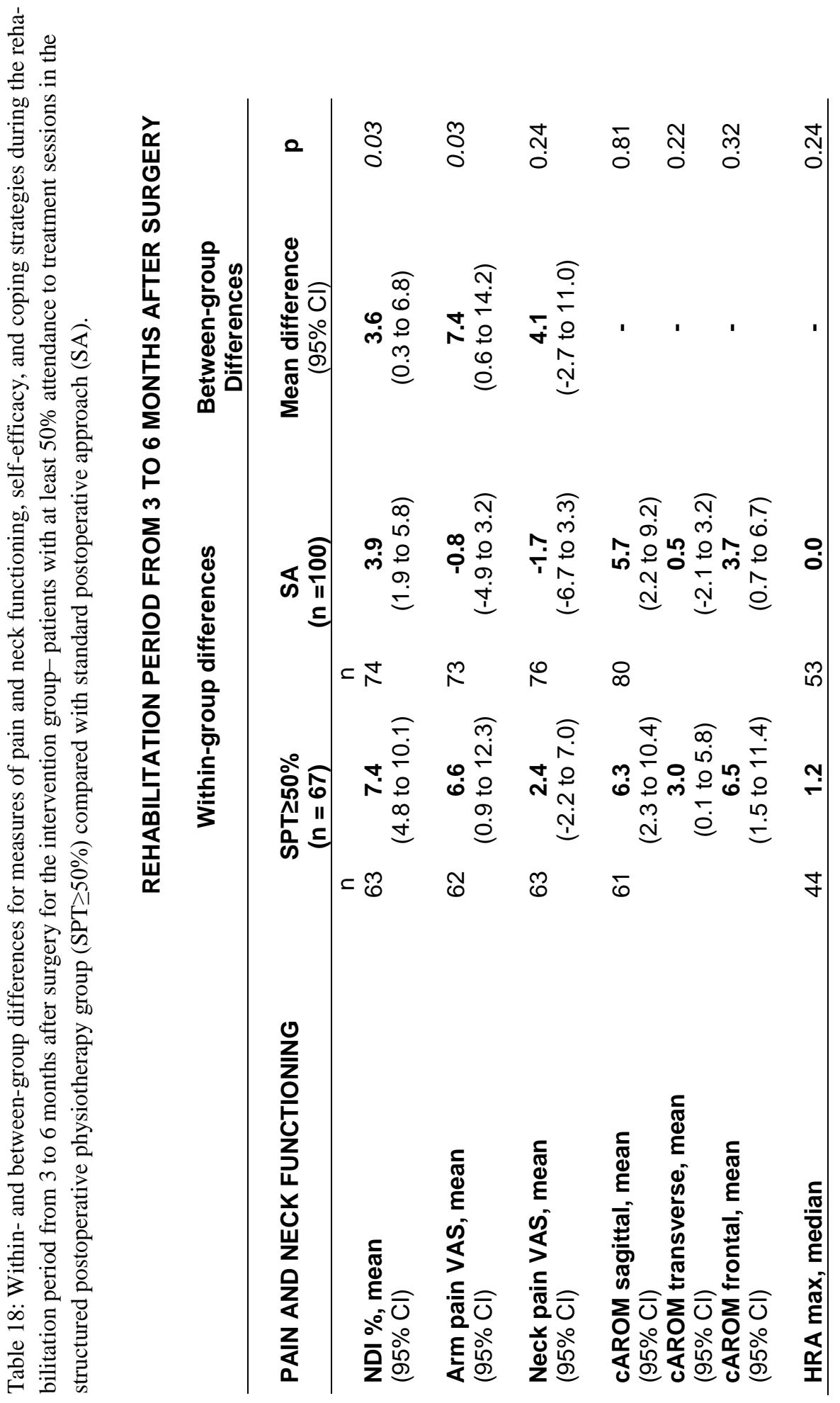




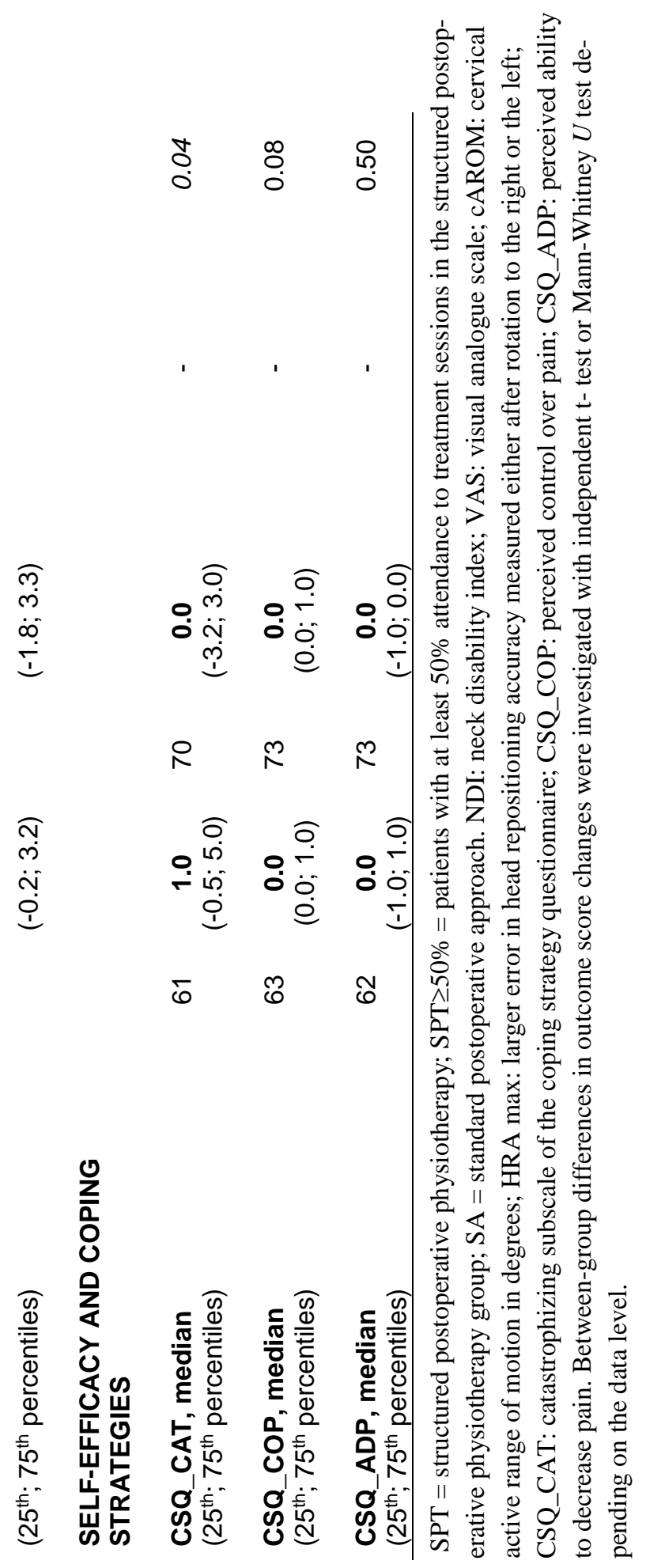




\section{Differences between patients who reported and did not report additional use of postoperative physiotherapy in the SA group}

At 6 months after surgery, additional use of postoperative physiotherapy was reported by $61 \%$ of the patients in the SA group $(n=47)$. No difference was found based on background variables and preoperative outcome measures $(p=0.06$ to $\mathrm{p}=0.93$ ) between patients who reported additional use of postoperative physiotherapy (PPT, $n=47$ ) in the SA group and patients who did not (No PPT, $n=30$ ) (Table 19). At 6 weeks, 3 months and 6 months after surgery, there was significantly fewer patients in the PPT group who reported a substantial improvement on global outcome of treatment compared with patients in the No PPT group $(p=0.03$ to $\mathrm{p}=0.05$ ) (Table 19). Patients in the PPT group also had worse outcomes on the NDI and VAS neck pain at 6 months follow-up compared with patients in the No PPT group $(\mathrm{p}=0.004$ to $\mathrm{p}=0.03$ ) (Table 19). 


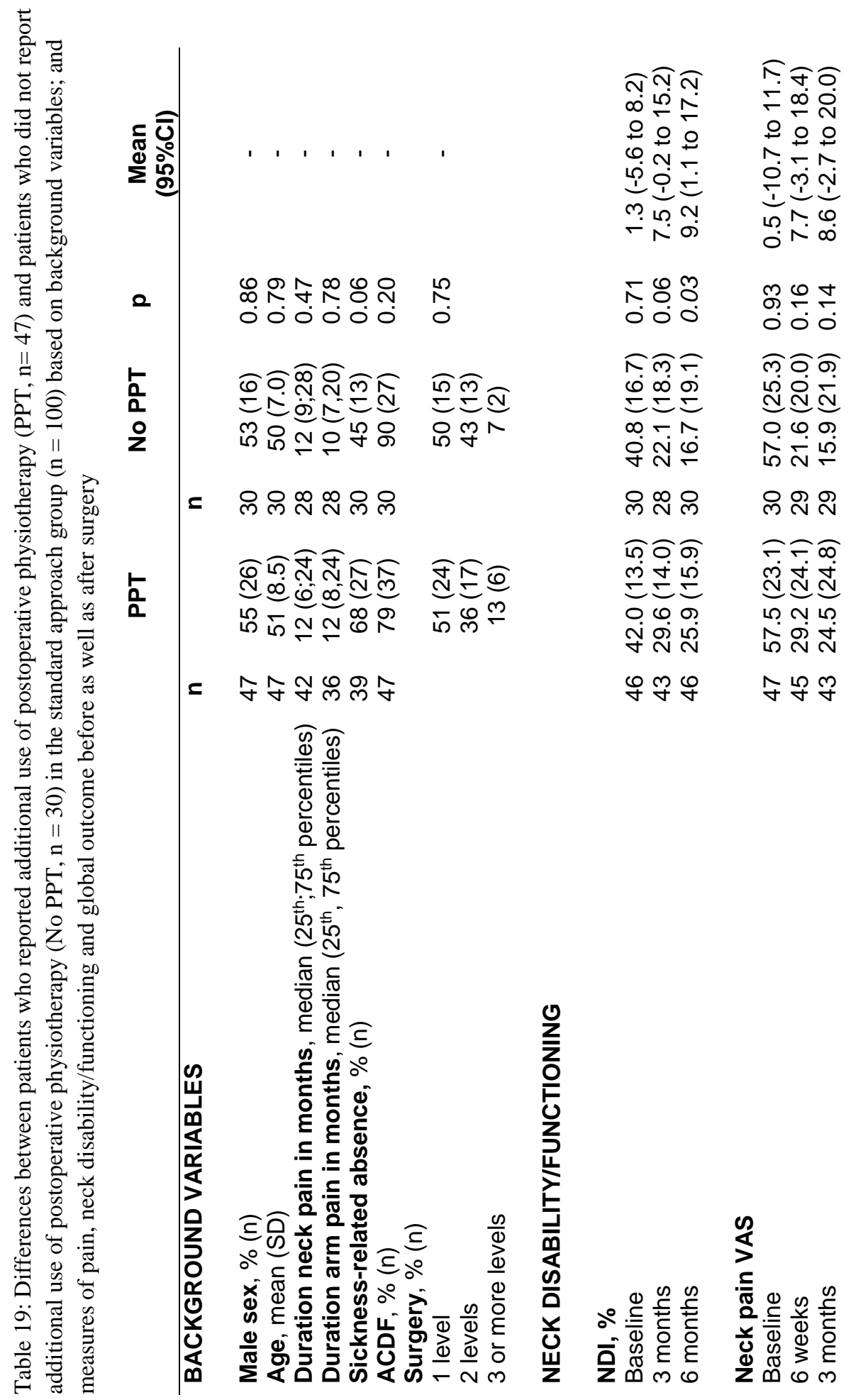




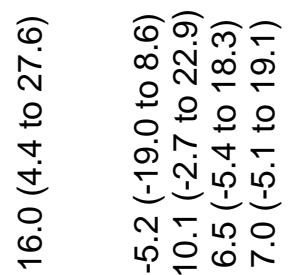

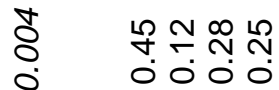

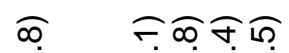

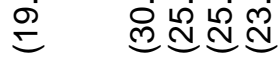

N $\quad 000 \mathrm{~m}$

ตூ กิ่กตั่

아 유류요

ก

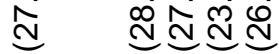

N $\quad \infty-N m$

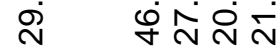

夺守导导

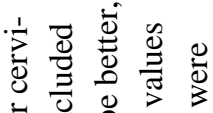

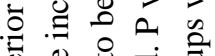

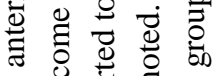

范总迨

《

$\therefore \frac{0}{3}$ on

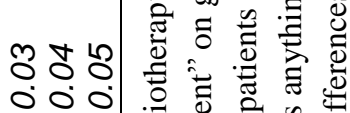

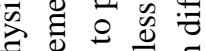

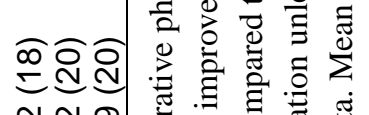

๙ ㅇ

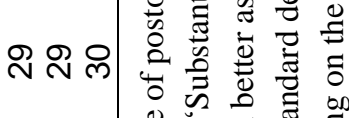

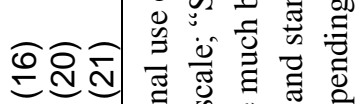

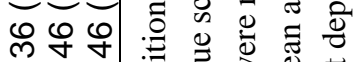

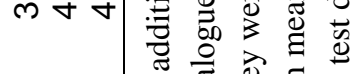

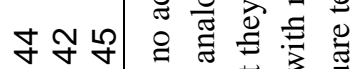

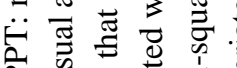

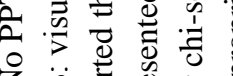

之 $\ddot{\text { n }}$

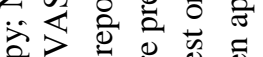

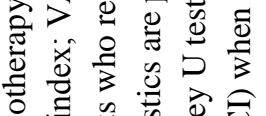

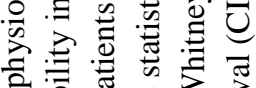

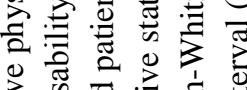

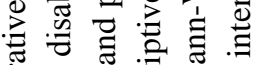

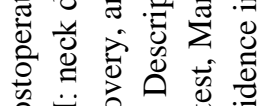

¿

乙 0 ठै

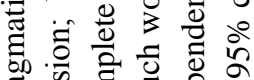

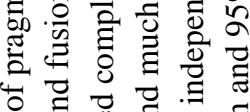

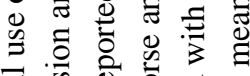

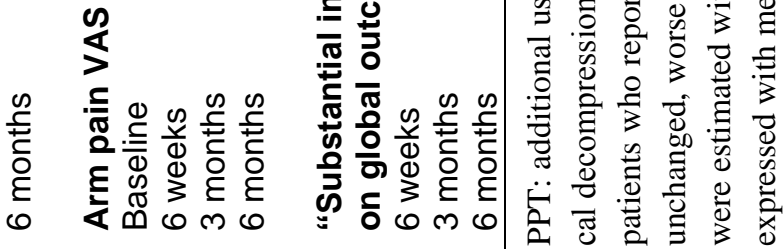




\section{DISCUSSION}

\section{Main findings}

The overall aims of this thesis were to investigate the additional benefit of SPT compared to SA in patients with CR at 6 months after surgery, and also to evaluate the contribution of different aspects of neck-related body functions and mental functions on preoperative neck disability in these patients.

The main results from the RCT of postoperative physiotherapy in patients with CR showed no between-group difference at 6 months after surgery based on patient-reported measures of pain, neck functioning, global outcome, clinical evaluations of neck-related body functions, self-efficacy and coping strategies. However, patients who received SPT (and SPT $\geq 50 \%$ ) reported greater expectation fulfilment at 6 months after surgery compared with patients who received SA. $\mathrm{SPT} \geq 50 \%$ patients also reported less neck pain frequency, and greater enablement at 6 months after surgery as was shown in better ability to understand and cope with their illness after treatment compared with those patients who received SA. There were no differences for changes in outcomes from before surgery to 6 months between the groups, but all outcomes significantly improved from baseline to 6 months in both groups. However, global outcome of treatment and neck pain frequency improved during the postoperative period only in patients who received SPT (and SPT $\geq 50 \%$ ); and larger improvements in patient-reported measure of arm pain, neck functioning, and catastrophizing were reported in $\mathrm{SPT} \geq 50 \%$ patients during the rehabilitation period from 3 to 6 months after surgery compared to patients who received SA. Sixty-one per cent of the patients who received SA reported additional use of postoperative physiotherapy at 6 months after surgery, and they had a worse surgical outcome compared with patients who reported no additional use of postoperative physiotherapy.

In patients with CR scheduled for surgery, larger errors in HRA measured with a CROM device were reported compared to neck-healthy individuals. Interpretation of the results remain limited due to questions regarding the measurement properties of the CROM device to assess HRA. Measures of pain and symptoms, mental functions, contextual factors, as well as clinical evaluations of neck-related body functions were associated with NDI scores in patients with CR who were scheduled for surgery. 


\section{Interpretation of the results}

\section{Assessment of HRA in patients with $\mathrm{CR}$ and neck-healthy individuals (Pa- per I)}

HRA measured with a CROM device was assessed in a sub-sample of patients with CR who were scheduled for surgery, and compared to neck-healthy individuals. Significant between-group differences were found. The results may be compared with previous reports of HRA impairments in individuals with other neck disorders [130, 131, 149, 150]. Larger errors in HRA in patients suffering from neck pain might reflect disturbances in sensorimotor control originating from the neck [103]. Moreover, sensorimotor control disturbances have been suggested to occur more in patients with WAD, in patients with upper cervical region pain $[132,151]$, as well as in patients with WAD who report dizziness [132]. The presence of disturbances in sensorimotor motor control have been more uncertain in patients with nonspecific neck pain [152]. In the present study, $21 \%$ of the patients with CR who were enrolled in the RCT reported daily dizziness. Association between HRA impairments and dizziness was not investigated, nor was a specific screening for upper cervical region pain performed [151]. The deep cervical muscles have been shown to have a high density of muscle spindles [153], and dysfunction in sensory input from muscle spindles in the deep cervical muscles has been suggested as a potential origin to sensorimotor control disturbances in patients with neck pain [103, 131, 132]. Muscular fatigue of the scapula elevator muscles HRA was shown to affect HRA in neck-healthy individuals [154]. However, control of head movement is known to be complex $[155,156]$, and the underlying mechanisms to sensorimotor control disturbances as well as their clinical importance remains poorly understood.

Consensus on the most appropriate method and protocol to assess HRA is lacking [157], and in this thesis a CROM device was used [130]. Consequently, comparison of the results for HRA between studies is limited due to differences in study population, assessment methods and protocols, as well as choice of statistical analysis $[130,158]$. The ICC values that were reported for test-retest reliability of HRA measurement with a CROM device in patients with CR may be compared to that reported for a laser in individuals with neck pain $(\mathrm{ICC}=0.68)$ [158]. However, SEM for the CROM device in patients with CR may call into question the clinical importance of the reported between-group difference of $1^{\circ}$. Determination of HRA impairment in patients with CR was directly related to the used method. The use of a ROC curve improved the sensitivity but reduced the specificity of the discriminative value as compared to the use of the $90^{\text {th }}$ percentile of HRA max in neckhealthy individuals. 


\section{Neck disability in patients with CR and scheduled for surgery (Paper II)}

Factors associated with neck disability in patients with CR scheduled for surgery were investigated. No influence of sex or age on preoperative NDI scores was found which is in accordance with previous findings in patients with CR [11].

Moderate to high correlations have been reported between low back muscle endurance with activity limitations and participation restrictions in patients with lumbar disc herniation [159]. Evaluation of low back muscle endurance is currently recommended in patients with lumbar disc herniation [159]. Likewise, based on the assessment of NME and CAROM reported in this thesis, increasing the description of neck-related body functions in relation to neck disability in patients with CR may be recommended.

The influence of psychosocial factors on patient-reported disability has been studied in patients with lumbar fusion [160]. Interestingly, conflicting results have been reported regarding the importance of preoperative psychological distress for the outcome of spinal surgery [99, 100, 161]. Psychological distress may be a predictor of poor surgical outcome based on the NDI in patients with CR $[13,99]$. Psychosocial distress may also be a consequence of long-standing pain; likely to improve when the symptoms resolved after treatment and worsen in patients with a poor outcome [100]. On the other hand, both preoperative and postoperative fear avoidance beliefs about movements and physical activity have been associated with a poor outcome in spine surgery $[19,100]$. The results suggest that negative and maladaptive beliefs and coping strategies may be more concerning for the outcome of surgery than preoperative psychological distress. It has been suggested that active strategies to modify maladaptive beliefs and coping strategies in patients with CR should be integrated in physiotherapy treatments $[19,100]$.

Our model may be compared to that recently proposed in patients with CR who were non-surgically treated and that suggested assessment of fear avoidance and anxiety to be included in the evaluation to broaden the clinical picture of patients with CR [39]. The number and the spread of the variables included in both analysis, as well as the use of explorative approaches might have positively influenced the results. In comparison, a model in patients with chronic neck pain explained $37 \%$ of the variance in NDI scores [147]; the model presented in this thesis explained $73 \%$ of the variance in NDI scores.

Patient-reported and clinical measures of neck-related body functions, as well as evaluation of mental functions and other contextual factors provided details about impairments and disability in individuals which improved the description of neck disability as measured with the NDI (Fig. 4). On the other hand, the potential confounding effects of psychosocial factors on NDI scores may call into question the responsiveness of the NDI to evaluate treatment outcomes after surgery [162]. 


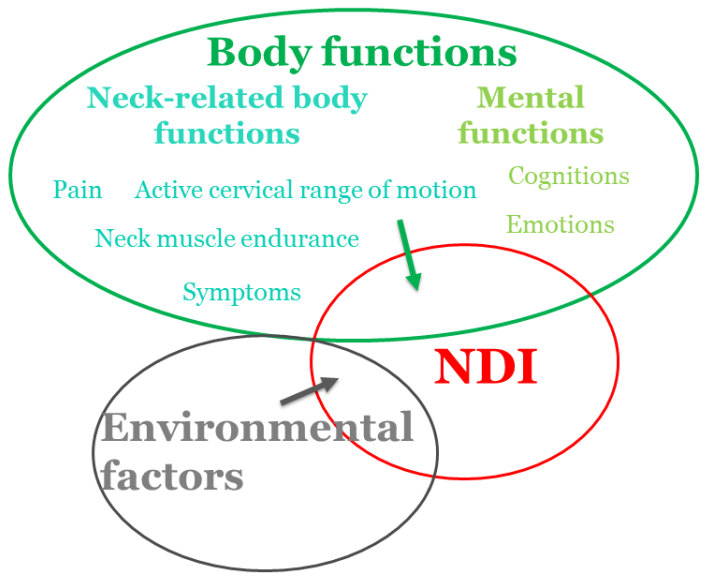

Fig. 4: A broader preoperative evaluation in patients with CR based on the International Classification of Functioning, Disability and Health and including assessment of neck-related body functions, mental functions, and environmental factors improved the description of neck disability as measured with the Neck Disability Index (NDI).

\section{Evaluation of SPT compared to SA in patients with CR (Paper III \& IV)}

\section{Outcomes at 6 months after surgery}

The treatment groups differed significantly at 6 months after surgery for expectation fulfilment only. Greater expectations fulfilment has been linked to higher postoperative satisfaction and better functional outcomes after cervical spine surgery [108]. No between-group difference was found based on functional outcomes in the present study. Patients with surgically treated lumbar radiculopathy who received a preoperative neuroscience education program were more satisfied with the outcome of surgery and showed $50 \%$ less health care consumption during the following year as compared to the control group [163]. Although, no betweengroup difference was reported based on measures of pain and functioning at 1 year follow-up [163]. Likewise, patients after lumbar fusion who received postoperative rehabilitation with psychomotor therapy combining exercises with a psychosocial approach reported reduced use of external health care for back pain at 2-3 years follow-up compared with patients who received home-based exercises [89]. In a per-protocol approach, we also found less neck pain frequency and greater enablement in SPT $\geq 50 \%$ compared to patients who received SA. The importance of physiotherapist-supervised treatment sessions for perceived treatment effects 
has previously been suggested in physiotherapy [92]. The clinical importance of between-group differences based on greater expectation fulfilment and enablement (for e.g future health care consumption) should be investigated in future studies.

In the present study, evaluation of between-group differences based on measures of pain and neck functioning at 6 months after surgery may have been too early to detect differences considering that recovery was not complete and that some effects may be delayed after surgery [65, 66]. However, we evaluated group differences at the end of the SPT intervention. Future studies could investigate the long-term effects of SPT compared to SA in patients with CR. This is particularly important because the NDI may fluctuate over time [12].

Earlier RCTs comparing different surgical methods in patient with CR have not reported between-group differences in clinical outcomes [9, 11, 69, 164]. It is reasonable to assume that patients with $\mathrm{CR}$ are a rather heterogeneous group, and that different subgroups may need different kinds of interventions. These factors might help to explain the lack of statistically and clinically important differences between groups. More RCTs of postoperative physiotherapy are needed to identify subgroups of patients with CR that might benefit more from extensive physiotherapy rehabilitation. The results from this first study may help guide future research.

SPT combined individual physiotherapist-supervised treatment sessions with home-based exercises. Moreover, SPT was monitored by a total of 45 physiotherapists with a broad spectrum of levels of experience, competence, and specialized knowledge mirroring the clinical set-up of most departments. Consequently, knowledge about the physiotherapist's ability to individualize and progress the neck-specific exercises, as well as their confidence in applying the behavioural approach is limited. Swedish physiotherapists are introduced to CBT as part of their education, and the physiotherapists recruited in the study were considered to have basic knowledge about combining exercise therapy with a behavioural approach. However, the physiotherapist's own beliefs and pain coping strategies are known to influence decision-making and management in low back pain [165-168]. Larger treatment effects may have been observed if specialist musculoskeletal physiotherapists were involved in the study, or, if physiotherapists had been recruited based on their specific interest in neck rehabilitation and had received a more extended education as part of a planned implementation strategy [169]. On the other hand, this may have reduced the generalizability of the results. Specific training of functional and daily activities were not the focus of the treatment sessions, although, the NDI includes items that have been directly linked to activity limitations and participation restrictions in daily activities [117].

\section{Changes in outcomes from before surgery to 6 months after surgery}

No between-group difference was found for changes in outcomes from before surgery to 6 months follow-up. However, large improvements were observed in both groups for patient-reported measures of pain and neck functioning compared to 
older studies $[9,11-13,164]$. This may be related to improvements in surgical techniques as well as patient selection for surgery during recent years. Consequently, the potential to further improve the outcomes with physiotherapy in the immediate postoperative period may have been limited. Though, more than half of the patients who received SA reported additional use of postoperative physiotherapy at 6 months after surgery. This suggests that patients with CR perceive a need for additional treatments after surgery. Moreover, the within-group changes in the NDI and VAS neck and arm pain from before surgery to 6 months in patients who received SPT may be compared to that reported by Engquist et al. in patients with CR who were also treated with surgery combined with SPT [65], and the results from both studies may suggest a benefit from combining surgery with SPT in patients with $\mathrm{CR}$.

There was a tendency for larger improvements in NME in extension from before surgery to 6 months in men and women who received SPT (and SPT $\geq 50 \%$ ) compared with patients who received SA, however no statistical difference was found. Improvements in NME have been reported following different interventions in patients with CR including surgery, structured as well as pragmatic physiotherapy, and surgery combined with SPT $[13,15,66]$. This may limit the interpretation of potential treatment mechanisms. Other factors such as pain tolerance, fear of test-induced pain, as well as motivation may interfere with the results from clinical evaluations of physical function [29]. However, cervical muscle fatigue (measured with surface electromyography EMG) was more strongly associated to measures of NME in patients with CR than were patient-reported measures of pain, neck disability, fatigue, and fear of movement [29]. A framework to interpret the clinical importance of changes in NME is lacking due to restricted knowledge about systematic and random errors for measures of NME in patients with CR [170].

Conflicting results have been reported regarding post-surgical improvements in cAROM in patients with CR $[13,30,66]$. The nature of cervical disc disease generally concerning several levels, as well as the suggestion of increased risk for more rapid degeneration of adjacent vertebra levels after fusion [171] should both be taken into account when interpreting changes in cAROM after treatments in patients with CR. No other study of HRA assessment was available in patients with CR.

The improvements in catastrophizing that were observed in SPT $\geq 50 \%$ were comparable to those reported at 6 months follow-up in patients who were undergoing postoperative rehabilitation with psychomotor therapy after lumbar fusion [89]. The results may suggest similar effect mechanisms, although the intervention contents differed.

\section{Treatment effects during the postoperative period}

Significant differences in treatment effects from 3 to 6 months after surgery were observed only between SPT $\geq 50 \%$ and patients who received SA. The importance 
of physiotherapist-supervised treatment sessions for treatment effects has previously been suggested in physiotherapy [92]. The larger improvements in arm pain, neck functioning and catastrophizing that were observed in SPT $\geq 50 \%$ compared to patients who received SA were combined with a significant increase in the proportion of patients who reported a substantial improvement on the global outcome in $\mathrm{SPT} \geq 50 \%$ only. Reduced catastrophizing has been suggested to mediate the effects of both exercise therapy and CBT on function and pain in patients with chronic low back pain [172]. Moreover, global outcome has been reported to be a valid and responsive descriptor of overall effect compared with a range of other instruments in RCTs in patients with low back pain [173]. Global outcome may reflect domains important to the individual that may not be captured by other outcomes [174], and it has been suggested to have the potential to capture in an overall sense, the aspects of recovery or improvement that are most meaningful and relevant to individual patients [175].

Greater effects of surgery on arm pain than on neck pain have previously been reported $[3,9,11]$. The greater treatment effect on arm pain compared to neck pain from 3 to 6 months after surgery may reflect a delayed effect of surgery as well as be an effect of SPT. Indeed, physiotherapy combining neck-specific exercises with a behavioural approach was previously shown to reduce arm pain in patients with CR with no difference compared to surgery [65].

It has been recommended that evaluation of pain should include both measure of pain intensity, frequency, as well as consumption of analgesics [105]. In the present study, small changes in neck pain intensity as measured with a VAS were reported in both group from 3 to 6 months after surgery. However, neck pain frequency significantly improved in patients who received SPT (and SPT $\geq 50 \%$ ) from 3 to 6 months after surgery but remained unchanged in patients who received SA. This difference could reflect a treatment effect of SPT on neck pain.

\section{Differences between patients who reported or did not report additional use of postoperative physiotherapy in the SA group}

More than half of the patients who received SA reported additional use of postoperative physiotherapy. The results suggest that many patients with CR perceived a need for additional treatments after surgery. Based on measures of pain and neck functioning, the differences in surgical outcomes between patients who reported additional use of postoperative physiotherapy compared to those who did not may be regarded as clinically important [65]. Patients with a poor surgical outcome may be more likely to seek additional treatments after surgery due to remaining pain and disability. Therefore, the benefit of SPT compared to SA could be investigated in patients with CR with a poor outcome after surgery [176]. 


\section{Methodological considerations}

Findings in this thesis should be interpreted in the light of some methodological challenges.

\section{Generalization of the results}

Patients included in the RCT were comparable to patients with CR included in previous studies based on mean age $[11,16,19,31,65,76]$, as well as the proportion of men and women, and preoperative scores on NDI [19, 65, 76]. Patients with myelopathy symptoms were excluded, and the patients with CR who were included were considered to be representative of patients with CR without myelopathy who are scheduled for surgery [65]. Patients who were included in the final analyses in Paper II did not differ from the patients who were excluded due to missing data based on preoperative NDI scores. The model may be generalizable to patients with CR without myelopathy who are scheduled for surgery.

Loss of patients to follow-up should always be regarded as a threat to the generalization of the results in intervention studies [177]. There was no significant difference between groups in the number patients lost to follow-up. However, patients who were lost to follow-up had worse preoperative scores on the NDI, and SES. They also had lower NME compared to the patients who were followed up. The exact effect on our results stemming from this potential bias is uncertain, but it may have compromised the generalization of the results.

RCT are regarded as the gold standard to evaluate treatment effectiveness, and to inform evidence-based clinical guidelines for the treatment of patients. We reported our results in accordance with the CONSORT statement for parallel group RCT to ensure high quality research [178]. The outcome measures for pain and neck functioning had been validated in patients with $\mathrm{CR}$, and they are recommended outcome measures after cervical spine surgery [7, 102]. A broad evaluation of pain was used and included both assessment of pain intensity, pain frequency, and consumption of analgesics as is recommended in chronic pain trials [105]. A total of 45 physiotherapists with a broad spectrum of experience and competence mirroring the clinical set-up of most departments monitored SPT. This may also contribute to the generalization of the results.

\section{Study design}

The sample size estimation used in the RCT of postoperative physiotherapy in patients with CR was based on preliminary findings in NDI scores in a previous study that compared structured physiotherapy alone with surgery combined with SPT [65]. No other study was available at that time. The probability to detect a $10 \%$ 
between-group difference in the NDI at 6 months after surgery in this thesis may be questionable considering that all patients had surgery and that only small changes on the NDI were observed from 3 to 6 months after surgery.

At 6 months after surgery, 26\% of the patients in the SPT group, and $27 \%$ of the patients in the SA group were classified with no disability (NDI < 8\%) [179]. Similarly, $63 \%$ and $70 \%$ of the patients were classified as having no or mild disability (NDI < 30\%) [179]. A floor effect has been suggested to occur when $\geq 15 \%$ of participants achieve the lowest score [102], and the responsiveness of the NDI to detect changes in the postoperative period may be questionable. The Cervical Spine Outcome Questionnaire was suggested to have greater responsiveness compared to the NDI in patients undergoing cervical spine surgery [180]. The use of different outcome measures may have showed different results.

At the 3-month follow-up, we did not perform NME measurement due to restricted loading of the neck following fusion surgery, and we did not evaluate SES to limit the number of questions in the questionnaire. Thus, a limitation of the study was the lack of evaluation of within-group differences in SES and NME during the rehabilitation period from 3 to 6 months after surgery. Evaluation of fear of movement and pain-related fear in patients with CR may also have provided additional perspectives when comparing the effects of SPT to SA [39]. Similarly, knowledge about anatomical and biomechanical factors such as a congenitally narrow spinal canal and increased cervical spine mobility in patients with CR may have improved the interpretation of the results [51].

Differences between the treatment groups in preoperative duration of neck and arm pain occurred by chance. Patients who were randomized to SA also reported less arm pain frequency before surgery. Symptom duration was not associated with the 6 months outcomes with the exception of a weak association between arm pain duration and NDI (Spearman correlation, $r=0.17, p=0.05$ ). In addition, the influence of preoperative pain duration on surgical outcomes is uncertain $[3,161,181$, 182], and the longer preoperative symptom duration in patients who received SPT was not expected to have influenced the results.

Patients with CR were operated with $\mathrm{ACDF}$ or PCF, and different interbody cages were used in ACDF at the four spinal centers. The use of a plate was previously suggested to increase fusion and was used in most 2-levels ACDF as well as in 1-level ACDF in some patients. Similar fusion rates have been reported for different intervertebral cages $[9,11]$. In addition, the importance of fusion for the clinical outcomes after surgery is uncertain [164, 183]. No difference was found between patients who had surgery with ACDF or PCF before as well as after treatment based on measures of pain and neck disability/functioning. Evidence for the superiority of any surgical technique is lacking $[69,70,72]$, and the surgeon's choice of surgical technique was not considered to have influenced the results.

The influence of sex differences on treatment effects were not investigated within the frame of the thesis but should be considered in future studies. Better 
surgical outcomes have been reported in men both at short and long-term compared to women $[17,182]$. Higher levels of patient-reported neck disability and pain catastrophizing were reported in women compared with men at 10-13 years follow-up after surgery for CR [17]. In addition, differences in NME have been reported between men and women $[15,114]$. 


\section{CONCLUSIONS}

Patients with CR who received SPT reported greater expectation fulfilment at 6 months after surgery compared to patients who received SA; and global outcome of treatment as well as frequency of neck pain improved during the postoperative period in patients who received SPT only. However, no additional benefit of SPT compared to SA was found in patients with CR 6 months after surgery based on patient-reported measures of pain, neck functioning, global outcome, clinical evaluations of neck-related body functions, self-efficacy and coping strategies. At 6 months after surgery, patients with at least $50 \%$ attendance to treatment sessions in the SPT group reported less neck pain frequency, and greater expectation fulfillment and enablement than those who received SA. These patients also had greater improvements in arm pain, neck functioning, and catastrophizing during the rehabilitation period from 3 to 6 months after surgery. Thus, the results may suggest a benefit from combining surgery with SPT in patients with CR. Moreover, the results confirm that neck-specific exercises are tolerated by patients with $\mathrm{CR}$ after surgery. The possibility to further address impairments in neck-related body functions, and improve self-efficacy and coping strategies in patients with CR with physiotherapy should be addressed in future studies.

Sixty-one percent of the patients who received SA reported additional use of postoperative physiotherapy after surgery. This finding suggests that many patients with CR perceive a need for additional treatment after surgery, and that there is a need for more studies to develop evidence-based clinical guidelines for the treatment of patients with CR.

$\mathrm{CR}$ is a heterogeneous condition and because of this specific subgroups of patients are likely to benefit from different interventions. Patients who reported additional use of postoperative physiotherapy in the SA group had a poorer surgical outcome compared with patients who reported no additional use of postoperative physiotherapy. The benefit of SPT compared to SA should be evaluated in subgroups of patients who are more likely to benefit from extended postoperative rehabilitation e.g patients with $\mathrm{CR}$ with a poor outcome of surgery.

In patients with CR who were scheduled for surgery, HRA was assessed with a CROM device and larger errors were reported compared to neck-healthy individuals. Interpretation of the results remains limited due to questions regarding the measurement properties of the CROM device to assess HRA.

A broader preoperative assessment in patients with CR to include evaluation of patient-reported and clinical measures of neck-related body functions, as well as evaluation of mental functions and other contextual factors improved the description of patient-reported neck disability. 


\section{CLINICAL IMPLICATIONS}

- A few significant differences were found between SPT $\geq 50 \%$ and SA at 6 months after surgery, as well as for changes in outcomes during the rehabilitation period from 3 to 6 months after surgery. These results may suggest a benefit from combining surgery with SPT in patients with CR.

- The results from the present thesis confirm that neck-specific exercises are tolerated by patients with CR after surgery. Neck-specific exercises may be initiated from six weeks after surgery in patients with CR; starting with nonresistance exercises in supine position aiming to activate the deep cervical muscles. Next, neck-specific exercises may be progressed to isometric and graded resistance exercises to improve neuromuscular control and endurance of the cervical muscles.

- A broader preoperative assessment in patients with CR to include evaluation of patient-reported and clinical measures of neck-related body functions, as well as evaluation of mental functions and other contextual factors provided details about impairments and disability in patients with CR; and improved the description of patient-reported neck disability as measured with the NDI. Such an assessment may be used as a basis for enhanced dialogue between patients and health care professionals about treatment alternatives. 


\section{FUTURE RESEARCH}

- $\mathrm{CR}$ is a heterogeneous condition and specific subgroups of patients are likely to benefit from different interventions. Thus, more studies are needed to develop evidence-based guidelines for the treatment of patients with CR. The benefit of SPT compared to SA should be investigated in subgroups of patients who may be more likely to benefit from extended postoperative rehabilitation (e.g patients with CR with a poor outcome of surgery). This could also be compared to the benefit of rehabilitating all patients with $\mathrm{CR}$ preoperatively with structured physiotherapy.

- The results confirmed that neck-specific exercises are tolerated by patients with CR after surgery, and future studies should investigate whether the involvement of physiotherapists who are specialized in the management of musculoskeletal disorders can further improve impairments in neck-related body functions, as well as self-efficacy and coping strategies in patients with CR before as well as after surgery.

- Future studies should consider the benefit or early versus later rehabilitation with SPT in patients with CR, as well as different dosages of neck-specific exercises.

- The benefit of SPT compared to SA in patients with CR should be investigated at long-term based on measures of patient-reported neck functioning as well as work ability, and also taking into account the costs associated with prolonged use of additional treatments in patients with CR after surgery.

- More research on the influence of sex differences on the outcome of surgery and benefit of SPT at short and long term is also needed.

- There is a need to investigate the contribution of impairments in neck-related body function, as well as mental functions to patient-reported disability in specific subgroups of patients with CR to enable the development of effective treatment strategies. 



\section{SUMMARY IN SWEDISH}

Disksjukdom i nacken kan orsaka inklämning av en eller flera nervrötter i halsryggraden och ge upphov till utstrålande smärta i kombination med känselbortfall och svaghet i armen/armarna. Förekomst av nacksmärta är vanligt, och symptomen är starkt kopplade till både fysiskt och psykiskt lidande samt sjukskrivning. Kunskap om tillståndet är fortfarande begränsat och det finns både operativa och ickeoperativa alternativ till behandling. Vid operativ behandling tas diskmassa och benpålagringar bort i nacken med syftet att dekomprimera nerven och positiva effekter på armsmärta och neurologiska symptom finns rapporterade. Effekterna av operation på nackfunktionen är mer oklara med studier som visar på kvarstående funktions- och aktivitetsnedsättning, samt minskad delaktighet. Det finns idag vetenskapliga bevis för att nack-specifik träning och kognitiv beteende-medicinsk insats har effekt vid behandling av långvariga nackbesvär. Randomiserade kontrollerade studier avseende rehabilitering efter kirurgisk behandling för patienter med utstrålande smärta orsakad av disksjukdom i halsryggraden saknas. Därmed finns inte heller något underlag för att utveckla kliniska riktlinjer för fysioterapeutisk behandling efter operation hos dessa patienter.

Det övergripande syftet med avhandling var att utvärdera effekterna av strukturerad fysioterapi jämfört med sedvanligt omhändertagande efter operation för patienter med utstrålande armsmärta orsakad av disksjukdom i halsryggraden. Ett ytterligare syfte var att studera betydelsen av olika individuella faktorer för självskattad nackfunktion före operation.

Sammanlagt 202 patienter med planerad operation inkluderades i studien och randomiserades före kirurgi till strukturerad fysioterapi eller sedvanligt omhändertagande efter operation. Strukturerad fysioterapi kombinerade nack-specifik träning med en kognitiv beteende-medicinskt insats. Sedvanligt omhändertagande efter operation var enligt svensk praxis, vilket innebar att patienter efter ett återbesök till kirurgen ca 6 veckor efter kirurgi hänvisades till primärvården för fortsatt behandling vid behov. Patienterna utvärderades före operation, samt 6 veckor, 3 och 6 månader efter operation med enkäter och kliniska undersökningar. De två behandlingsgrupperna jämfördes avseende självskattad smärta, nackfunktion, global effekt av behandlingen, klinisk uppmätta funktionsnedsättningar i nacken, kognitiva faktorer såsom tilltro till egen förmåga och copingstrategier, samt uppfyllelse av förväntningar, och egenmakt. Ett urval av patienter $(n=71)$ jämfördes dessutom med nackfriska individer $(\mathrm{n}=173)$ avseende mätningar av repositionssinnet $\mathrm{i}$ nacken med en CROM plasthjälm. Sambanden mellan olika individuella faktorer och självskattad nackfunktion studerades före operation.

Patienter som genomgick strukturerad fysioterapi rapporterade uppfyllda förväntningar 6 månader efter operation $(\mathrm{p}=0.01)$ i högre utsträckning än gruppen som fått sedvanligt omhändertagande. Under perioden efter operation förbättrades 
globalt upplevd effekt av behandling och frekvens av nacksmärta $(\mathrm{p}<0.01)$ enbart för patienter i gruppen strukturerad fysioterapi. När patienter med $\geq 50 \%$ närvaro vid behandlingstillfällena i gruppen strukturerad fysioterapi jämfördes med patienter som genomgick sedvanligt omhändertagande efter operation så rapporterade de lägre frekvens av nacksmärta och högre egenmakt 6 månader efter operation. De förbättrades också i högre utsträckning avseende självskattad nackfunktion, armsmärta och katastroftankar under rehabiliteringsperioden från 3 till 6 månader efter operation. Inga andra skillnader hittades mellan grupperna efter 6 månader. Det fanns inte heller några skillnader mellan grupperna avseende förändringar från före operation till 6 månaders uppföljningen, men samtliga variabler förbättrades signifikant över tid i båda grupperna $(\mathrm{p}<0.001)$. Patienter med utstrålande smärta orsakad av disksjukdom i halsryggraden uppvisade i högre utsträckning funktionsnedsättning i repositionssinnet i nacken före operation jämfört med nackfriska individer. Självskattade och klinisk uppmätta funktionsnedsättningar förklarade tillsammans $73 \%$ av variationen i självskattad nackfunktion före operation hos patienter med utstrålande smärta orsakad av disksjukdom i halsryggraden.

Resultaten från avhandlingen antyder att patienter med utstrålande armsmärta orsakad av disksjukdom i halsryggraden kan ha viss nytta av att kombinera operation med strukturerad fysioterapi. Resultaten bekräftar även att patienter klarar belastad träning för nacken efter operation. Patienter med utstrålande armsmärta orsakad av disksjukdom i halsryggraden bildar en heterogen grupp och det är högst troligt att patienter kan ha nytta av olika typer av interventioner. Fler studier behövs därmed för att generera vetenskapligt underlag för behandling av patienter med utstrålande smärta orsakad av disksjukdom i halsryggraden och för att utveckla kliniska riktlinjer. En bredare utvärdering av patienter före operation kan förbättra beskrivningen av självskattad nackfunktion. 


\section{ACKNOWLEDGEMENTS}

I wish to express my gratitude to all the people who have contributed to this work in different ways, and helped and supported me throughout my $\mathrm{PhD}$ studies. In particular, I would like to thank:

Anneli Peolsson, associate professor, PT, main supervisor and co-author. Thank you for giving me the opportunity to become a $\mathrm{PhD}$ student, and for all your guidance, support, and encouragement along the journey.

Åsa Dedering, PhD, PT, supervisor and co-author. Thank you for all your help and support in critical moments and for sharing your knowledge and research experience with me.

Håkan Löfgren, $\mathrm{PhD}, \mathrm{MD}$, supervisor and co-author. Thank you for your help and support during my $\mathrm{PhD}$ studies, and for sharing with me your experience as a spine surgeon treating patients with $\mathrm{CR}$.

Birgitta Öberg, professor, PT, supervisor and co-author. Thank you for your scientific guidance along the journey.

Peter Zsigmond, PhD, MD; and Liselott Persson, PhD, PT, co-authors for collaboration on Paper II, III \& IV.

Jacques Vaillant, PhD, PT; and Nicolas Vuillerme, $\mathrm{PhD}$, co-authors and working in Grenoble, France, for collaboration on Paper I.

Margaretha R. Jonsson, PT; and Maria Andell, PT, co-authors for collaboration on Paper IV, and for your help testing patients in the study.

Barbro M. Johansson at the Department of neurosurgery at the university Hospital in Linköping for your precious help when including patients to the study.

Catarina Rostedt, PT; and Annelie Hellberg, PT for your help testing patients in the study when I was on maternity leave.

All participants for taking the time to complete the questionnaires and performing the tests, and all physiotherapists treating patients in the study. 
Henrik Magnusson for statistical support during the years working on the thesis.

My fellow PhD students at the department of Physiotherapy at the University of Linköping. A special thanks to Gunnel Peterson, Maria Landen Ludvigsson, and Anna Hermansen for your support, encouragement, and many interesting discussions during the journey.

Clare Ardern, PhD, PT, for language revisions in important part of the thesis.

All my colleagues at the Department of Physiotherapy at Linköping University.

Charlotte Wåhlin, $\mathrm{PhD}, \mathrm{PT}$, for persuading me to take the opportunity to become a PhD student.

Lionel and Hannelore Wibault, for all your support, encouragement, and help taking good care of Stella so I could finish this thesis.

Emma Wibault, for your inspiration and help in designing the cover illustration, and Lionel Wibault, for your colorful illustration in the thesis.

Mathias Wibault, and Anouk Faivre Picon. I know that the time that I have spent in the cross-country tracks during the last years have contributed to this work somehow.

Marie-charlotte Häll, for being my best friend through the ups and downs in life.

And finally, Franck and Stella for being the most important in my life.

This study was supported by the Swedish Research Council, the Swedish Society of Medicine, the Medical Research Council of Southeast Sweden, County Council of Region Östergötland, Lions, and Futurum (Academy of Health and care, Jönköping County Council). 


\section{REFERENCES}

1. Carette S, Fehlings MG. Clinical practice. Cervical radiculopathy. N Engl J Med. 2005;353(4):392-9.

2. Caridi JM, Pumberger M, Hughes AP. Cervical radiculopathy: a review. HSS journal : the musculoskeletal journal of Hospital for Special Surgery. 2011;7(3):265-72.

3. Lied B, Roenning PA, Sundseth J, Helseth E. Anterior cervical discectomy with fusion in patients with cervical disc degeneration: a prospective outcome study of 258 patients (181 fused with autologous bone graft and 77 fused with a PEEK cage). BMC Surg. 2010;10:10.

4. Daffner SD, Hilibrand AS, Hanscom BS, Brislin BT, Vaccaro AR, Albert TJ. Impact of neck and arm pain on overall health status. Spine (Phila Pa 1976). 2003;28(17):2030-5.

5. Radhakrishnan K, Litchy WJ, O'Fallon WM, Kurland LT. Epidemiology of cervical radiculopathy. A population-based study from Rochester, Minnesota, 1976 through 1990. Brain. 1994;117 ( Pt 2):325-35.

6. Goldstein B. Anatomic issues related to cervical and lumbosacral radiculopathy. Phys Med Rehabil Clin N Am. 2002;13(3):423-37.

7. Bono CM, Ghiselli G, Gilbert TJ, et al. An evidence-based clinical guideline for the diagnosis and treatment of cervical radiculopathy from degenerative disorders. Spine J. 2011;11(1):64-72.

8. Strömqvist B, Fritzell P, Hägg O, et al. The Swedish Spine Register 2014 report.

9. Löfgren H, Engquist M, Hoffmann P, Sigstedt B, Vavruch L. Clinical and radiological evaluation of Trabecular Metal and the Smith-Robinson technique in anterior cervical fusion for degenerative disease: a prospective, randomized, controlled study with 2-year follow-up. Eur Spine J. 2010;19(3):464-73.

10. Löfgren H, Johansen F, Skogar O, Levander B. Reduced pain after surgery for cervical disc protrusion/stenosis: a 2 year clinical follow-up. Disabil Rehabil. 2003;25(18):1033-43.

11. Vavruch L, Hedlund R, Javid D, Leszniewski W, Shalabi A. A prospective randomized comparison between the cloward procedure and a carbon fiber cage in the cervical spine: a clinical and radiologic study. Spine (Phila Pa 1976). 2002;27(16):1694-701.

12. Hermansen A, Hedlund R, Vavruch L, Peolsson A. A comparison between the carbon fiber cage and the cloward procedure in cervical spine surgery: a ten- to thirteen-year follow-up of a prospective randomized study. Spine (Phila Pa 1976). 2011;36(12):919-25.

13. Peolsson A, Vavruch L, Öberg B. Disability after anterior decompression and fusion for cervical disc disease. Advances in Physiotherapy. 2002;4(3):111-24. 
14. Hermansen AM, Cleland JA, Kammerlind AS, Peolsson AL. Evaluation of physical function in individuals 11 to 14 years after anterior cervical decompression and fusion surgery-a comparison between patients and healthy reference samples and between 2 surgical techniques. J Manipulative Physiol Ther. 2014;37(2):87-96.

15. Peolsson A, Kjellman G. Neck muscle endurance in nonspecific patients with neck pain and in patients after anterior cervical decompression and fusion. $\mathrm{J}$ Manipulative Physiol Ther. 2007;30(5):343-50.

16. Ylinen JJ, Savolainen S, Airaksinen O, Kautiainen H, Salo P, Hakkinen A. Decreased strength and mobility in patients after anterior cervical diskectomy compared with healthy subjects. Arch Phys Med Rehabil. 2003;84(7):1043-7.

17. Hermansen A, Hedlund R, Vavruch L, Peolsson A. Positive predictive factors and subgroup analysis of clinically relevant improvement after anterior cervical decompression and fusion for cervical disc disease: a 10- to 13-year follow-up of a prospective randomized study: clinical article. J Neurosurg Spine. 2013;19(4):403-11.

18. Persson LC, Lilja A. Pain, coping, emotional state and physical function in patients with chronic radicular neck pain. A comparison between patients treated with surgery, physiotherapy or neck collar--a blinded, prospective randomized study. Disabil Rehabil. 2001;23(8):325-35.

19. Archer KR, Wegener ST, Seebach C, et al. The effect of fear of movement beliefs on pain and disability after surgery for lumbar and cervical degenerative conditions. Spine (Phila Pa 1976). 2011;36(19):1554-62.

20. Gross A, Kay TM, Paquin JP, et al. Exercises for mechanical neck disorders. Cochrane Database Syst Rev. 2015.

21. Monticone M, Ambrosini E, Cedraschi C, et al. Cognitive-behavioral Treatment for Subacute and Chronic Neck Pain: A Cochrane Review. Spine (Phila Pa 1976). 2015;40(19):1495-504.

22. Rao R. Neck pain, cervical radiculopathy, and cervical myelopathy: pathophysiology, natural history, and clinical evaluation. Instr Course Lect. 2003;52:479-88.

23. Misterska E, Jankowski R, Glowacki J, Shadi M, Walczak M, Glowacki M. Kinesiophobia in pre-operative patients with cervical discopathy and coexisting degenerative changes in relation to pain-related variables, psychological state and sports activity. Med Sci Monit. 2015;21:181-94.

24. Karlberg M, Persson L, Magnusson M. Impaired postural control in patients with cervico-brachial pain. Acta Otolaryngol Suppl. 1995;520 Pt 2:440-2.

25. Peolsson A, Kammerlind A, Ledin T. Dynamic posturography in patients with cervical disc disease compared with patients with whiplash-associated disorders and healthy volunteers. Advances in Physiotherapy. 2004;6(4):173-81.

26. Fowler SB, Anthony-Phillips P, Mehta D, Liebman K. Health-related quality of life in patients undergoing anterior cervical discectomy fusion. J Neurosci Nurs. 2005;37(2):97-100. 
27. Peolsson A, Vavruch L, Oberg B. Can the results 6 months after anterior cervical decompression and fusion identify patients who will have remaining deficit at long-term? Disabil Rehabil. 2006;28(2):117-24.

28. Henderson CM, Hennessy RG, Shuey HM, Jr., Shackelford EG. Posterior-lateral foraminotomy as an exclusive operative technique for cervical radiculopathy: a review of 846 consecutively operated cases. Neurosurgery. 1983;13(5):504-12.

29. Halvorsen M, Abbott A, Peolsson A, Dedering A. Endurance and fatigue characteristics in the neck muscles during sub-maximal isometric test in patients with cervical radiculopathy. Eur Spine J. 2014;23(3):590-8.

30. Hilibrand AS, Balasubramanian K, Eichenbaum M, et al. The effect of anterior cervical fusion on neck motion. Spine (Phila Pa 1976). 2006;31(15):1688-92.

31. Persson LC, Carlsson CA, Carlsson JY. Long-lasting cervical radicular pain managed with surgery, physiotherapy, or a cervical collar. A prospective, randomized study. Spine (Phila Pa 1976). 1997;22(7):751-8.

32. Tanaka N, Fujimoto Y, An HS, Ikuta Y, Yasuda M. The anatomic relation among the nerve roots, intervertebral foramina, and intervertebral discs of the cervical spine. Spine (Phila Pa 1976). 2000;25(3):286-91.

33. Lee MW, McPhee RW, Stringer MD. An evidence-based approach to human dermatomes. Clin Anat. 2008;21(5):363-73.

34. Adams MA, Roughley PJ. What is intervertebral disc degeneration, and what causes it? Spine (Phila Pa 1976). 2006;31(18):2151-61.

35. Irvine DH, Foster JB, Newell DJ, Klukvin BN. Prevalence of Cervical Spondylosis in a General Practice. Lancet. 1965;1(7395):1089-92.

36. Teresi LM, Lufkin RB, Reicher MA, et al. Asymptomatic degenerative disk disease and spondylosis of the cervical spine: MR imaging. Radiology. 1987;164(1):83-8.

37. Kuijper B, Tans JT, Schimsheimer RJ, et al. Degenerative cervical radiculopathy: diagnosis and conservative treatment. A review. Eur J Neurol. 2009;16(1):15-20.

38. Howe JF, Loeser JD, Calvin WH. Mechanosensitivity of dorsal root ganglia and chronically injured axons: a physiological basis for the radicular pain of nerve root compression. Pain. 1977;3(1):25-41.

39. Halvorsen M, Kierkegaard M, Harms-Ringdahl K, Peolsson A, Dedering A. Dimensions Underlying Measures of Disability, Personal Factors, and Health Status in Cervical Radiculopathy: A Cross-Sectional Study. Medicine (Baltimore). 2015;94(24):e999.

40. Grubb SA, Kelly CK. Cervical discography: clinical implications from 12 years of experience. Spine (Phila Pa 1976). 2000;25(11):1382-9.

41. Dwyer A, Aprill C, Bogduk N. Cervical zygapophyseal joint pain patterns. I: A study in normal volunteers. Spine (Phila Pa 1976). 1990;15(6):453-7.

42. Panjabi MM, Cholewicki J, Nibu K, Grauer J, Babat LB, Dvorak J. Critical load of the human cervical spine: an in vitro experimental study. Clin Biomech (Bristol, Avon). 1998;13(1):11-7. 
43. Mayoux-Benhamou MA, Revel M, Vallee C, Roudier R, Barbet JP, Bargy F. Longus colli has a postural function on cervical curvature. Surg Radiol Anat. 1994;16(4):367-71.

44. Mayoux-Benhamou MA, Revel M, Vallee C. Selective electromyography of dorsal neck muscles in humans. Exp Brain Res. 1997;113(2):353-60.

45. Falla D. Unravelling the complexity of muscle impairment in chronic neck pain. Man Ther. 2004;9(3):125-33.

46. Falla D, Bilenkij G, Jull G. Patients with chronic neck pain demonstrate altered patterns of muscle activation during performance of a functional upper limb task. Spine (Phila Pa 1976). 2004;29(13):1436-40.

47. Falla DL, Jull GA, Hodges PW. Patients with neck pain demonstrate reduced electromyographic activity of the deep cervical flexor muscles during performance of the craniocervical flexion test. Spine (Phila Pa 1976). 2004;29(19):2108-14.

48. Boudreau SA, Falla D. Chronic neck pain alters muscle activation patterns to sudden movements. Exp Brain Res. 2014;232(6):2011-20.

49. Meisingset I, Woodhouse A, Stensdotter AK, et al. Evidence for a general stiffening motor control pattern in neck pain: a cross sectional study. BMC Musculoskelet Disord. 2015;16:56.

50. O'Leary S, Jull G, Kim M, Vicenzino B. Cranio-cervical flexor muscle impairment at maximal, moderate, and low loads is a feature of neck pain. Man Ther. 2007;12(1):34-9.

51. Fouyas IP, Sandercock PA, Statham PF, Nikolaidis I. How beneficial is surgery for cervical radiculopathy and myelopathy? BMJ. 2010;341:c3108.

52. Lees F, Turner JW. Natural History and Prognosis of Cervical Spondylosis. British medical journal. 1963;2(5373):1607-10.

53. Thoomes EJ, Scholten-Peeters W, Koes B, Falla D, Verhagen AP. The effectiveness of conservative treatment for patients with cervical radiculopathy: a systematic review. Clin J Pain. 2013;29(12):1073-86.

54. Wong JJ, Cote P, Quesnele JJ, Stern PJ, Mior SA. The course and prognostic factors of symptomatic cervical disc herniation with radiculopathy: a systematic review of the literature. Spine J. 2014;14(8):1781-9.

55. Tong HC, Haig AJ, Yamakawa K. The Spurling test and cervical radiculopathy. Spine (Phila Pa 1976). 2002;27(2):156-9.

56. Rubinstein SM, Pool JJ, van Tulder MW, Riphagen, II, de Vet HC. A systematic review of the diagnostic accuracy of provocative tests of the neck for diagnosing cervical radiculopathy. Eur Spine J. 2007;16(3):307-19.

57. Woods BI, Hilibrand AS. Cervical Radiculopathy: Epidemiology, Etiology, Diagnosis and Treatment. J Spinal Disord Tech. 2015;10.1097.

58. Fouyas IP, Statham PF, Sandercock PA. Cochrane review on the role of surgery in cervical spondylotic radiculomyelopathy. Spine (Phila Pa 1976). 2002;27(7):73647. 
59. Thoomes EJ, Scholten-Peeters GG, de Boer AJ, et al. Lack of uniform diagnostic criteria for cervical radiculopathy in conservative intervention studies: a systematic review. Eur Spine J. 2012;21(8):1459-70.

60. Anderberg L, Annertz M, Persson L, Brandt L, Saveland H. Transforaminal steroid injections for the treatment of cervical radiculopathy: a prospective and randomised study. Eur Spine J. 2007;16(3):321-8.

61. Persson LC, Carlsson JY, Anderberg L. Headache in patients with cervical radiculopathy: a prospective study with selective nerve root blocks in 275 patients. Eur Spine J. 2007;16(7):953-9.

62. Persson L, Anderberg L. Repetitive transforaminal steroid injections in cervical radiculopathy: a prospective outcome study including 140 patients. Evid Based Spine Care J. 2012;3(3):13-20.

63. Salt E, Wright C, Kelly S, Dean A. A systematic literature review on the effectiveness of non-invasive therapy for cervicobrachial pain. Man Ther. 2011;16(1):53-65.

64. Nee RJ, Vicenzino B, Jull GA, Cleland JA, Coppieters MW. Neural tissue management provides immediate clinically relevant benefits without harmful effects for patients with nerve-related neck and arm pain: a randomised trial. Journal of physiotherapy. 2012;58(1):23-31.

65. Engquist M, Löfgren H, Öberg B, et al. Surgery versus nonsurgical treatment of cervical radiculopathy: a prospective, randomized study comparing surgery plus physiotherapy with physiotherapy alone with a 2-year follow-up. Spine (Phila Pa 1976). 2013;38(20):1715-22.

66. Peolsson A, Soderlund A, Engquist M, et al. Physical function outcome in cervical radiculopathy patients after physiotherapy alone compared with anterior surgery followed by physiotherapy: a prospective randomized study with a 2-year follow-up. Spine (Phila Pa 1976). 2013;38(4):300-7.

67. Dedering A, Halvorsen M, Cleland J, Svensson M, Peolsson A. Neck-specific training with a cognitive behavioural approach compared with prescribed physical activity in patients with cervical radiculopathy: a protocol of a prospective randomised clinical trial. BMC Musculoskelet Disord. 2014;15:274.

68. Matz PG, Holly LT, Groff MW, et al. Indications for anterior cervical decompression for the treatment of cervical degenerative radiculopathy. $\mathbf{J}$ Neurosurg Spine. 2009;11(2):174-82.

69. Verhagen AP, van Middelkoop M, Rubinstein SM, et al. Effect of various kinds of cervical spinal surgery on clinical outcomes: a systematic review and metaanalysis. Pain. 2013;154(11):2388-96.

70. Wirth FP, Dowd GC, Sanders HF, Wirth C. Cervical discectomy. A prospective analysis of three operative techniques. Surg Neurol. 2000;53(4):340-6; discussion 6-8.

71. Smith GW, Robinson RA. The treatment of certain cervical-spine disorders by anterior removal of the intervertebral disc and interbody fusion. J Bone Joint Surg Am. 1958;40-A(3):607-24. 
72. Jacobs W, Willems PC, Kruyt M, et al. Systematic review of anterior interbody fusion techniques for single- and double-level cervical degenerative disc disease. Spine (Phila Pa 1976). 2011;36(14):E950-60.

73. Sampath P, Bendebba M, Davis JD, Ducker T. Outcome in patients with cervical radiculopathy. Prospective, multicenter study with independent clinical review. Spine (Phila Pa 1976). 1999;24(6):591-7.

74. Peolsson A. Investigation of clinically important benefit of anterior cervical decompression and fusion. Eur Spine J. 2007;16(4):507-14.

75. Zoega B, Karrholm J, Lind B. Outcome scores in degenerative cervical disc surgery. Eur Spine J. 2000;9(2):137-43.

76. Landers MR, Addis KA, Longhurst JK, Vom Steeg BL, Puentedura EJ, Daubs MD. Anterior cervical decompression and fusion on neck range of motion, pain, and function: a prospective analysis. Spine J. 2013;13(11):1650-8.

77. Abbott A, Halvorsen M, Dedering A. Is there a need for cervical collar usage post anterior cervical decompression and fusion using interbody cages? A randomized controlled pilot trial. Physiother Theory Pract. 2013;29(4):290-300.

78. O'Leary S, Falla D, Elliott JM, Jull G. Muscle dysfunction in cervical spine pain: implications for assessment and management. J Orthop Sports Phys Ther. 2009;39(5):324-33.

79. Bronfort G, Evans R, Nelson B, Aker PD, Goldsmith CH, Vernon H. A randomized clinical trial of exercise and spinal manipulation for patients with chronic neck pain. Spine (Phila Pa 1976). 2001;26(7):788-97.

80. Chiu TT, Lam TH, Hedley AJ. A randomized controlled trial on the efficacy of exercise for patients with chronic neck pain. Spine (Phila Pa 1976). 2005;30(1):E1-7.

81. Kay TM, Gross A, Goldsmith $\mathrm{CH}$, et al. Exercises for mechanical neck disorders. Cochrane Database Syst Rev. 2012.

82. Kay TM, Gross A, Goldsmith C, Santaguida PL, Hoving J, Bronfort G. Exercises for mechanical neck disorders. Cochrane Database Syst Rev. 2005.

83. Croft PR, Lewis M, Papageorgiou AC, et al. Risk factors for neck pain: a longitudinal study in the general population. Pain. 2001;93(3):317-25.

84. Ariens GA, van Mechelen W, Bongers PM, Bouter LM, van der Wal G. Psychosocial risk factors for neck pain: a systematic review. Am J Ind Med. 2001;39(2):180-93.

85. Thompson DP, Urmston M, Oldham JA, Woby SR. The association between cognitive factors, pain and disability in patients with idiopathic chronic neck pain. Disabil Rehabil. 2010;32(21):1758-67.

86. Thompson DP, Oldham JA, Urmston M, Woby SR. Cognitive determinants of pain and disability in patients with chronic whiplash-associated disorder: a crosssectional observational study. Physiotherapy. 2010;96(2):151-9.

87. Thompson DP, Oldham JA, Woby SR. Does adding cognitive-behavioural physiotherapy to exercise improve outcome in patients with chronic neck pain? A randomised controlled trial. Physiotherapy. 2015;10.1016. 
88. Landen Ludvigsson M, Peterson G, S OL, Dedering A, Peolsson A. The effect of neck-specific exercise with, or without a behavioral approach, on pain, disability and self-efficacy in chronic whiplash-associated disorders: a randomized clinical trial. Clin J Pain. 2014;10.1097

89. Abbott AD, Tyni-Lenne R, Hedlund R. Early rehabilitation targeting cognition, behavior, and motor function after lumbar fusion: a randomized controlled trial. Spine (Phila Pa 1976). 2010;35(8):848-57.

90. Bennell KL, Dobson F, Hinman RS. Exercise in osteoarthritis: moving from prescription to adherence. Best Pract Res Clin Rheumatol. 2014;28(1):93-117.

91. Campbell R, Evans M, Tucker M, Quilty B, Dieppe P, Donovan JL. Why don't patients do their exercises? Understanding non-compliance with physiotherapy in patients with osteoarthritis of the knee. J Epidemiol Community Health. 2001;55(2):132-8.

92. Hayden JA, van Tulder MW, Tomlinson G. Systematic review: strategies for using exercise therapy to improve outcomes in chronic low back pain. Ann Intern Med. 2005;142(9):776-85.

93. Gatchel RJ, Gardea MA. Psychosocial issues: their importance in predicting disability, response to treatment, and search for compensation. Neurol Clin. 1999;17(1):149-66.

94. Gatchel RJ, Peng YB, Peters ML, Fuchs PN, Turk DC. The biopsychosocial approach to chronic pain: scientific advances and future directions. Psychol Bull. 2007;133(4):581-624.

95. Foster NE, Pincus T, Underwood MR, Vogel S, Breen A, Harding G. Understanding the process of care for musculoskeletal conditions--why a biomedical approach is inadequate. Rheumatology (Oxford). 2003;42(3):401-4.

96. Laisne F, Lecomte C, Corbiere M. Biopsychosocial predictors of prognosis in musculoskeletal disorders: a systematic review of the literature. Disabil Rehabil. 2012;34(5):355-82.

97. Koes BW, van Tulder M, Lin CW, Macedo LG, McAuley J, Maher C. An updated overview of clinical guidelines for the management of non-specific low back pain in primary care. Eur Spine J. 2010;19(12):2075-94.

98. Dagenais S, Tricco AC, Haldeman S. Synthesis of recommendations for the assessment and management of low back pain from recent clinical practice guidelines. Spine J. 2010;10(6):514-29.

99. Peolsson A, Vavruch L, Oberg B. Predictive factors for arm pain, neck pain, neck specific disability and health after anterior cervical decompression and fusion. Acta Neurochir (Wien). 2006;148(2):167-73.

100. Havakeshian S, Mannion AF. Negative beliefs and psychological disturbance in spine surgery patients: a cause or consequence of a poor treatment outcome? Eur Spine J. 2013;22(12):2827-35.

101. World Health Organization. International classification of functioning, disability and health: ICF short version. Geneva: WHO; 2001.

102. McCormick JD, Werner BC, Shimer AL. Patient-reported Outcome Measures in Spine Surgery. J Am Acad Orthop Surg. 2013;21(2):99-107. 
103. Kristjansson E, Treleaven J. Sensorimotor function and dizziness in neck pain: implications for assessment and management. J Orthop Sports Phys Ther. 2009;39(5):364-77.

104. Treleaven J. Sensorimotor disturbances in neck disorders affecting postural stability, head and eye movement control. Man Ther. 2008;13(1):2-11.

105. Dworkin RH, Turk DC, Farrar JT, et al. Core outcome measures for chronic pain clinical trials: IMMPACT recommendations. Pain. 2005;113(1-2):9-19.

106. Sitzia J, Wood N. Patient satisfaction: a review of issues and concepts. Soc Sci Med. 1997;45(12):1829-43.

107. Skolasky RL, Albert TJ, Vaccaro AR, Riley LH, 3rd. Patient satisfaction in the cervical spine research society outcomes study: relationship to improved clinical outcome. Spine J. 2009;9(3):232-9.

108. Soroceanu A, Ching A, Abdu W, McGuire K. Relationship between preoperative expectations, satisfaction, and functional outcomes in patients undergoing lumbar and cervical spine surgery: a multicenter study. Spine (Phila Pa 1976). 2012;37(2):E103-8.

109. Howie JG, Heaney DJ, Maxwell M, Walker JJ. A comparison of a Patient Enablement Instrument (PEI) against two established satisfaction scales as an outcome measure of primary care consultations. Fam Pract. 1998;15(2):165-71.

110. Johnston V, Jull G, Sheppard DM, Ellis N. Applying principles of selfmanagement to facilitate workers to return to or remain at work with a chronic musculoskeletal condition. Man Ther. 2013;18(4):274-80.

111. Mead N, Bower P, Roland M. Factors associated with enablement in general practice: cross-sectional study using routinely-collected data. Br J Gen Pract. 2008;58(550):346-52.

112. Fairbank JC, Couper J, Davies JB, O'Brien JP. The Oswestry low back pain disability questionnaire. Physiotherapy. 1980;66(8):271-3.

113. Croft PR, Macfarlane GJ, Papageorgiou AC, Thomas E, Silman AJ. Outcome of low back pain in general practice: a prospective study. BMJ. 1998;316(7141):1356-9.

114. Peolsson A, Almkvist C, Dahlberg C, Lindqvist S, Pettersson S. Age- and sexspecific reference values of a test of neck muscle endurance. J Manipulative Physiol Ther. 2007;30(3):171-7.

115. Landen Ludvigsson M, Peterson G., Peolsson A.; Available from: www.divaportal.org/smash/get/diva2:785214/FULLTEXT02.pdf.

116. Vernon $\mathrm{H}$, Mior S. The Neck Disability Index: a study of reliability and validity. $\mathbf{J}$ Manipulative Physiol Ther. 1991;14(7):409-15.

117. Ferreira ML, Borges BM, Rezende IL, et al. Are neck pain scales and questionnaires compatible with the international classification of functioning, disability and health? A systematic review. Disabil Rehabil. 2010;32(19):1539-46.

118. Cleland JA, Fritz JM, Whitman JM, Palmer JA. The reliability and construct validity of the Neck Disability Index and patient specific functional scale in patients with cervical radiculopathy. Spine (Phila Pa 1976). 2006;31(5):598-602. 
119. Young IA, Cleland JA, Michener LA, Brown C. Reliability, construct validity, and responsiveness of the neck disability index, patient-specific functional scale, and numeric pain rating scale in patients with cervical radiculopathy. Am J Phys Med Rehabil. 2010;89(10):831-9.

120. Ackelman BH, Lindgren U. Validity and reliability of a modified version of the neck disability index. J Rehabil Med. 2002;34(6):284-7.

121. Williamson A, Hoggart B. Pain: a review of three commonly used pain rating scales. J Clin Nurs. 2005;14(7):798-804.

122. Carlsson AM. Assessment of chronic pain. I. Aspects of the reliability and validity of the visual analogue scale. Pain. 1983;16(1):87-101.

123. Peolsson A. HC, Albinsson A-K., Engdahl S., Kvist J. . Test position and reliability in measurements of dorsal neck muscle endurance. Adv Physiotherapy. 2007;9:181-9.

124. de Koning CH, van den Heuvel SP, Staal JB, Smits-Engelsman BC, Hendriks EJ. Clinimetric evaluation of methods to measure muscle functioning in patients with non-specific neck pain: a systematic review. BMC Musculoskelet Disord. 2008;9:142.

125. Youdas JW, Carey JR, Garrett TR. Reliability of measurements of cervical spine range of motion--comparison of three methods. Phys Ther. 1991;71(2):98-104.

126. de Koning CH, van den Heuvel SP, Staal JB, Smits-Engelsman BC, Hendriks EJ. Clinimetric evaluation of active range of motion measures in patients with nonspecific neck pain: a systematic review. Eur Spine J. 2008;17(7):905-21.

127. Peolsson A, Hedlund R, Oberg B. Intra- and inter-tester reliability and reference values for hand strength. J Rehabil Med. 2001;33(1):36-41.

128. Wainner RS, Fritz JM, Irrgang JJ, Boninger ML, Delitto A, Allison S. Reliability and diagnostic accuracy of the clinical examination and patient self-report measures for cervical radiculopathy. Spine (Phila Pa 1976). 2003;28(1):52-62.

129. Albert HB, Manniche $\mathrm{C}$. The efficacy of systematic active conservative treatment for patients with severe sciatica: a single-blind, randomized, clinical, controlled trial. Spine (Phila Pa 1976). 2012;37(7):531-42.

130. Loudon JK, Ruhl M, Field E. Ability to reproduce head position after whiplash injury. Spine (Phila Pa 1976). 1997;22(8):865-8.

131. Revel M, Andre-Deshays C, Minguet M. Cervicocephalic kinesthetic sensibility in patients with cervical pain. Arch Phys Med Rehabil. 1991;72(5):288-91.

132. Treleaven J, Jull G, Sterling M. Dizziness and unsteadiness following whiplash injury: characteristic features and relationship with cervical joint position error. J Rehabil Med. 2003;35(1):36-43.

133. Altmaier EM RD, Kao CF, Lehmann TR, Weinstein JN, . Role of self-efficacy in rehabilitation outcome among chronic low back pain patients. Journal of Counseling Psychology. 1993;40(3):335-9.

134. Denison E, Asenlof P, Lindberg P. Self-efficacy, fear avoidance, and pain intensity as predictors of disability in subacute and chronic musculoskeletal pain patients in primary health care. Pain. 2004;111(3):245-52. 
135. Denison E, Asenlof P, Sandborgh M, Lindberg P. Musculoskeletal pain in primary health care: subgroups based on pain intensity, disability, self-efficacy, and fear-avoidance variables. J Pain. 2007;8(1):67-74.

136. Rosenstiel AK, Keefe FJ. The use of coping strategies in chronic low back pain patients: relationship to patient characteristics and current adjustment. Pain. 1983;17(1):33-44.

137. Jensen IL, SJ. Coping strategies questionnaire: reliability of the Swedish version of the CSQ. Scandinavian Journal of Behavioral Therapy. 1993;22:139-45.

138. Cherkin DC, Deyo RA, Street JH, Barlow W. Predicting poor outcomes for back pain seen in primary care using patients' own criteria. Spine (Phila Pa 1976). 1996;21(24):2900-7.

139. Iles RA, Davidson M, Taylor NF, O'Halloran P. Systematic review of the ability of recovery expectations to predict outcomes in non-chronic non-specific low back pain. J Occup Rehabil. 2009;19(1):25-40.

140. Zung WW. A Self-Rating Depression Scale. Arch Gen Psychiatry. 1965;12:63-70.

141. Main CJ. The Modified Somatic Perception Questionnaire (MSPQ). J Psychosom Res. 1983;27(6):503-14.

142. Hoving JL, Koes BW, de Vet HC, et al. Manual therapy, physical therapy, or continued care by a general practitioner for patients with neck pain. A randomized, controlled trial. Ann Intern Med. 2002;136(10):713-22.

143. van der Roer N, Ostelo RW, Bekkering GE, van Tulder MW, de Vet HC. Minimal clinically important change for pain intensity, functional status, and general health status in patients with nonspecific low back pain. Spine (Phila $\mathrm{Pa} 1976$ ). 2006;31(5):578-82.

144. Roost M, Zielinski A, Petersson C, Strandberg EL. Reliability and applicability of the Patient Enablement Instrument (PEI) in a Swedish general practice setting. BMC Fam Pract. 2015;16:31.

145. de Vet HC, Terwee CB, Knol DL, Bouter LM. When to use agreement versus reliability measures. J Clin Epidemiol. 2006;59(10):1033-9.

146. Bland JM, Altman DG. Statistical methods for assessing agreement between two methods of clinical measurement. Lancet. 1986;1(8476):307-10.

147. Saavedra-Hernandez M, Castro-Sanchez AM, Cuesta-Vargas AI, Cleland JA, Fernandez-de-las-Penas C, Arroyo-Morales M. The contribution of previous episodes of pain, pain intensity, physical impairment, and pain-related fear to disability in patients with chronic mechanical neck pain. Am J Phys Med Rehabil. 2012;91(12):1070-6.

148. Field A, ed. Discovering statistics using SPSS for windows. 3rd ed. London: SAGE Publications; 2009.

149. Kristjansson E, Dall'Alba P, Jull G. A study of five cervicocephalic relocation tests in three different subject groups. Clin Rehabil. 2003;17(7):768-74.

150. Heikkila HV, Wenngren BI. Cervicocephalic kinesthetic sensibility, active range of cervical motion, and oculomotor function in patients with whiplash injury. Arch Phys Med Rehabil. 1998;79(9):1089-94. 
151. Treleaven J, Clamaron-Cheers C, Jull G. Does the region of pain influence the presence of sensorimotor disturbances in neck pain disorders? Man Ther. 2011;16(6):636-40.

152. Rix GD, Bagust J. Cervicocephalic kinesthetic sensibility in patients with chronic, nontraumatic cervical spine pain. Arch Phys Med Rehabil. 2001;82(7):911-9.

153. Boyd-Clark LC, Briggs CA, Galea MP. Muscle spindle distribution, morphology, and density in longus colli and multifidus muscles of the cervical spine. Spine (Phila Pa 1976). 2002;27(7):694-701.

154. Pinsault N, Vuillerme N. Degradation of cervical joint position sense following muscular fatigue in humans. Spine (Phila Pa 1976). 2010;35(3):294-7.

155. Peterson BW. Current approaches and future directions to understanding control of head movement. Prog Brain Res. 2004;143:369-81.

156. Armstrong B, McNair P, Taylor D. Head and neck position sense. Sports Med. 2008;38(2):101-17.

157. Swait G, Rushton AB, Miall RC, Newell D. Evaluation of cervical proprioceptive function: optimizing protocols and comparison between tests in normal subjects. Spine (Phila Pa 1976). 2007;32(24):E692-701.

158. Roren A, Mayoux-Benhamou MA, Fayad F, Poiraudeau S, Lantz D, Revel M. Comparison of visual and ultrasound based techniques to measure head repositioning in healthy and neck-pain subjects. Man Ther. 2009;14(3):270-7.

159. Dedering A, Harms-Ringdahl K, Nemeth G. Back extensor muscle fatigue in patients with lumbar disc herniation. Pre-operative and post-operative analysis of electromyography, endurance time and subjective factors. Eur Spine J. 2006;15(5):559-69.

160. Abbott AD, Tyni-Lenne R, Hedlund R. The influence of psychological factors on pre-operative levels of pain intensity, disability and health-related quality of life in lumbar spinal fusion surgery patients. Physiotherapy. 2010;96(3):213-21.

161. Engquist M, Löfgren H, Öberg B, et al. Factors affecting the outcome of surgical versus nonsurgical treatment of cervical radiculopathy - a randomized, controlled study. Spine (Phila Pa 1976). 2015;10.1097.

162. Young SB, Aprill C, Braswell J, Ogard WK, Richards JS, McCarthy JP. Psychological factors and domains of neck pain disability. Pain Med. 2009;10(2):310-8.

163. Louw A, Diener I, Landers MR, Puentedura EJ. Preoperative pain neuroscience education for lumbar radiculopathy: a multicenter randomized controlled trial with 1-year follow-up. Spine (Phila Pa 1976). 2014;39(18):1449-57.

164. Peolsson A, Vavruch L, Hedlund R. Long-term randomised comparison between a carbon fibre cage and the Cloward procedure in the cervical spine. Eur Spine J. 2007;16(2):173-8.

165. Linton SJ, Vlaeyen J, Ostelo R. The back pain beliefs of health care providers: are we fear-avoidant? J Occup Rehabil. 2002;12(4):223-32.

166. Darlow B, Fullen BM, Dean S, Hurley DA, Baxter GD, Dowell A. The association between health care professional attitudes and beliefs and the attitudes 
and beliefs, clinical management, and outcomes of patients with low back pain: a systematic review. Eur J Pain. 2012;16(1):3-17.

167. Simmonds MJ, Derghazarian T, Vlaeyen JW. Physiotherapists' knowledge, attitudes, and intolerance of uncertainty influence decision making in low back pain. Clin J Pain. 2012;28(6):467-74.

168. Domenech J, Sanchez-Zuriaga D, Segura-Orti E, Espejo-Tort B, Lison JF. Impact of biomedical and biopsychosocial training sessions on the attitudes, beliefs, and recommendations of health care providers about low back pain: a randomised clinical trial. Pain. 2011;152(11):2557-63.

169. Zidarov D, Thomas A, Poissant L. Knowledge translation in physical therapy: from theory to practice. Disabil Rehabil. 2013;35(18):1571-7.

170. Gatchel RJ, Mayer TG. Testing minimal clinically important difference: consensus or conundrum? Spine J. 2010;10(4):321-7.

171. Hilibrand AS, Robbins M. Adjacent segment degeneration and adjacent segment disease: the consequences of spinal fusion? Spine J. 2004;4(6 Suppl):190S-4S.

172. Smeets RJ, Vlaeyen JW, Kester AD, Knottnerus JA. Reduction of pain catastrophizing mediates the outcome of both physical and cognitive-behavioral treatment in chronic low back pain. J Pain. 2006;7(4):261-71.

173. Hagg O, Fritzell P, Oden A, Nordwall A, Swedish Lumbar Spine Study G. Simplifying outcome measurement: evaluation of instruments for measuring outcome after fusion surgery for chronic low back pain. Spine (Phila Pa 1976). 2002;27(11):1213-22.

174. Evans R, Bronfort G, Maiers M, Schulz C, Hartvigsen J. "I know it's changed": a mixed-methods study of the meaning of Global Perceived Effect in chronic neck pain patients. Eur Spine J. 2014;23(4):888-97.

175. Fischer D, Stewart AL, Bloch DA, Lorig K, Laurent D, Holman H. Capturing the patient's view of change as a clinical outcome measure. JAMA. 1999;282(12):1157-62.

176. Svendsen SW, Christiansen DH, Haahr JP, Andrea LC, Frost P. Shoulder function and work disability after decompression surgery for subacromial impingement syndrome: a randomised controlled trial of physiotherapy exercises and occupational medical assistance. BMC Musculoskelet Disord. 2014;15:215.

177. Fielding S, Fayers $P$, Ramsay CR. Analysing randomised controlled trials with missing data: choice of approach affects conclusions. Contemp Clin Trials. 2012;33(3):461-9.

178. Moher D, Hopewell S, Schulz KF, et al. CONSORT 2010 explanation and elaboration: updated guidelines for reporting parallel group randomised trials. Int J Surg. 2012;10(1):28-55.

179. MacDermid JC, Walton DM, Avery S, et al. Measurement properties of the neck disability index: a systematic review. J Orthop Sports Phys Ther. 2009;39(5):40017.

180. Holly LT, Matz PG, Anderson PA, et al. Functional outcomes assessment for cervical degenerative disease. J Neurosurg Spine. 2009;11(2):238-44. 
181. Burneikiene S, Nelson EL, Mason A, Rajpal S, Villavicencio AT. The duration of symptoms and clinical outcomes in patients undergoing anterior cervical discectomy and fusion for degenerative disc disease and radiculopathy. Spine J. 2015;15(3):427-32.

182. Peolsson A, Peolsson M. Predictive factors for long-term outcome of anterior cervical decompression and fusion: a multivariate data analysis. Eur Spine J. 2008;17(3):406-14.

183. Samartzis D, Shen FH, Lyon C, Phillips M, Goldberg EJ, An HS. Does rigid instrumentation increase the fusion rate in one-level anterior cervical discectomy and fusion? Spine J. 2004;4(6):636-43. 



\section{Papers}

The articles associated with this thesis have been removed for copyright reasons. For more details about these see:

http://urn.kb.se/resolve?urn=urn:nbn:se:liu:diva-122695 